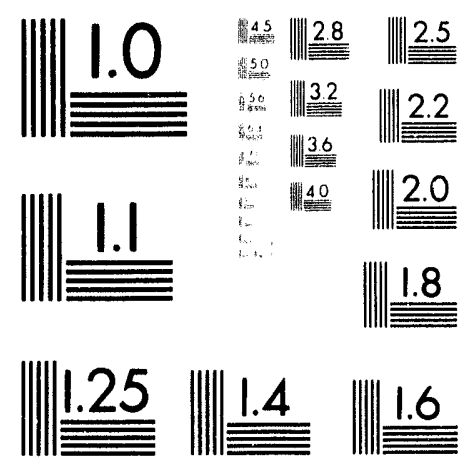



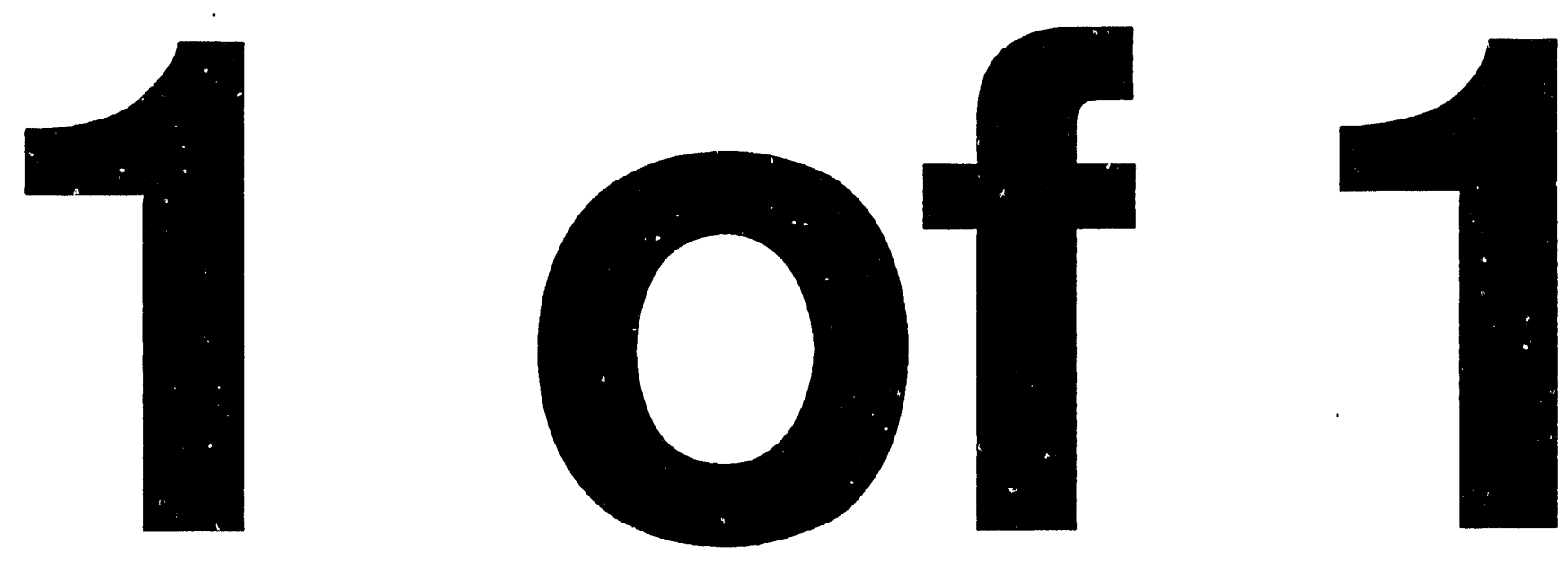
SAND91-2850 • TTC-1251

Distribution

Unlimited Release

Category UC-722

Printed September 1993

\title{
A Constitutive Model for Layered Wire Mesh and Aramid Cloth Fabric
}

\author{
M. K. Neilsen \\ Engineering Mechanics and Material Modeling Department \\ Sandia National Laboratories, Albuquerque, NM 87185 \\ J. D. Pierce \\ Transportation Systems Department. \\ Sandia National Iaboratories. Albuquerque, NM 87185 \\ R. D. Krieg \\ Engineering Sicience and Mechanics \\ University of Tennessee, Knoxville, TN 37996
}

\begin{abstract}
A new package for the air transport of hazardous materials is currently being developed in the Transportation Systems Department at Sandia National Laboratories. The baseline design has a unique impact limiter which uses layers of aluminum screen wire and aramid cloth fabric. A primary motivation for selecting this unusual combination of materials is the need for the impact limiter to not only limit the amount of load transmitted to the primary container but also remain in place during impact events so that it provides a thermal barrier during a subsequent fire. A series of uniaxial and confined compression tests indicated that the layered material does not behave like other well characterized materials. No existing constitutive models were able to satisfactorily capture the behavior of the layered material; thus, a new plasticity model was developed. The new material model was then used to characterize the response of air transport packages with layered impact limiters to hypothetical accidental impact events. Responses predicted by these analyses compared favorably with experiments at Sandia's rocket sled test facility in which a one-fourth scale package was subjected to side and end impacts at velocities of 428 and $650 \mathrm{fps}$, respectively.
\end{abstract}




\section{Acknowledgements}

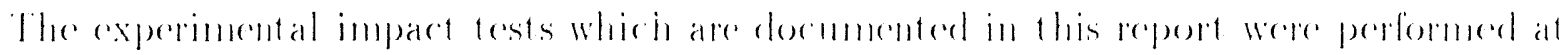

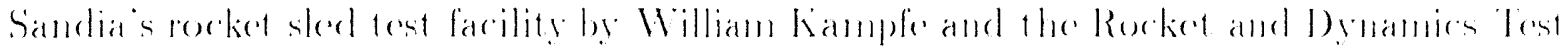

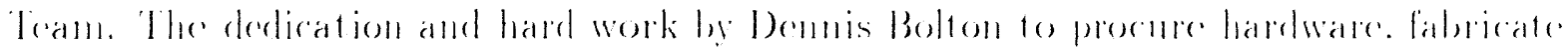

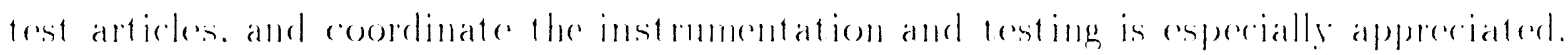

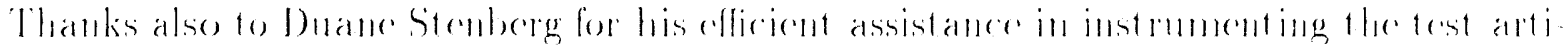

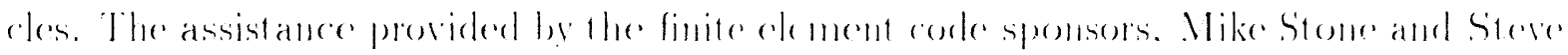

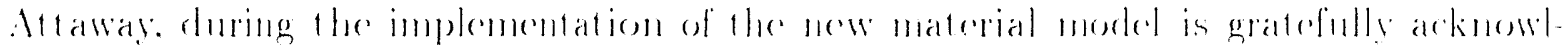
adged. 


\section{Contents}

1. Introduction . . . . . . . . . . . . . . . . . . . . . !

2. Experimental Data . . . . . . . . . . . . . . . . . . 11

3. Review of Existing Plasticity Models . . . . . . . . . . . . . Ii)

3.1 Voll Misess . . . . . . . . . . . . . . . . . . . . . . 16

3.2 Soil and cmohahble foam . . . . . . . . . . . . . . . . . . 17

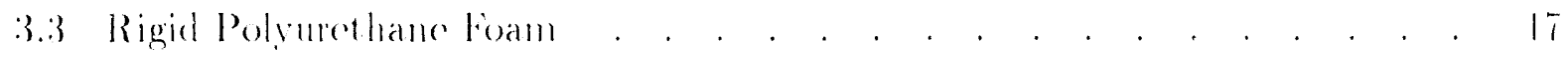

4. Development of a New Layered Material Model . . . . . . . . 19

5. Simulation of Material Characterization Tests . . . . . . . . 21

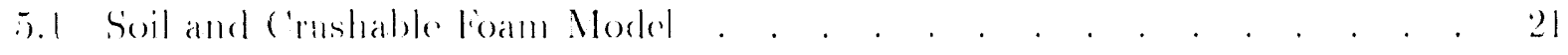

5.2 New Layered Material Model . . . . . . . . . . . . . . . . 25

6. Effect of Layered Material Modeling Variations . . . . . . . . . 2

7. Benchmark Analyses - Steel Container with Layered Material Limiter 35)

8. Air Transport Package Analyses - End Impact . . . . . . . . 11

9. Air Transport Package Analyses - Side Impact . . . . . . . . . 5.3

10. Summary . . . . . . . . . . . . . . . . . . . . . . . . . . . . . .

11. References . . . . . . . . . . . . . . . . . . . . . 


\section{Tables}

4.1 Material ('ues for the New Layered Material Model . . . . . . . . 19

5.1 Material Parameters for the Soil and (rushable Foan Model . . . . . 21

5.2 Material Parameters for the New Layered Material Model . . . . . . 25

6.1 Material Parameters Used in the Evaluation of Layered Material Modeling Variations . . . . . . . . . . . . . . . . . . . 28

7.I Material Parameters Used in the Benchmark Analyses . . . . . . . 360

7.2 Permanent Deformations Predicted by the Benchmark Analyses . . . . 10

8.1 Material Parameters Used in End Impact Analyses . . . . . . . . . 433

8.2 Permanent Deformations Predicted by the End Impact Analyses . . . . 17

9.1 Material Parameters Used in the Side Impact Analyses . . . . . . . 5. 


\section{Figures}

2.1 Results from Confined Compression lests. . . . . . . . . . . . . 12

2.2 Results from conlined compression Tests on a Linear-Log Plot. . . . . I2

2.3 Results from Uniaxial Compression Tests. . . . . . . . . . . . . . . 13

5.1 Axisymmetric Finite Eilement Morlel of Material Specimen . . . . . . 22

5.2 Axial and Radial Displacement of Node 4 During the Simulation of the Inconfined Compression 'Test - Soil and Crushable Foam Material Model 22

5.3 Iniaxial (ompression Load Path and Yeld Surfaces in Mean Stress-Lffective Stress Plane. . . . . . . . . . . . . . . . . . . . . . 24

5.1 (omparison of Analysis 5.4 with Lxperiment - Uniaxial ('ompression (Positive Axial Sitress is ('ompressive). . . . . . . . . . . . . . . 21

5.5 Comparison of Analyses 5.5 to 5.7 with Experiments - Thiaxial ('ompression (Positive Axial Stress is ('ompressive). . . . . . . . . . . . . 26

(i.) Two-1)inensional Plane Strain Morkel of Package Cross-Section. . . . . 27

(i.2) Container Displarement Predicted by Analyses with the New Layered Material Molel - Eeffect of Laver Morleling Variations. . . . . . . . . 29)

6.3 Container Aeceleration Predicted by Analyses with the Now layered Matrial Model - Liffect of Layer Morleling Variations. . . . . . . . . 29)

6.1 Defoment Shape of Finte Blement Morlel at Varous Time Steps Doring Analysis 6.1 - Iligh Lsotropic Tensile Strength. . . . . . . . . . . 30

(6.) Deformed Shape of Finte Blement Mockel at Varions Time Steps During Analysis (6.2 - Alternating High/Low Lsotropic lensile Strength. . . .

(iff Deformed Shape of Finte Blement Mordel at Various Time Steps During Analysis (6.3 - Low Isotropic Tonsile Strength. . . . . . . . . . . . 30

(i.7 Container Displarement Predieted by Analyses with the Now Layered Material Mortel- Effect of Material Parameter a. . . . . . . . . . . 31

6.s Contaner Acoeleration Predicted by Analyses with the New Layered Material Model - Eeffect of Material Parameter $a$. . . . . . . . . . . . 32

6.9) Deformed Shape of Finite Element Model at Various Time Siteps During Aualysis 6.4 - New Layered Material Model with $a=120$. . . . . . . 32

(i.10 C'ontainer Displacenent Predicted by Analysis (5.5) with the Soil and crushable Foam Model. . . . . . . . . . . . . . . . . . . . 33

6.11 Container Acederation Predieted by Analysis 6.5 with the Soil and (rushable Foam Morkl. . . . . . . . . . . . . . . . . . . . 31

6.12 Deformed Shape of Finite Element Morlel at Various Time Steps During Analysis (6.5 - Soil and (Tushable Foam Model.

7.l Three-1)imensional Finite Element Mordet of the Benchmark Parkage with a Streel container. 


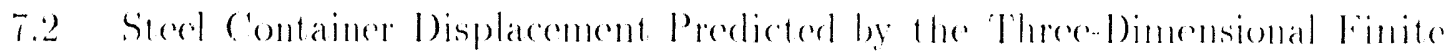
Element Analyses of a Sirle Impart. . . . . . . . . . . . . . . . 37

7.3 Sted Container Acceleration Predieded be the There-Dimensional Finite Element Analyses of a Side Lmpact. . . . . . . . . . . . . . 38

7.t Ineformed Shape of the Finite Element Model - Analysis 7.l. . . . . . 3!)

7.5 Deformed Shape of the Finite Element Model - Analysis T.2. . . . . . . 39)

7.6 Deformed Shape of the Finite Element Mordel - Analysis 7.3. . . . . . 39)

7.7 Location of Deformation Masurements Summarized in Table T.2. . . . 10

S.l Axisymmetrie Finte Element Model of an Air Transport Parkage. . . . 11

8.2 Axial Stress-Strain Behavior of Perforated Aluminmm Plate Material. . . 12

8.3 ('ontainer Displacement Predieted by the End Impact Analyses. . . . . I5

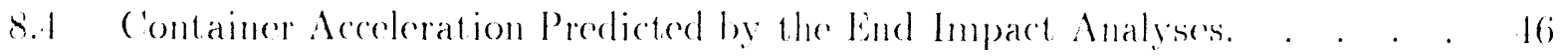

S.5 Deformed Shape of Finte Element Model After End Impart Event. . . . Is

8.6 Equivalent Pastic Strain (iemerated in ('ontainer During lmpact Event. . 19

S.T Deformed Shape of Sectioned Package After 6.50 fps End Lmpare Tesit. . . 50

S.s Deformed Shape of Sectioned ('ontainer After 6.50 fps Lind Impact Experiment. Il

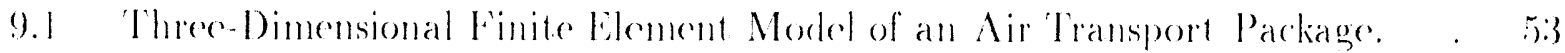

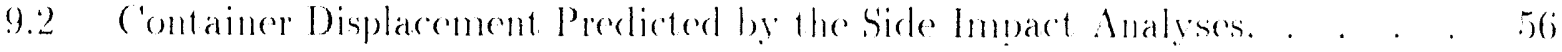

9.3 C'ontainer Accoleration Predicted by the Side Impare Analyses. . . . . 56

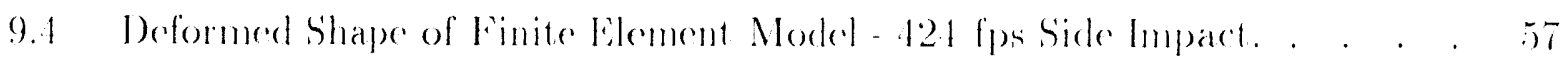

9.5) Deformed Shape of Finite Element Model - 650 fps Side Impact. . . . . 5

9.6 Deformed Shape of the Impart Limiter After it was Sectioned-les fps Side Impact Experimont. . . . . . . . . . . . . . . . . . . . . . . . 


\section{Introduction}

A new parkage for the air transport of hazardous materials is currently being developed in the Transportation Systems Department at Sandia National Laboratories. The baseline design has a unique impact limiter which uses multiple layers of alumimmon sereen wire

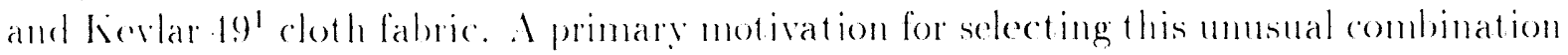
of materials is the need for the impact limiter to not only limit the amoment of load transmitted to the primary, internal containe hut also remain in place throughout impact crents so that it provides a thermal barrier during a possible subseguent fire. If the thermal insulation provided by the aluminum sereen wire and the kevar fabrie is not sufficient. then layers of insulating materials such as ceramic eloth may be adeled to the compesitestack-11p).

The mechanical helavior of the layered material was partially chatacterized by a series of minaxial and contined complession tests. These tests indicated that in compression the strength and stiffuess of the material is nearly isotropic: however, in tension the material is quite anisotropic. In a direction nomal to the layers, the material has no tensilestrength; whereas, in a direction parallel to the hayers the material has a significant amount of tensile strength.

A constitutive model for the layered wire mesh and kevlar fabric was needed to numerically investigate the behavior of air transport parkages during accidental impact erents. A review of existing constitutive models indicated that a plasticity model which was recently developed for rigid polyurethane foams by Neilsen, Morgan, and lirieg [1] could be modified to apture the isotropic crush behavior of the layered wire mesh and lievar fabric material. Results from the uniaxial and confined compression tests were used to obtain material parameters for the new layered material model. The miaxial and confined compression tests were then analyzed to ensure that the model captured the material behavior exhibited during these tests.

The new isotropic layered material model accurately simulated the material responses exhibited during the material characterization tests; however, as expected this isotropic plasticity model was not able to capture the anisotropic behavior of the layered material in tension. The effects of this weakness on impact limiter behavior predictions were evaluated by comparing results from analyses which used the new layered material model with andyeses in which layers of wire mesh and Kevar fabric were actually modeled using, a terhuigue developed by Attaway [2]. This craluation indicated that reasonable predictions of impact limiter behavior during a typical impact event conld be obtained with the new isotropic plasticity model.

'E.1. duPout de Nemours id ('o., Inc. 
Next, a sted container with a composite layered wire mesh and kevlar fabric impart lim. iter was subjected to a 424 feet per second side impact. This impact event was analyzerl to further benchmark the new layered material model. Finally, a 428 lps side impact test and a 650 fps end impact test were recently performed on scale model packages with composite layered material impact limiters. Finite clement andyses of these hypothetical accident events are compared with experimental observations in this report. Results liom both the finte element analyses and the experiments indicate that the havered wire mesh with Kevlar fabric material will remain intact even during a 650 fps impact cvent if an adequate mumber of Kevlar layers are used. However, the layered wire mesh with Kovlar fabric limiter allows for the transmission of high loads to the primary inner container. The primary container was not plastically deformed during the 121 fiss side impact cont but was plastically deformed during the 650 fpe end impact event. The amonnt of loarl transmitted to the primary container can be reduced by introducing layers of material which absorb more energy than the wire mesh into the impact limiter stack-11p. 'The analyses presented in this report also reveal that the behavior of the contents (material inside the primary container) can have a significant positive or negative effect on primary container deformation. ('ontent behavior must be considered in the dereloement of air transport package designs. 


\section{Experimental Data}

The behavior of layers of aluminum wire mesh with and without Kevlar fabric was characterized with a series of uniaxial compression and confined compression tests. In the uniaxial compression tests, the samples were compressed in one direction and allowed to expand in directions which are orthogonal to the loading direction. In the confined compression tests, the samples were compressed in one direction and not allowed to expand in the directions orthogonal to the loading direction. All of the samples used in the confined compression tests were manufactured by alternatively stacking up 20 layers of aluminum wire mesh and 2 layers of kevlar fabric. 'The wire mesh has an initial wire dianeter of 0.0105 inches, and the Kevlar fabric has a thickness of 0.017 inches. The undeformed samples liad a cubical shape with an edge dimension of 2.0 inches. The samples were loaded at various angles relative to the layer stack-up direction. Axial stress versus axial enginecring strain curves generated during the confined compression tests are shown in Fignres 2.1 and 2.2. In these figures, a positive axial stress or strain is compressive. These tests indicate that layer orientation has little effect on the response of the material; thus, the response of the matcrial to compressive loads is nearly isotropic. Also, the compressive strength, $\sigma^{c}$, varies exponentially with axial engineering strain, $e$, as shown in Figure 2.2. The solid line in Figures 2.1 and 2.2 represents a best fit to the experimental confined compression test data which is given by the following equation

$$
\sigma^{\circ}=17.0 \epsilon^{8.68 \%}
$$

Since the lateral displacements are constrained, the axial engineering strain, e, has the same magnitude as the ongineoring volume strain, ewol, in these lests.

In a second see of tests, layers of wire mesh and wire mesh with Kevlar fabric were nuconfined and smbjected to cyclic miaxial loads (Figme 2.3). The applied load was oriented nomal to the wire mesh and babric layers (i.e. a layer orientation of o degrees was used). 'lhe number of kevlat layers and the sample size was allowed to change. Various sample sizes were used to determine if the lateral comstraint dee to friction at the load platen to sample interface had any effect on the axial response of the layered material. In the first test, a sample with a length of (i.0 inches, a wirlth of 7.0 inches and the heright of 1.0 inch was used. In the remaining three test:s, samples with lengthe and widths of 2.0 inches and herghts of 1.0 inch were used. In the first two miaxial compression tests, the layering was identical to the layering used in the confined compression tests: $3 \mathrm{X}(20$ Almminum wire mesh / 2 lievlar fabric) for a total of 60 aluminmm wire mesh layers and 6 Kevlar fabric layers. In the last two experinonts, the kevlar layers were elimmated and a total of 62 layers of alummum wire mesh were used. These tests indicate that inchusion of the kevlar fabrie layers will slighty reduce the axial strain magnitude at which the 


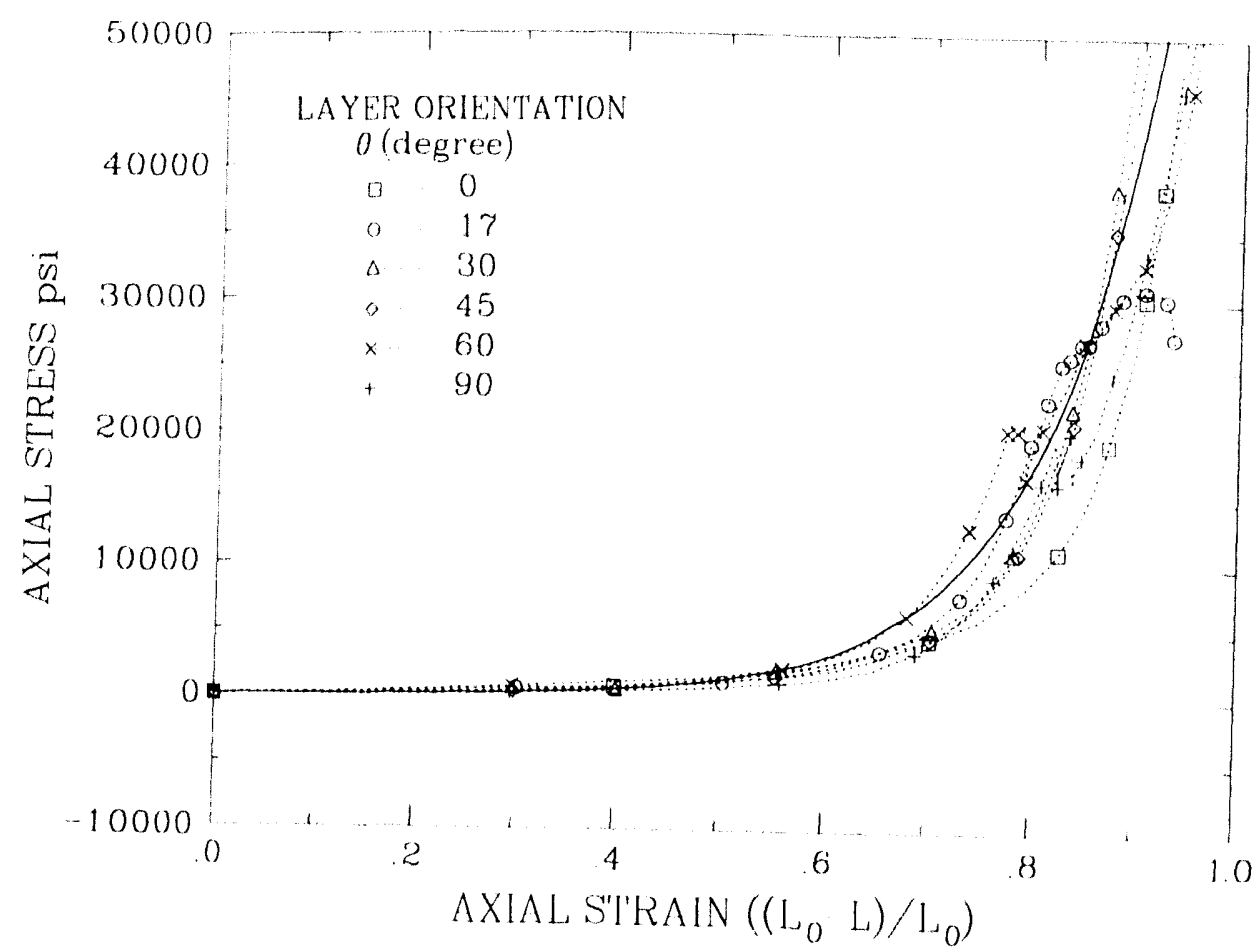

Figure 2.1. Results from Confined Compression 'Tests.

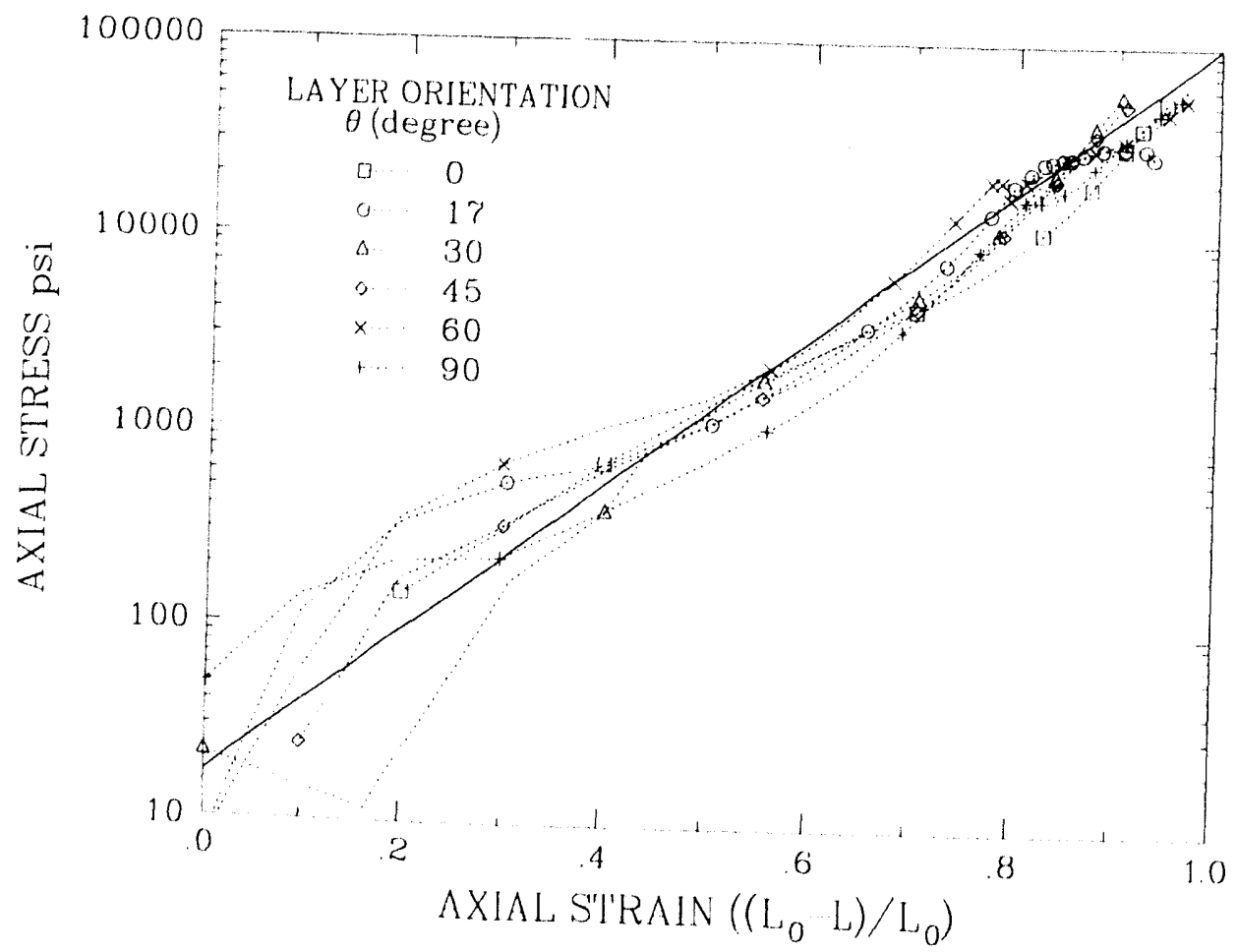

Figure 2.2. Results from Confined (ompression Tests on a Linear-Log Plot. 


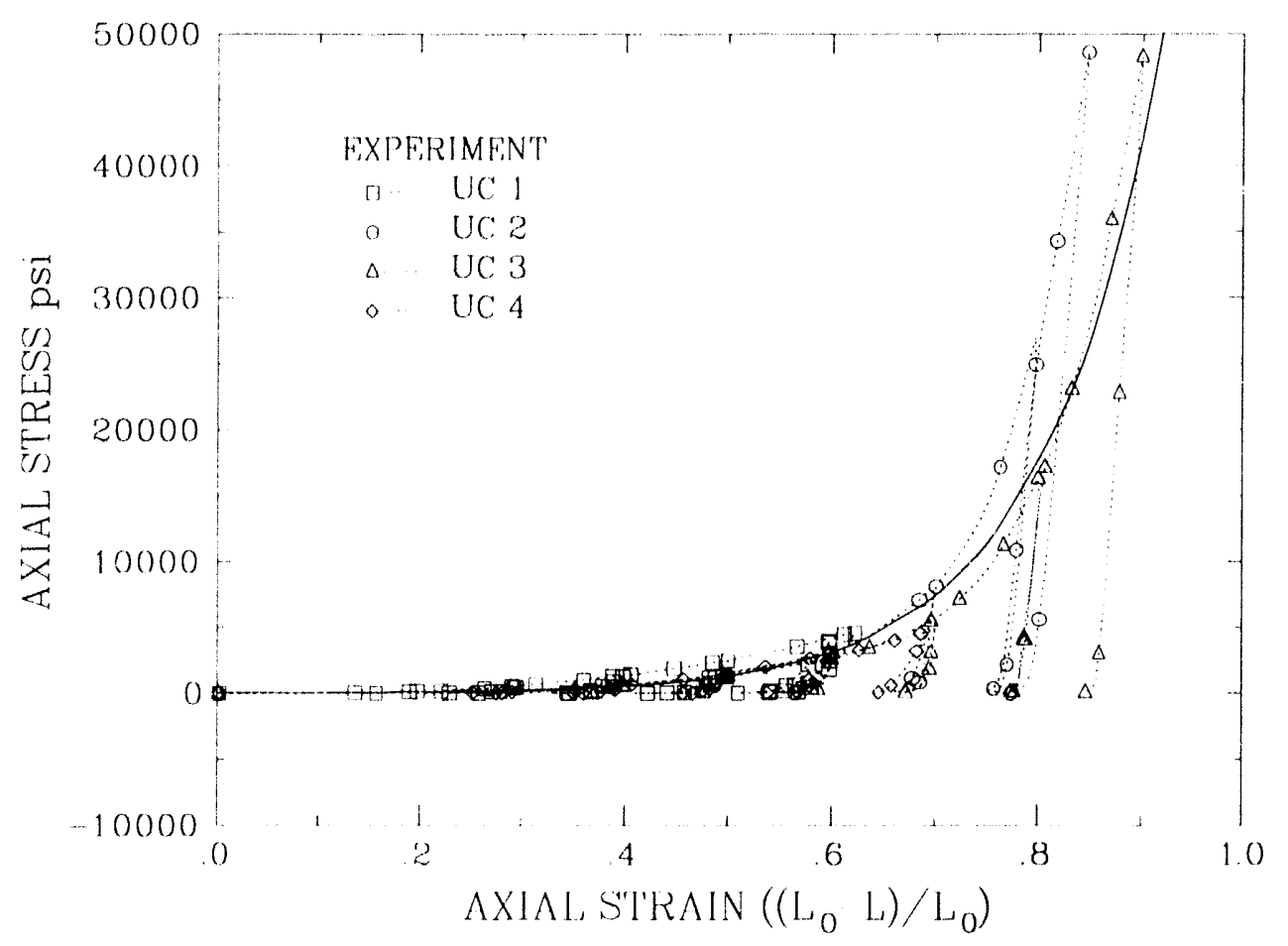

Figure 2.3. Results from Uniaxial ('ompression 'Tests.

load carrying capacity of the layered material begins to significantly increase. 'This occurs because the Kerlar fabric is much stiffer than the wire mesh in compression. Also, these experiments indicate that the lateral strains generated by uniaxial compression are small. Measurements of the deformed samples after the unconfined compression tests indicated that the lateral deformation generated during 'Tests II: 1 and UC 4 was negligible and during Tests UC 2 and UC 3 the sample width permanently increased from 2.0 inches to 2.2 inches. This means that the material has a Poisson's ratio that is nearly equal to zero. Furthermore, any plasticity model that is developed to capture the behavior of this material should predict small lateral strains when the material is loaded into the plastic regime. The solid line in Figure 2.3 represents a best fit to the confined compression test data (Equation 2.1). Results from the limited number of uriaxial compression tests indicates that Equation 2.1 also represents the miaxial compression data reasonably well. Since the layered material exhibited small lateral strains during the unconfined, uniaxial compression tests, the confining stress gencrated during the zero degree confined compression tests must have been small. Thus, the zero degree confined compression tests and the unconfined compression tests subjected the layered material to nearly the sane load path and the material behavior during these tests was nearly identical.

In tension, the layered material exhibits widely varying behavior. For example, when a single layer of wire mesh is loaded in-plane, it has a tensile strength of approximately 75 Ibs per inch of width [3]. A single kevlar fabric layer has an in-plane t nsile strength of $1.400 \mathrm{lbs}$ per inch of width [3]. The aluminum wire mesh has a much smaller in-plane strain to failure than the kevlar fabric: thus, the in-plane tensile strength of the layered 
material is equal to the maximum of the in-plane tensile strength of the Kevlar fabric or the aluminum wire mesh alone. When the layered material is loaded in a direction normal to the fabric layers the material exhibits essentially no strength as the layers are separated. 


\section{Review of Existing Plasticity Models}

A variety of finite element codes, SANTOS [4], PRONTO-2D [5] and PRONTO-3D [6], have been developed at Sandia National Laboratories to efficiently solve large solid mechanics problems on the (RAY-YMP. In this chapter, a number of plasticity theories which have been implemented in these codes are reviewed. The capability of these theories to capture layered material behavior are then evaluated by simulating the material characterization tests with the quasi-static code SANTOS [4]. Once appropriate material models and parameters for the layered material are identified, impact events can be simulated using the transient dynamic analysis codes PRONTO-2D [5], and PRONTO-3D $[6]$.

Plasticity theories are characterized by their yield function, $\Psi$, and their evolution equation for plastic deformation. The yield function defines a surface in stress space which bounds stress states for which the response of the material is elastic. The flow rule defines the nature of plastic deformation. In the finite element codes listed above, the material models are expressed in terms of the unrotated Cauchy stress, $\boldsymbol{\sigma}$, and the deformation rate, $\mathbf{d}$, in the unrotated configuration [6]. The deformation rate or stretching tensor is additively decomposed into its elastic, $\mathbf{d}^{e l}$, and plastic, $\mathbf{d}^{p l}$, parts as follows:

$$
\mathrm{d}=\mathrm{d}^{e l}+\mathbf{d}^{p l}
$$

The plastic part of the stretching tensor is given by the flow rule

$$
\mathbf{d}^{p l}=\dot{\omega} \mathbf{g}
$$

where $\dot{w}$ defines the magniturle of the plastic strain increment and the second-order tensor

g defines the orientation of the plastic strain increment. The constitutive relation is given l,y

$$
\dot{\boldsymbol{\sigma}}=\mathbf{E}: \mathrm{d}^{\epsilon l}
$$

where $\mathbf{E}$ is the fourth-order elasticity tensor and the double dot indicates a contraction on two of the indices. 'Thus in indicial notation, Equation 3.3 would be written as follows:

$$
\dot{\sigma}_{i j}=E_{i j k l}^{\prime} d_{k l}^{r l}
$$

Lepuations 3.1 to 3.3 can by combined to obtain the following expression:

$$
\dot{\boldsymbol{\sigma}}=\mathbf{E}:(\mathbf{d}-\dot{\omega} \mathbf{g})
$$

All of the constitutive theories reviewed in this chapter assmme that the elastic response is linear and isotropic: thus. E is given by

$$
\mathbf{E}=3 h \mathbf{P}^{s p}+2\left(i \mathbf{P}^{d}\right.
$$


where $K$ is the bulk modulus and $G$ is the shear modulus. 'The bulk and shear moduli are related to Young's modulus, $E$, and Poisson's ratio, $v$, as follows

$$
K=\frac{E}{3(1-2 v)} \quad\left(i=\frac{E}{2(1+v)}\right.
$$

'The fourth-order spherical projection operator, $\mathbf{P}^{s p}$, and the deviatoric projection operator, $\mathbf{P}^{d}$, are given by

$$
\mathbf{P}^{s p}=\frac{1}{3} \mathbf{i} \mathbf{i} \quad \mathbf{P}^{d}=\mathbf{I}-\mathbf{P}^{s p}
$$

where $\mathbf{I}$ is the symmetric fourth-order identity tensor, and $\mathbf{i}$ is the second-order identity. In indicial notation, the symmetric fourth-order identity and the projection operators can be expressed as follows:

$$
I_{i j k l}=\frac{1}{2}\left(\delta_{i k} \delta_{j l}+\delta_{i l} \delta_{j k}\right) \quad P_{i, j k l}^{s p}=\frac{1}{3} \delta_{i j} \delta_{k l} \quad P_{i, j k l}^{d}=I_{i, j k l}-P_{i, j k l}^{s p}
$$

where $\delta_{i, j}$ is the kronecker delta.

In the remainder of this chapter, three different plasticity models which are currently available in finite element codes are reviewed to determine if any of them can capture the behavior exhibited by the layered material. The three models include a von Mises or conventional deviatoric plasticity model, a soil and crushable foam model which was developed by hireg [7], and a rigid polyurethane foam model [1].

\subsection{Von Mises}

The von Mises or conventional deviatoric plasticity model is available in most solid me. chanics finite element codes. It has a yield function given by

$$
\Psi=\sigma-k \quad \sigma=\left(\frac{3}{2} \boldsymbol{\sigma}^{d}: \boldsymbol{\sigma}^{d}\right)^{\frac{1}{2}}
$$

where $\sigma$ is the von Mises effective stress, $k$ is the deviatoric yield strength, and $\boldsymbol{\sigma}^{d}$ is the deviatoric stress tensor. The associated flow rule for this model is as follows:

$$
\mathbf{d}^{p l}=\dot{\omega} \frac{\boldsymbol{\sigma}^{d}}{\left(\boldsymbol{\sigma}^{d}: \boldsymbol{\sigma}^{d}\right)^{\frac{1}{2}}}
$$

The yield function, $\Psi=0$, mathematically represents a yield surface that is an infinitely long cylinder with the hydrostat as its axis. The flow rule for this model indicates that the plastic deformations are purely deviatoric and that the volume of the material does not permanently change. This model is obviously not appropriate for the layered material which exhibits significant permanent volume changes when it is crushed. 


\subsection{Soil and Crushable Foam}

The soil and crushable foam model [7] uses two separate yield functions, one for the volumetric response and one for the deviatoric response. This model assumes that the volumetrie response is independent of the deviatoric response but that the deviatoric response depends on the mean stress. The yield functions and flow rule for this model arc as follows:

$$
\begin{gathered}
\Psi^{s p}=p-f\left(c_{v, d}\right) \\
\Psi^{d}=\sigma-\left(a_{0}+a_{1} p+a_{2} p^{2}\right) \\
\mathbf{d}^{p l}=\dot{\omega}^{s p} \mathbf{i}+\dot{\omega}^{d} \mathbf{g}^{d} \quad \mathbf{g}^{d}=\frac{\boldsymbol{\sigma}^{d}}{\left(\boldsymbol{\sigma}^{d}: \boldsymbol{\sigma}^{d}\right)^{\frac{1}{2}}}
\end{gathered}
$$

where $c_{\text {wol }}$ is the engineering volume strain, $p$ is the mean stress, $p=-\boldsymbol{\sigma}: \mathrm{i} / 3$, and $\mathbf{i}$ is the second-order identity. The deviatoric yield function, $\Psi^{d}=0$, represents a surface which depends on the mean stress, and the volumetric yield function, $\Psi^{s p}=0$, represents a planar (ap) nomal to the hydrostat. 'The evolution equation for plastic deformation indicates that both volumetric and deviatoric permanent deformations can be generated with this model. Since $f$ in Equation 3.12 can be chosen to accurately describe the volumetric response of the layered material, this material model should be able to capture the layered material behavior exhibited during the confined compression tests.

\subsection{Rigid Polyurethane Foam}

The rigid polyurethane foam model [1] has yield functions and a flow rule given by

$$
\begin{gathered}
\psi^{i}=\boldsymbol{\sigma}: \mathbf{P}^{i}: \boldsymbol{\sigma}-h\left(c_{w o l}\right) \quad i=1,2,3 \\
\mathbf{d}^{p l}=\dot{\omega}^{\prime} \mathbf{P}^{1}: \boldsymbol{\sigma}+\dot{\omega}^{2} \mathbf{P}^{2}: \boldsymbol{\sigma}+\dot{\omega}^{3} \mathbf{P}^{3}: \boldsymbol{\sigma}
\end{gathered}
$$

$\mathbf{P}^{i}$ is the fourth-order principal projection operator defined as follows:

$$
\mathbf{P}^{i}=\mathbf{n}^{i} \Leftrightarrow \mathbf{n}^{i} \Theta \mathbf{n}^{i} \mathbf{n}^{i} \quad i=1,2,3
$$

where $\mathbf{n}^{i}$ is a vector oriented in a principal stress direction. The yield functions, $\Psi^{i}=0$, actually represent 3 pairs of planar yield surfaces with normals given by $\mathbf{n}^{i}$. 'The flow rule for this model indicates that a permanent deformation increment may be associated with each principal stress direction depending on the magnitude of the principal stress. This model can capture the behavior exhibited by the layered material in the mitaxial 
and confined compression tests if an appropriate form for the function $h$ in Equation 3.15 is selected. Also, this model can be modified to exhibit behavior in tension which is significantly different than its 'sehavior in compression by simply making the function $h$. in Equation 3.15 depend on the sign of the principal stress. 


\section{Development of a New Layered Material Model}

In this chapter, a new layered material model which is similar in many respects to the existing rigid polyurethane foam model [1] is developed. This new model, like the existing rigid foam model, has yield functions expressed in terms of principal stresses. The static uniaxial and confined compression tests indicated that an appropriate form for the compressive yield function would be as follows

$$
\Psi^{i}=-\sigma^{i}-a e^{-b \epsilon_{v o l}}
$$

where $\sigma^{i}$ is a principal stress which is negative in compression, $a$ and $b$ are material constants and $e_{\text {rol }}$ is the engineering volume strain which is also negative in compression. ln tension, we assume that the material is elastic perfectly plastic. Thus, the yield function for tensile principal stresses is

$$
\Psi^{i}=\sigma^{i}-T
$$

where $\tau$ is a material constant that represents the isotropic tensile strength of the layered material. These yield functions represent three pairs of intersecting planar yield surfaces. The flow rule for the new layered material model is identical to the flow rule for the rigid polyurethane foam model, Equation 3.16 .

The new layered material model was implemented in the static and dynamic finite elements codes SANTOS [4], PRONTO-2D [5], and PRONTO-3D [6]. 'The sponsor's of these codes have made the material subroutines and interfaces nearly identical; thus, implementation of the model into several codes was nearly as easy as implementation into a single code. In these codes, the new material is referred to as WIRE MESH and uses the material cues given in Table 4.1.

\begin{tabular}{|c|c|c|}
\hline Cue & Units & Description \\
\hline YOUNGS MOIDULUIS & Force/Length ${ }^{2}$ & \\
\hline POISSONS RATIO & & \\
\hline $\mathrm{A}$ & Forece/Length ${ }^{2}$ & a in Ey. 1.1 \\
\hline B & & b in E. 1. 1.1 \\
\hline THESSION & Force/Lengthe & $T$ in lick. 1.2 \\
\hline
\end{tabular}

Table 4.1. Material Cues for the New Layered Material Model 


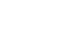




\section{Simulation of Material Characterization Tests}

In this chapter, we attempt to use both the soil and crushable foam model and the new layered material model to simulate the layered material behavior exhibited during the minaxial compression tests which were presented in (hapter 2.

\subsection{Soil and Crushable Foam Model}

With the soil and crushable foam model [7], the user is required to prescribe the volumetric resporso of the material. Since no hydrostatic compression tests were performed on the layered material, results from the confined compression tests were used to estimate the hydrostatic response of the layered material. In the confined compression tests, the rngincering volume strain is efual to the measured axial strain because lateral displacements were constrained during these tests. Bufortumately, the confining stress was not measured during the confined compression tests. The mean stress generated during these tests was estimated by assuming that the confining stress was negligible compared with the axial stress and that the mean stress is, thus, approximately equal to the axial stress divided by 3. The user is also required to prescribe the dependence of the deviatoric yield surface on the mean stress by defining the material parameters $a_{0}$, $a_{1}$, and $a_{2}$ in Equation 3.11. Since there was not enough experimental data to characterize this dependence, three analyses were completed using various combinations of material parameters $a_{0}, a_{1}$, and $a_{2}$. The primary purpose of these analyses was to determine if material parameters $a_{0}, a_{1}$, and $a_{2}$ could be selected such that the material behavior exhibited during the unconfined compression tests by the layered material could be captured with this material model.

These analyses were performed using a one element model of an axisymmetric matrial specimen (Figure 5.1) and the quasistatic finite clement code SANTOS [4]. The model was subjected to a uniaxial compressive load to simulate the experimental, unconfined compression tests. Material parameters given in Table 5.1 were used in these analyses.

Table 5.1. Material Parameters for the Soil and Crushable Fram Model

\begin{tabular}{|c|c|c|c|c|c|}
\hline $\begin{array}{c}\text { Analysis } \\
\text { Number }\end{array}$ & $\begin{array}{c}\text { Elastic } \\
\text { Modulus } \\
(\mathrm{psi})\end{array}$ & $\begin{array}{c}\text { Poisson's } \\
\text { Ratio }\end{array}$ & $a_{0}$ & $a_{1}$ & $a_{2}$ \\
\hline 5.1 & $1.0 \times 10^{5}$ & 0.0 & 100.0 & 0.0 & 0.0 \\
5.2 & $1.0 \times 10^{5}$ & 0.0 & $100.0 \times 10^{6}$ & 0.0 & 0.0 \\
$5.3,5.4$ & $1.0 \times 10^{5}$ & 0.0 & 0.1 & 3.0 & 0.0 \\
\hline
\end{tabular}




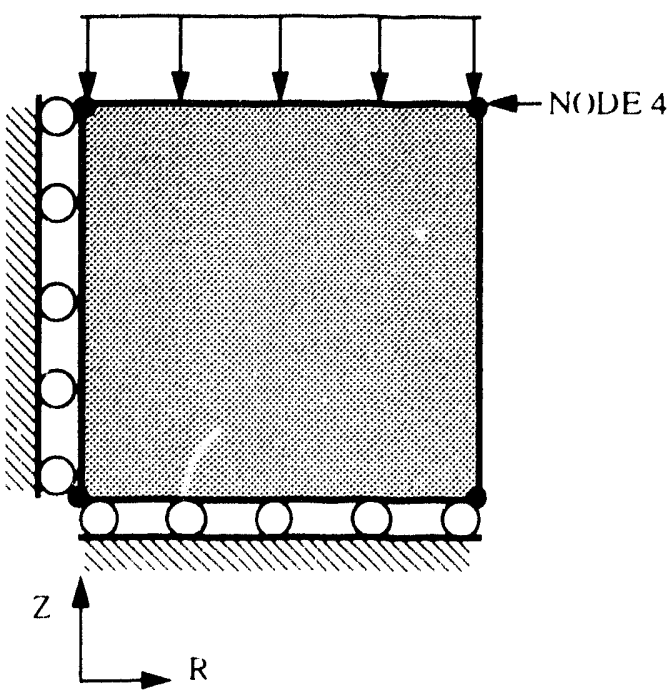

Figure 5.1. Axistumetrie Finte Flement Morled of Matrial Siperiment

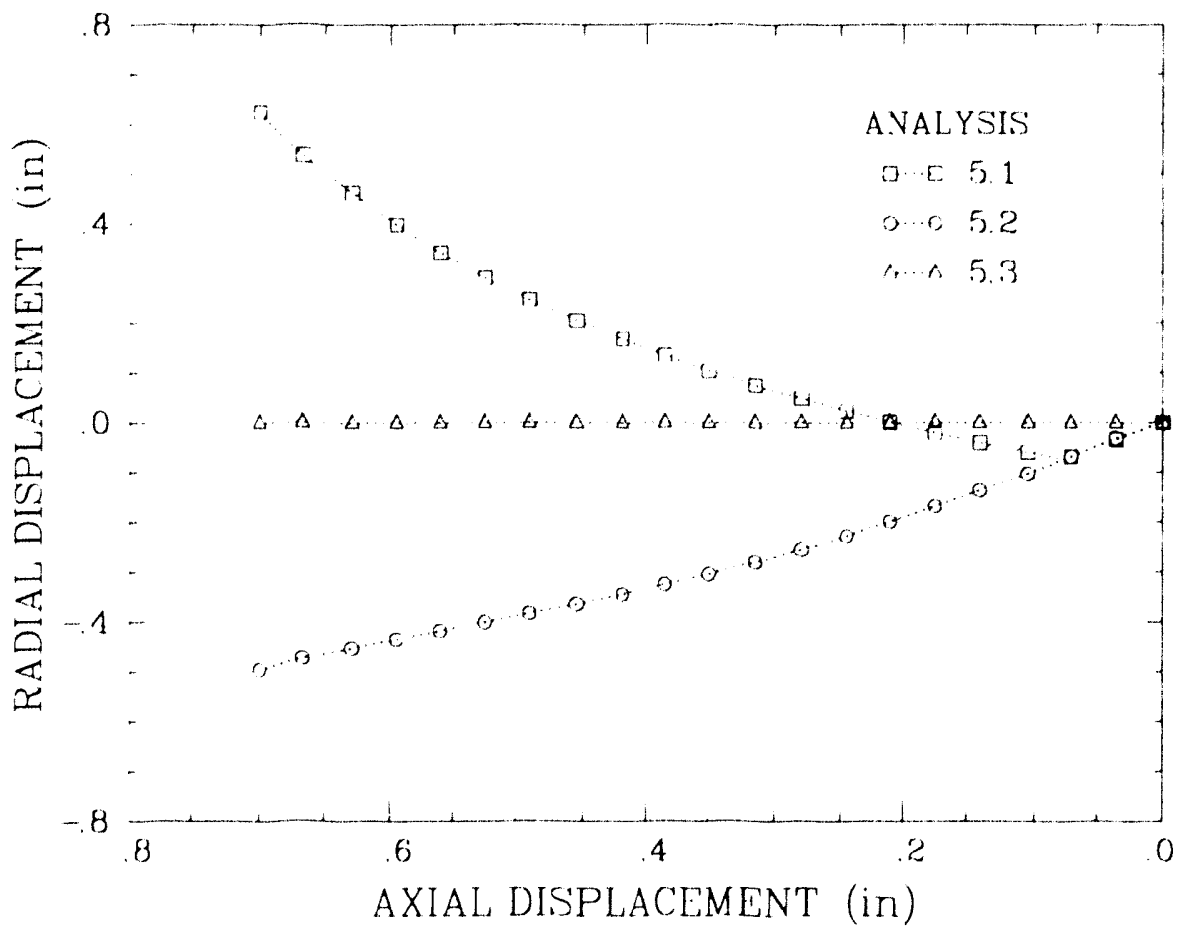

Figure 5.2. Axial and Radial Displacement of Vorle 1 Doring the Simulation of the

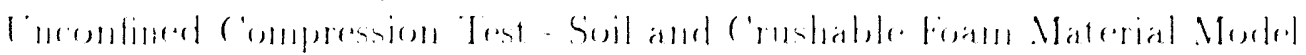


In Analysis 5.1, the material was given a low deviatoric yield strength of 100 psi. When the sample was compressed in the axial direction, it exhibited large displacements in the radial direction (Figure 5.2). This significant radial expansion of a material specimen subjected to unconfined compression is typical for soils but was certainly not exhibited by the layered wire mesh, Kevlar fabric material when it was compressed in a direction normal to the layers.

In Analysis 5.2, the layered material was given a large deviatoric yield strength of $10.0 \times$ $10^{6}$ psi. With this high deviatoric yield strength, the model exhibited radial contraction when it was compressed in the axial direction (Figure 5.2). This occurs because the selection of a large deviatoric yield strength prevents the generation of any deviatoric plastic strains and only allows for the generation of volumetric plastic strains. This radial contraction associated with uniaxial compression is not exhibited by the layered material.

In Analysis 5.3, the material parameters were chosen such that the deviatoric yield surface and the uniaxial load path are nearly coincident (Figure 5.3). The deviatoric yield surface and uniaxial load path would be identically coincident if a value of 0.0 psi was used for material parameter $a_{0}$; however, $a_{0}$ is required to be positive so that the material has at least some tensile strength. Thus, a small positive value of 0.1 psi was used for $a_{0}$. This choice of material parameters is expected to allow for the generation of both volumetric and deviatoric plastic strains when the material is subjected to uniaxial compression. With these material parameters, the finite element analysis of the uniaxial compression test predicted only smali radial displacements when the sample was compressed in the axial direction (Figure 5.2). This analysis indicates that by using the third set of deviatoric yield function parameters, $a_{0}=0.1, a_{1}=3.0$, and $a_{2}=0.0$, this model will predict the behavior exhibited by the layered material subject to uniaxial compression in a direction normal to the layers.

Next, the cyclic unconfined compression test on the layered material was analyzed using the soil and crushable foam model and the third set of deviatoric yield function parameters. A comparison of analytical and experimental results (Figure 5.4) indicates that the soil and crushable foam model does capture the compressive behavior of the layered material. In Figure 5.4, a positive axial stress or strain is compressive. In tension, the layered material exhibits either a significant amount of tensile strength or layer separation depending on the orientation of the tensile loads. The soil and crushable foam model is not able to capture the significant reduction in material stiffness associated with layer separation and instead predicts plastic deformation at very low tensile stress levels. Unfortunately, no plasticity model will be able to capture the material behavior associated with layer separation, and a much more complex, coupled plasticity-continuum damage theory is needed if capturing this tensile behavior is important. 


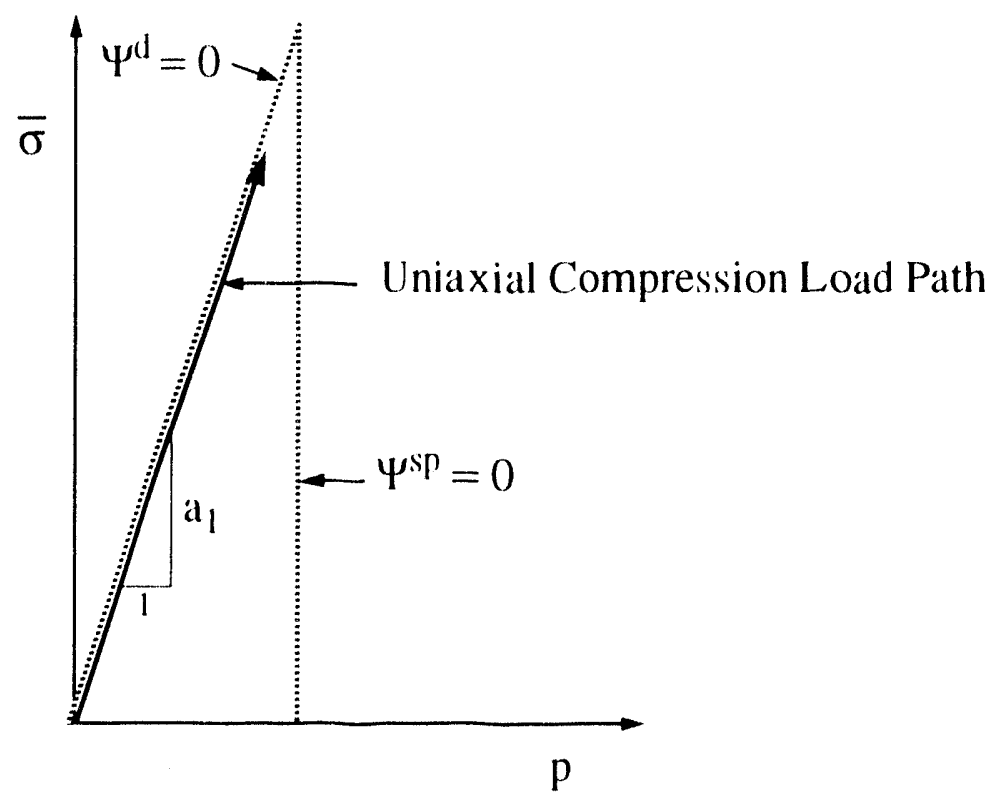

Figure 5.3. Hniaxial compression Load Path and Yield Sinfaces in Mean Stress-Eflfertive Stress Plane.

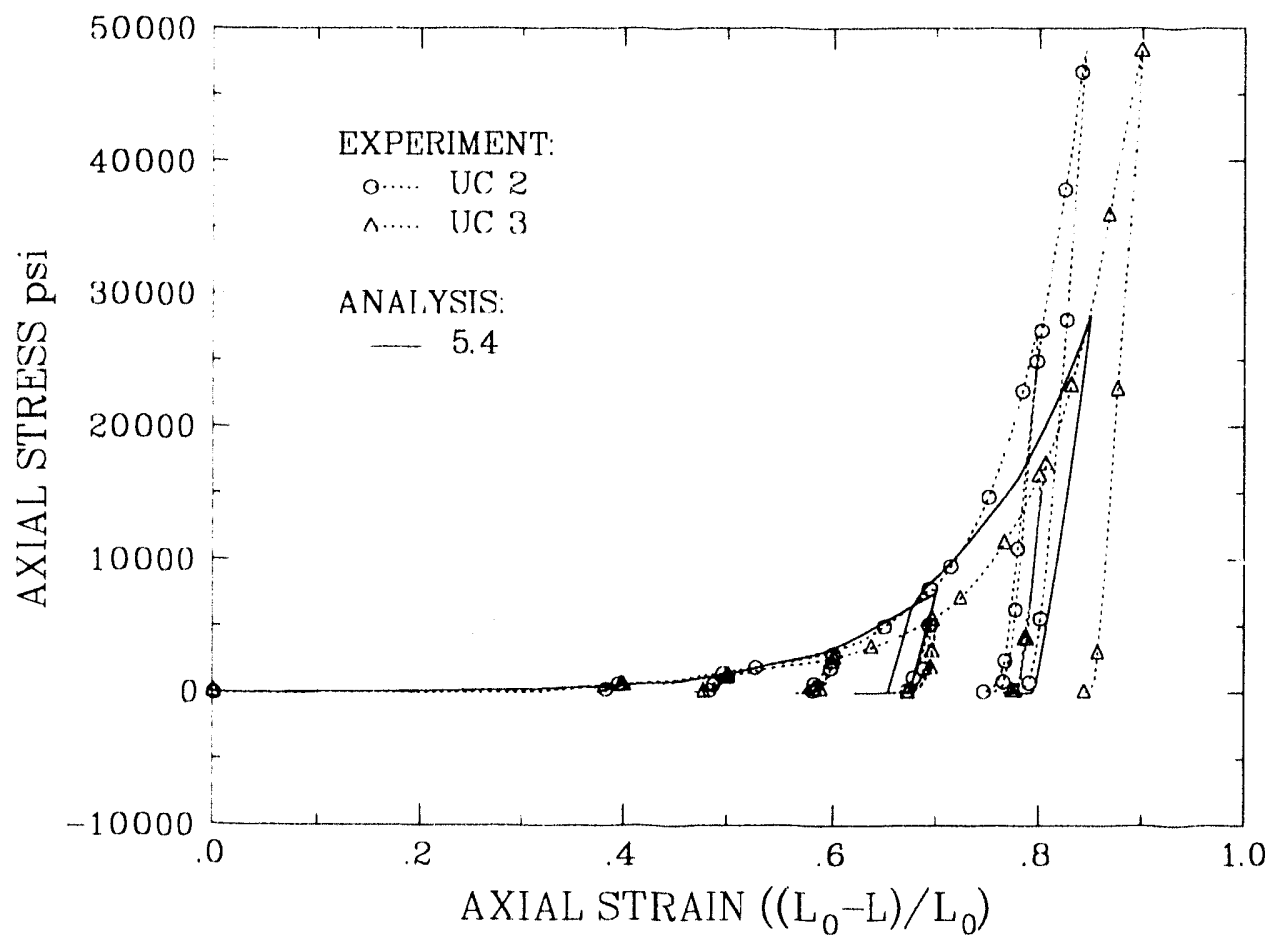

Figure 5.4. ('omparison of Analysis 5.t with Experiment - Vhiaxial (ompression (Positive Axial Streress is ('ompressive). 


\subsection{New Layered Material Model}

In this section, the uniaxial compression tests ate analyzed using the new layered material model to determine if this me del captures the behavior exhibited by the layered material. The one element model of an axisymmetrie material specimen shown in Figure 5.1 was used in these analyses. The model was smbjected to a cyclic, miaxial, compressive load to simulate a uniaxial compression test. Material parameters given in Table 5.2 were used in these analyses.

Table 5.2. Material Parameters for the New Layered Material Model

\begin{tabular}{|c|c|c|c|c|c|}
\hline $\begin{array}{c}\text { Analysis } \\
\text { Number }\end{array}$ & $\begin{array}{c}\text { Elastic } \\
\text { Modulus } \\
(p s i)\end{array}$ & $\begin{array}{c}\text { Poisson's } \\
\text { Ratio }\end{array}$ & $a$ & $b$ & $\tau$ \\
\hline 5.5 & $1.0 \times 10^{5}$ & 0.0 & 17.0 & 8.68 & 20.0 \\
5.6 & $1.0 \times 10^{5}$ & 0.0 & 17.0 & 8.68 & $12.0 \times 10^{3}$ \\
5.7 & $1.0 \times 10^{5}$ & 0.0 & 120.0 & 8.68 & $12.0 \times 10^{3}$ \\
\hline
\end{tabular}

In Analysis 5.5, material parameters which are appropriate for loading in a direction perpendicular to the layers, as in the unconfined compression test, were used. When the linite element model was compressed in the axial direction, it accurately predicted a layered material behavior of axial deformation only. In Analysis 5.6, the material was given a large temsile strength which is appropriate for loading in a direction parallel to the layers. Again, the model accurately represented the axial compression of the material (Figure 5.5), and in tension the material exhibited a significant amount of tensile strength. This response is appropriate for layered material loaded in a direction parallel to the layers. In Analysis 5.7, material paranoter a was increased to 120.0 psi. This analysis indicated that the axial strain associated with censification and a significant increase in the load carrying capacity of the layered material can be modified by changing material parameter a (Figure 5.5). If the layered material is precompressed dining manufacture of the impact limiter, then material parameter a can be modified to account for this precompression. These analyses indicate that with an appropriate selection of material parameters, uniaxial compression tests on the layered material can be simulated with the new layered material model. 'This new model can be given either very lit te or a significant. amount of tensile strength withont changing the compressive response of the model. This foature was attractive for the layered material, since it exhibits temsile behavior which is significantly different than its compressive behavior.

Unfortunately, no plasticity model will be able to capture the significant reduction in material stiffuess associated with layer separation or the increase in material stiffuess that is generated when the layered material is compressed into the lock-up regime. To capture both changes in the elastic response and the permanent deformations, a much more complex coupled plasticity-continum clanage model will be needed. However, use of the new plasticity model developed in (hapter th is expected to generate reasonable 


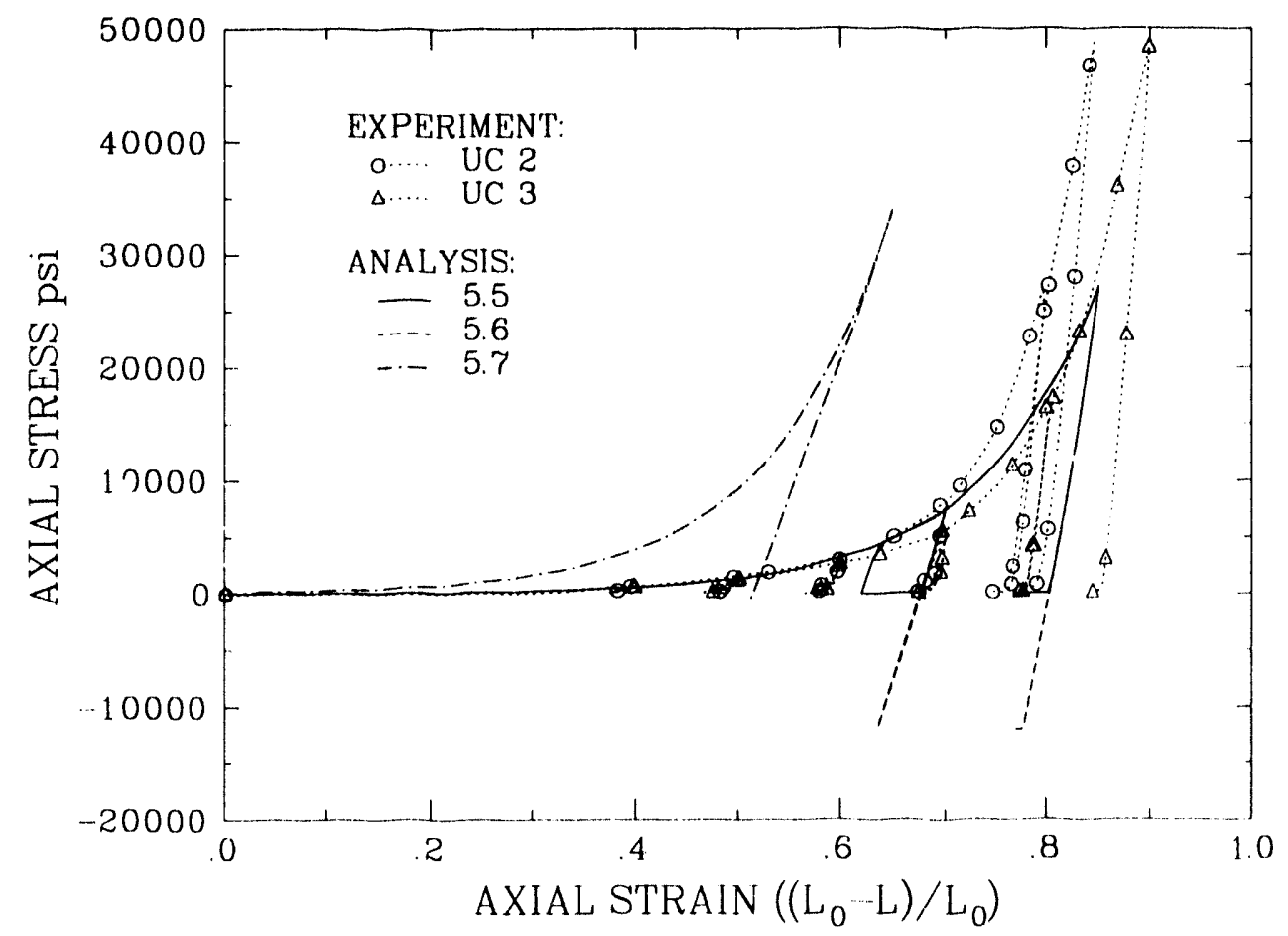

Figure 5.5. Comparison of Analyses 5.5 to 5.7 with Experiments - Uniaxial Compression (Positive Axial Stress is Compressive).

predictions for the behavior of the layered material in an impact limiter during a typical accident event because the amount cyclic loading generated during such an event is negligible. Also, the most important behavior, the permanent deformation and energy absorption of the layered material between the container and the impacting surface, will be captured with the new layered material model. 


\section{Effect of Layered Material Modeling Variations}

In this chapter, a series of two-dimensional, plane strain analyses were performed to investigate the importance of apturing the anisotropie temsile behavior of the layered material during a typical side impact event. These allalyses were performed using the finite element model shown in Figure 6.1 and PRONT()-2]) [5]. The parkage imparted a flat, rigicl target with an impact velocity of 424 fps in all of these analyses. However, a variety of material models and parameters were nsed to describe the impart limiter material (Table 6.1). The sterel container and contents were morleled ats a solid elatetic rod with the sance weight per unit length as a typical filled rombiner.

In Analysis fi.l, the impart limiter material was simmbated using the new lavereed material model with an isotropie tersile sterength of 12,000 psi which is appropriate for loalding in a direction paralled to the lavers. In Analysis 6.2. the impact limiter was moreled with

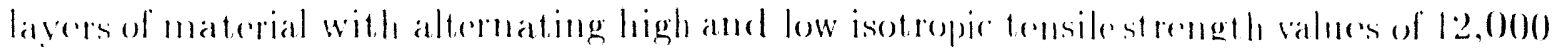
psi and 20 psi. The dark lavers in Figure fi.l were given a high wensile strength, and the

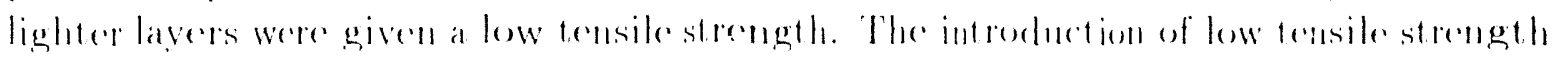
lavers allows laver separation in a direction mormal to the fabrie layers. This approach

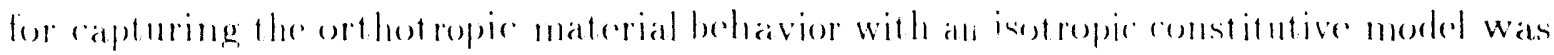

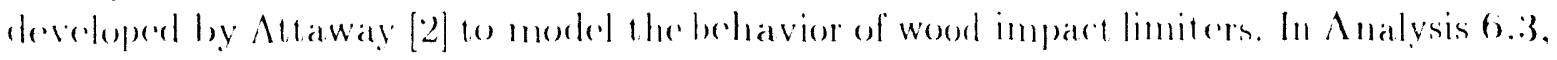

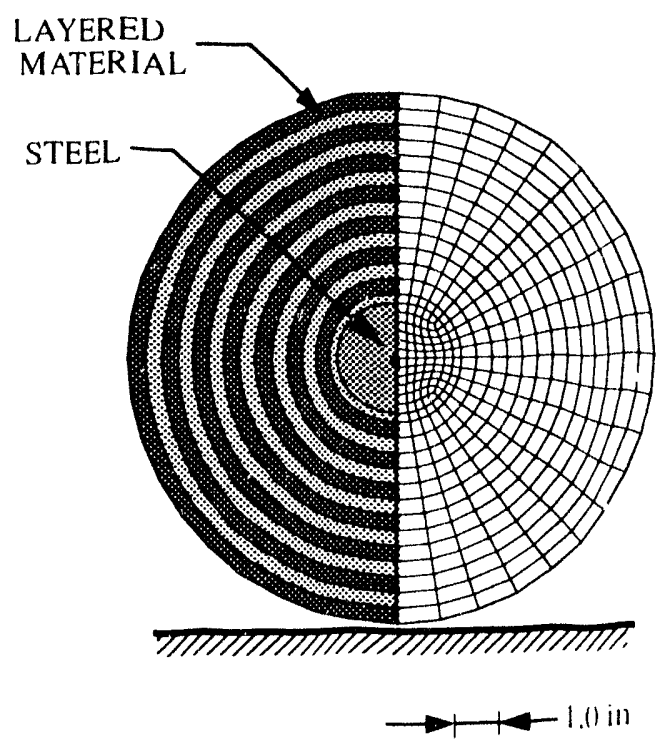

Figure 6.1. Two-I)imensional Plane Strain Mlodel ol Parkinge ('ross-Sétion. 
Table 6.1. Material Parameters Used in the Evaluation of Layered Material Modeling Variations

\begin{tabular}{|c|c|c|c|c|c|c|}
\hline \multicolumn{6}{|c|}{ Layered Material: New Model } \\
\hline $\begin{array}{c}\text { Analysis } \\
\text { Number }\end{array}$ & $\begin{array}{c}\text { Elastic } \\
\text { Modulus } \\
(\mathrm{psi})\end{array}$ & $\begin{array}{c}\text { Poisson's } \\
\text { Ratio }\end{array}$ & $a$ & $\mathrm{~b}$ & $\tau$ & Density \\
\hline 6.1 & $1.0 \times 10^{5}$ & 0.0 & 17.0 & 8.68 & 12,000 & $4.17 \times 10^{-5}$ \\
6.2 & $1.0 \times 10^{5}$ & 0.0 & 17.0 & 8.68 & $12,000 / 20.0$ & $4.17 \times 10^{-5}$ \\
6.3 & $1.0 \times 10^{5}$ & 0.0 & 17.0 & 8.68 & 20.0 & $4.17 \times 10^{-5}$ \\
6.4 & $1.0 \times 10^{5}$ & 0.0 & 120.0 & 8.68 & 12,000 & $4.17 \times 10^{-5}$ \\
\hline
\end{tabular}

\begin{tabular}{|c|c|c|c|c|c|c|}
\hline \multicolumn{2}{|c|}{ Layered Material: Soil and Crushable Foam Model } \\
\hline $\begin{array}{c}\text { Analysis } \\
\text { Number }\end{array}$ & $\begin{array}{c}\text { Elastic } \\
\text { Modulus } \\
(\mathrm{psi})\end{array}$ & $\begin{array}{c}\text { Poisson's } \\
\text { Ratio }\end{array}$ & $a_{0}$ & $a_{1}$ & $a_{2}$ & Density \\
$(\mathrm{psi})$ & 0.1 & 3.0 & 0.0 & $(1 / \mathrm{psi})$ & $\left(\mathrm{lb} \mathrm{s}^{2} \mathrm{in}^{-4}\right)$ \\
\hline 6.5 & $1.0 \times 10^{5}$ & 0.0 & $4.17 \times 10^{-5}$ \\
\hline
\end{tabular}

\begin{tabular}{|c|c|c|c|c|l|l|}
\hline \multicolumn{2}{|c|}{ Container/Contents: Elastic } \\
\hline $\begin{array}{c}\text { Analysis } \\
\text { Number }\end{array}$ & $\begin{array}{c}\text { Elastic } \\
\text { Modulus } \\
(\mathrm{psi})\end{array}$ & $\begin{array}{c}\text { Poisson's } \\
\text { Ratio }\end{array}$ & Density & & & \\
\hline 6.1 to 6.5 & $30.0 \times 10^{6}$ & 0.3 & $4.135 \times 10^{-4}$ & & & \\
\hline
\end{tabular}

all of the layers were given a low tensile strength of 20 psi. Results from these analyses indicate that the predicted displacement of the container is rather insensitive to these layer modeling variations (Figure 6.2). Also, nearly identical acceleration-time histories were obtained when all of the layers were given a high tensile strength (Analysis 6.1) and when alternating layers with high and low tensile strength were used (Analysis 6.2). However, the predicted peak acceleration of the container is significantly lower when all of the layers are given a low tensile strength of 20 psi (Figure 6.3).

Plots of the deformed shape of the impact limiter generated during and after the inpact event are shown in Figures 6.4 to 6.6. Densification of the layered material between the container and the impacting surface is followed by compression of the layered material above the container. A comparison of the deformed shapes predicted by the first three analyses indicates that the manner in which the layers are modeled affects the predicted deformed shape of the impact limiter. Specifically, inclusion of layers with low tensile strengths tends to increase the predicted amount of lateral deformation generated during the numerical simulation. 


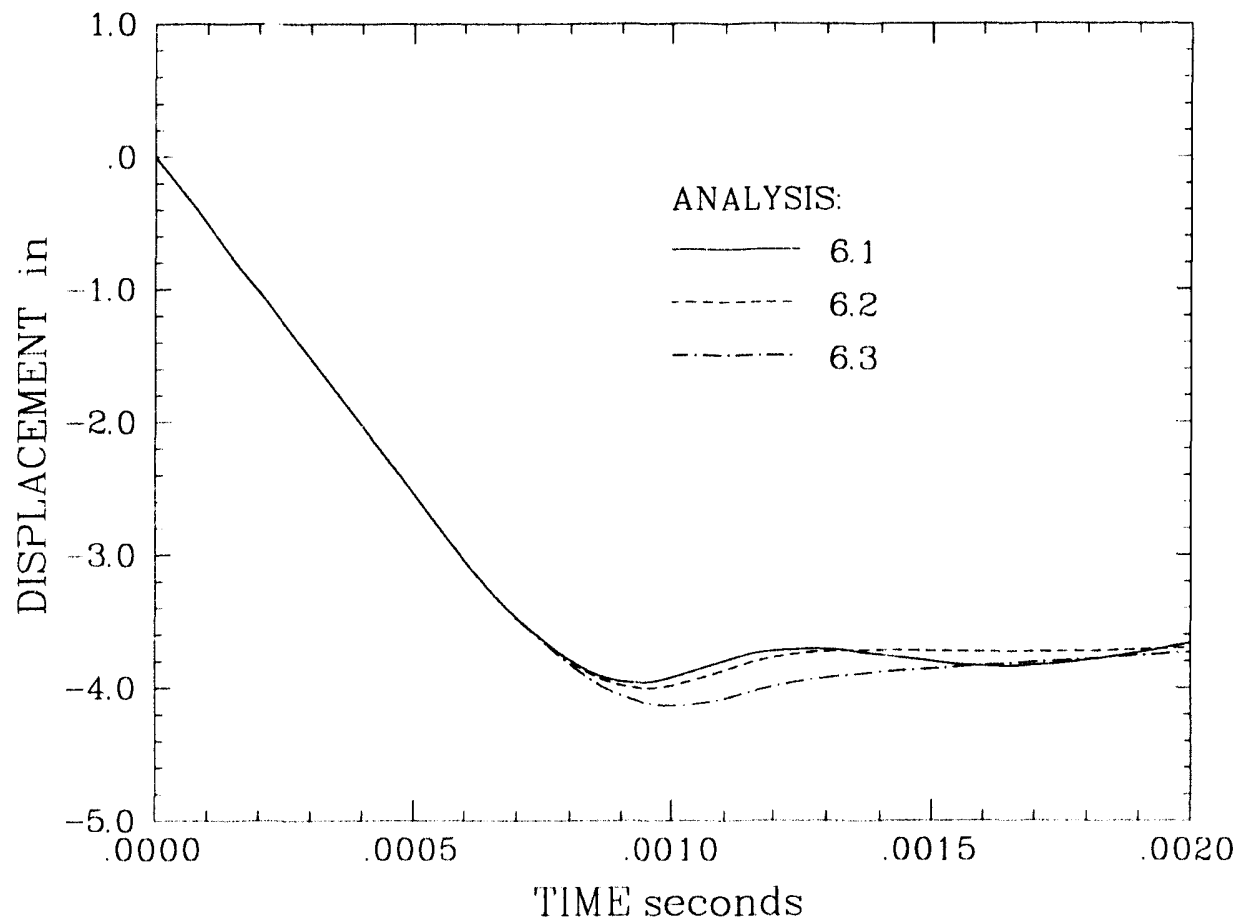

Figure 6.2. Container Displacement Predicted by Analyses with the New Layered Material Model - Effect of Layer Modeling Variations.

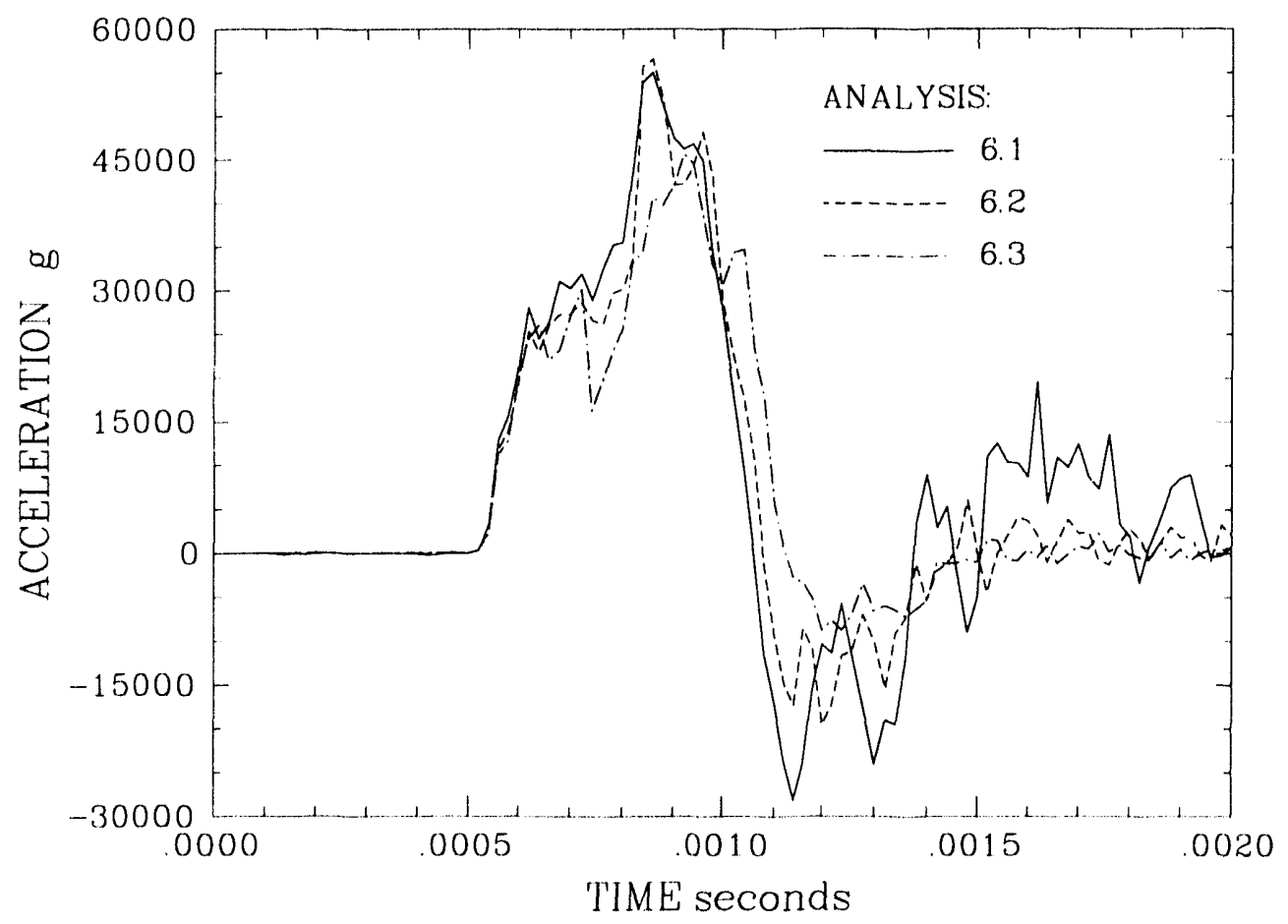

Figure 6.3. Container Acceleration Predicted by Analyses with the New Layered Material Model - Effect of Layer Modeling Variations. 


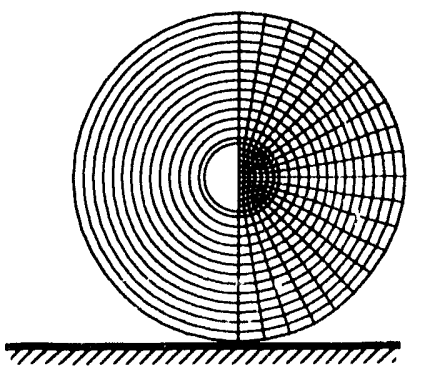

$0.0 \mathrm{msec}$.

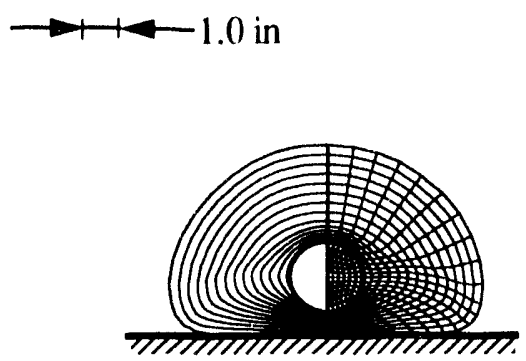

$1.0 \mathrm{msec}$.

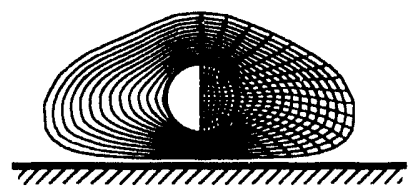

$2.0 \mathrm{msec}$.

Figure 6.4. Deformed Shape of Finite Element Model at Varions Time Steps Inuring Analysis 6.1 - High Isotropic Tensile Strength.

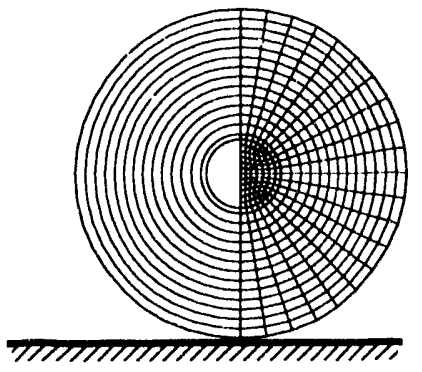

$0.0 \mathrm{msec}$.

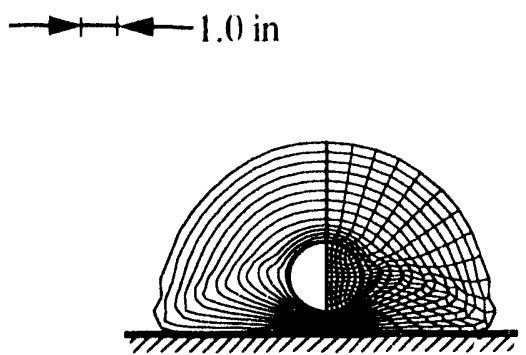

$1.0 \mathrm{msec}$.

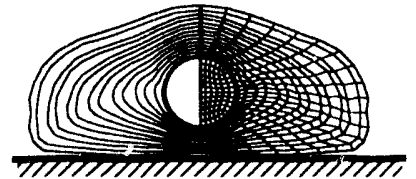

$2.0 \mathrm{msec}$.

Figure 6.5. Deformed Shape of Finite Element Model at Various Time Steps IDuring Analysis 6.2 - Alternating High/Low Isotropic Tensile Strength.

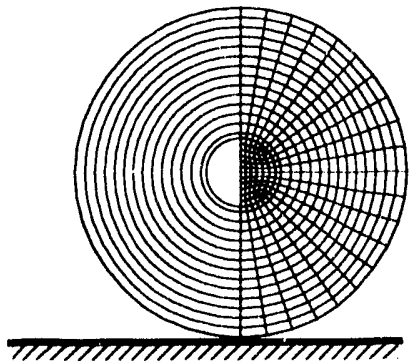

$0.0 \mathrm{msec}$.

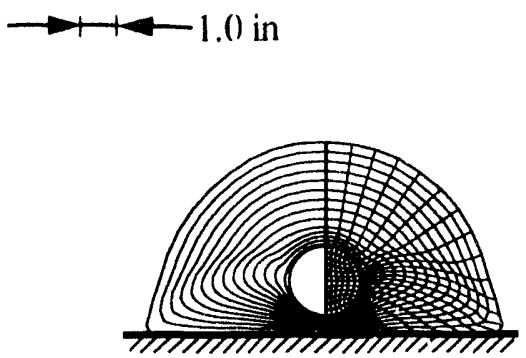

$1.0 \mathrm{msec}$.

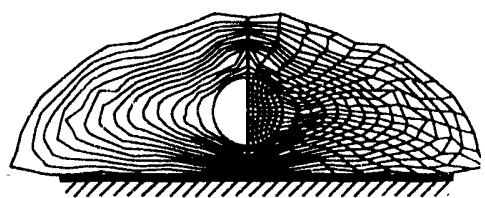

$2.0 \mathrm{msec}$.

Figure 6.6. Deformed Shape of Finite Element Model at Varions Time Steps During Analysis 6.3 - Low Isotropic: Tensile Strength. 


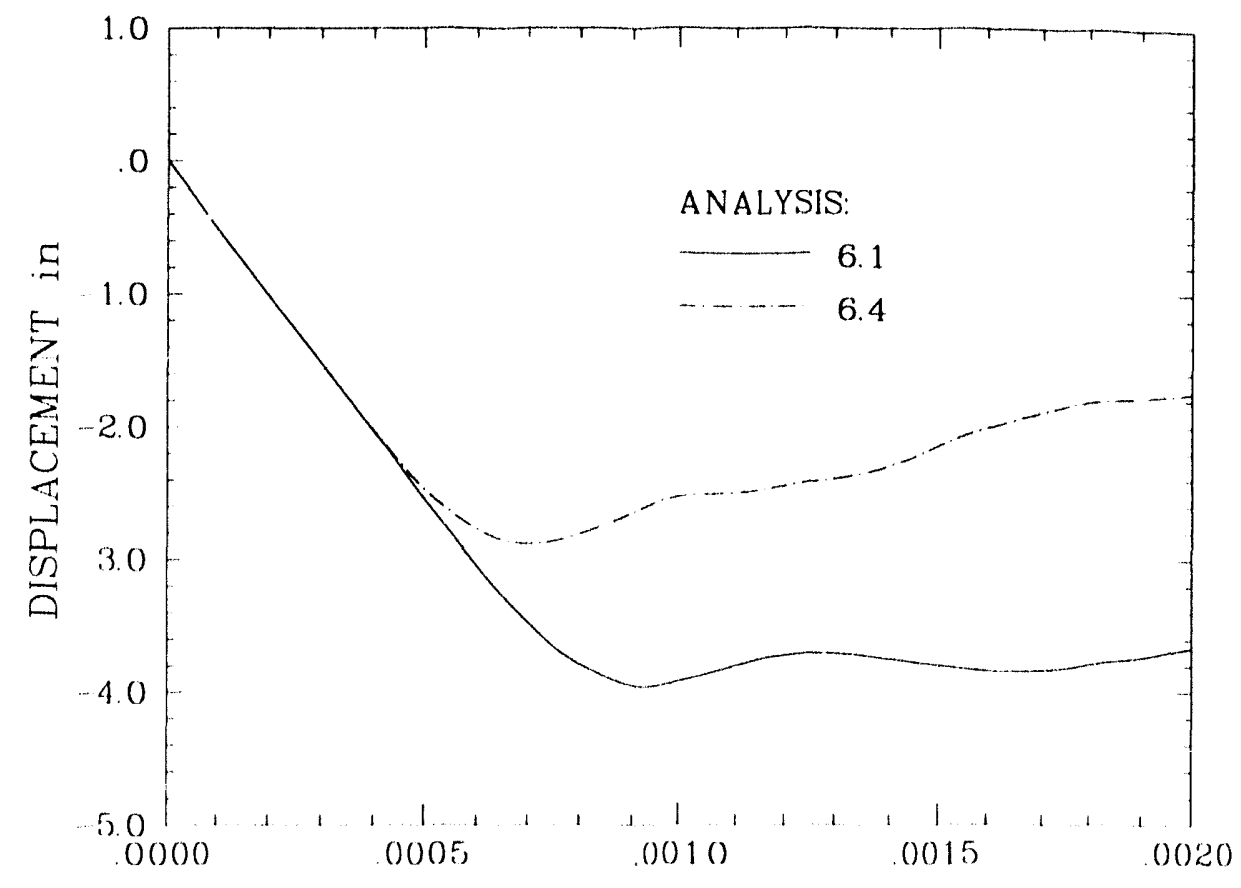

'TIME' seconds

Figure 6.7. Container Displacement Predicted by Analyses with the New Layered Material Model - Effect of Material Parameter $a$.

In Analysis 6.4, the effects of precompressing the impact limiter during manufacture were investigated by increasing material parameter a to 120 psi. As expected, the predicted amount of impact limiter crush-up is reduced when the limiter material is precompressed and material parameter $a$ is increased (Figure 6.7). However, the predicted peak accelcration of the container is only 10 percent higher when material parameter a is changed from 17 psi to 120 psi (Figure 6.8). Thus, precompression of the layered limiter material during manufacture will have a significant effect on limiter deformation during an impact event but little effect on the loads applied to the primary container. A plot of the deformed shape of the model (Figure 6.9) also shows that an increase in material parameter a reluces the amount of impact limiter deformation.

In Analysis 6.5, the layered material was simulated using the soil and crushable foam model. 'The material parameters were chosen such that the behavior of the layered material exhibited during the static uniaxial compression tests were captured ('Table 6.1 ). Results obtained with the new layered material model and the soil and crushable foam model are compared in Figures 6.10 and $61:$ Similar container displacement predictions are generated with these two material models. However, when the soil and crushable form model was used, the solution algorithm became unstable during the later stages of the analysis and failed to generate an acceptable solution (Figure 6.12). The lack of stable behavior can probably be attributed to the low tensile strength needed by the soil and 


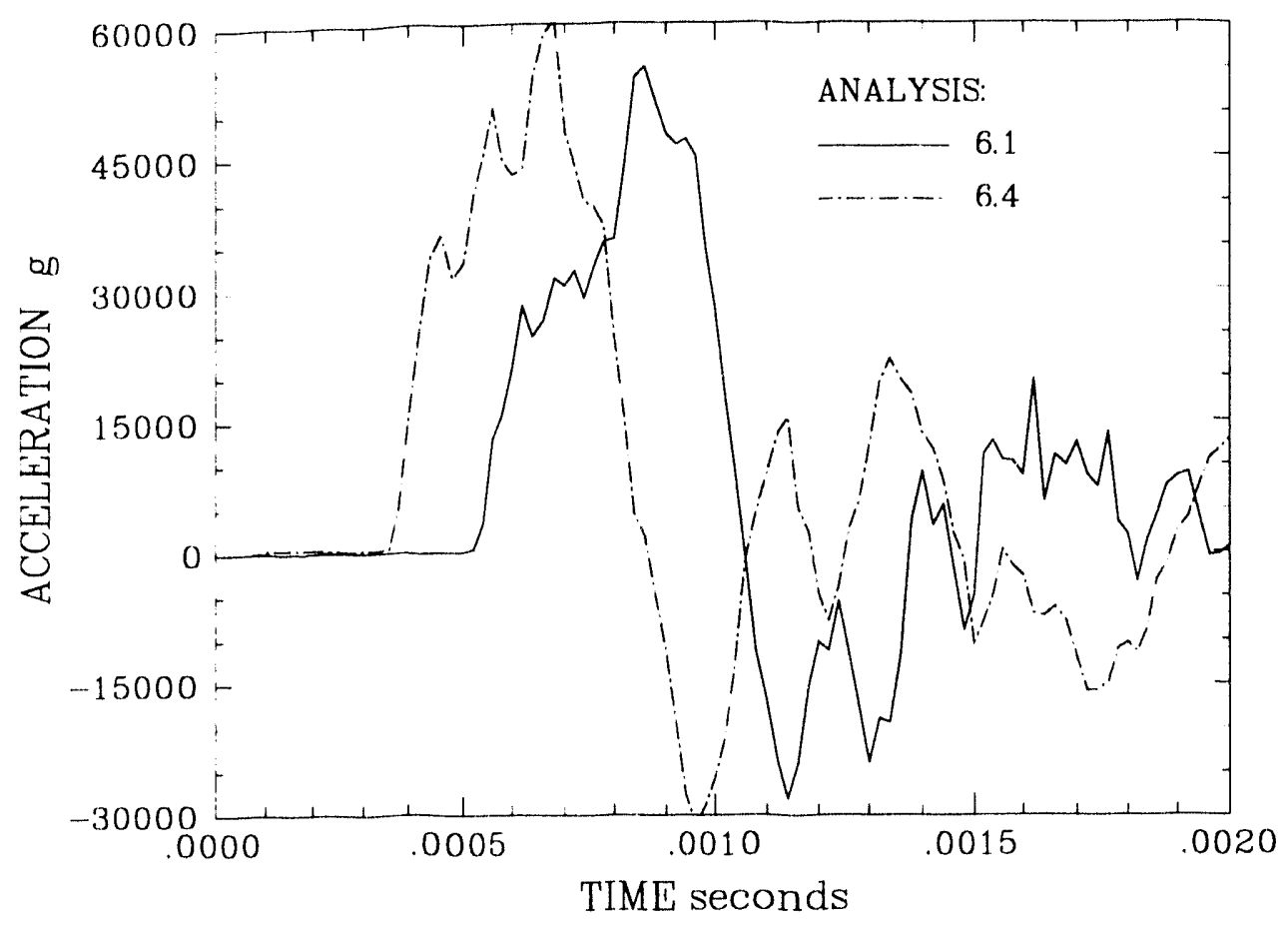

Figure 6.8. ('ontainer Acreleration Predieted by Analyses with the New Layered Material Mortel - Effect of Material Paranoter a.

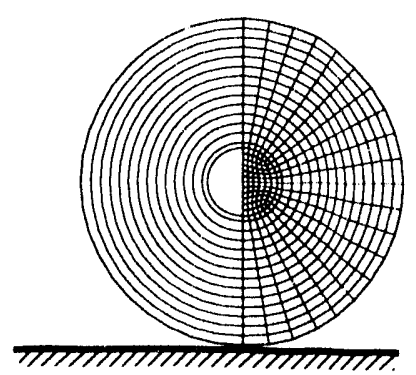

$0.0 \mathrm{msec}$.

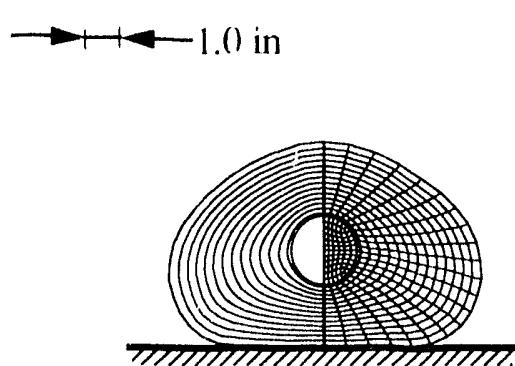

$1.0 \mathrm{msec}$.

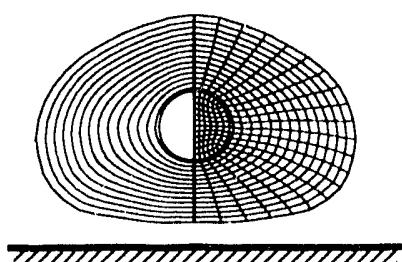

$2.0 \mathrm{msec}$.

Figure 6.9. Deformed Shape of Finite Element Model at Various Time Steps Douring Aualysis (i.4 - New Layered Material Model with $a=120$. 


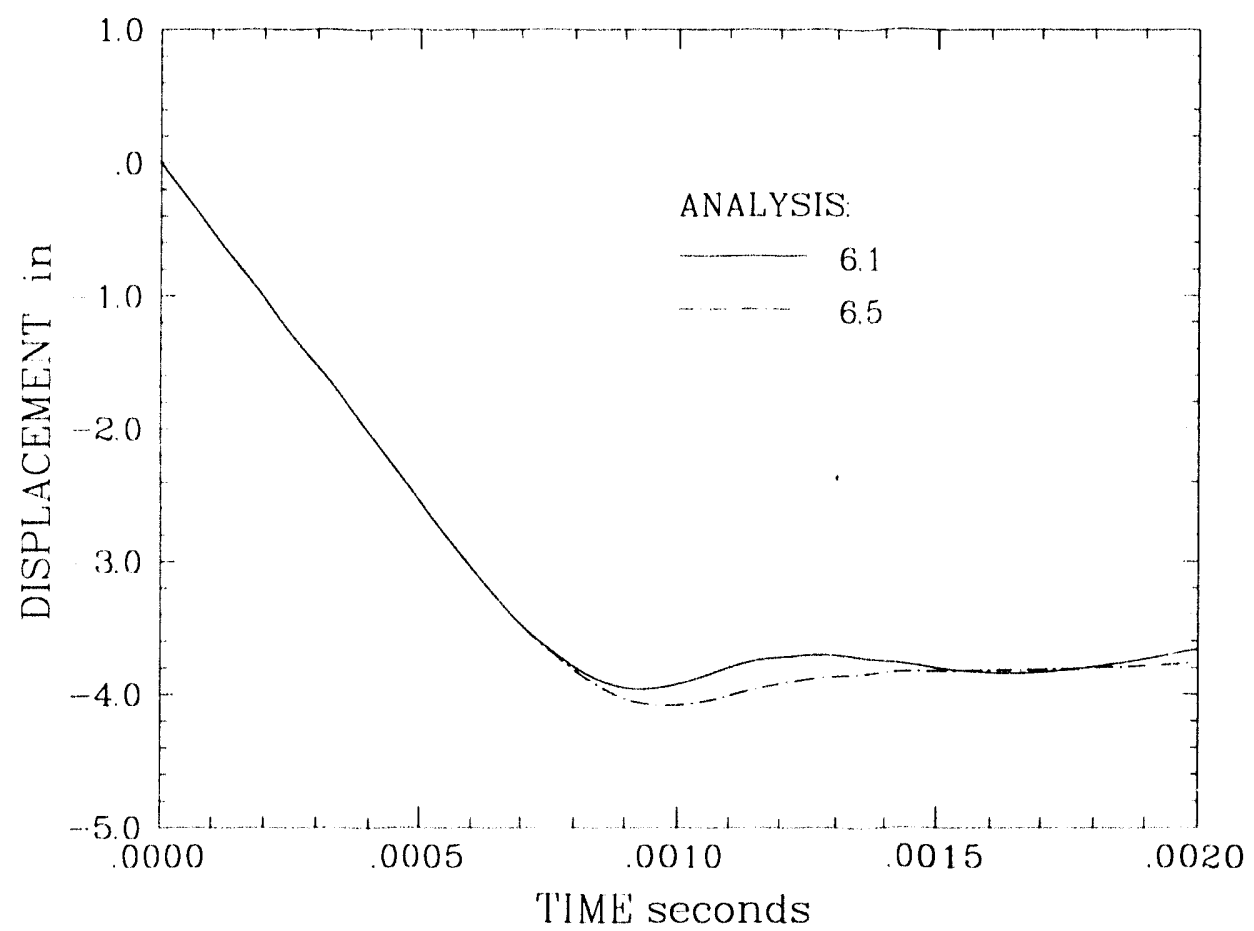

Figure 6.10. Container Displacement Predicted by Analysis 6.5 with the Soil and (rushable Foam Model.

crushable foam model to duplicate the uniaxial compression tests. Since the soil and crushable foam model failed to gencrate an acceptable solution to this relatively simple t.wo-dimensional problem, it was not used in subsequent three-dimensional analyses. 


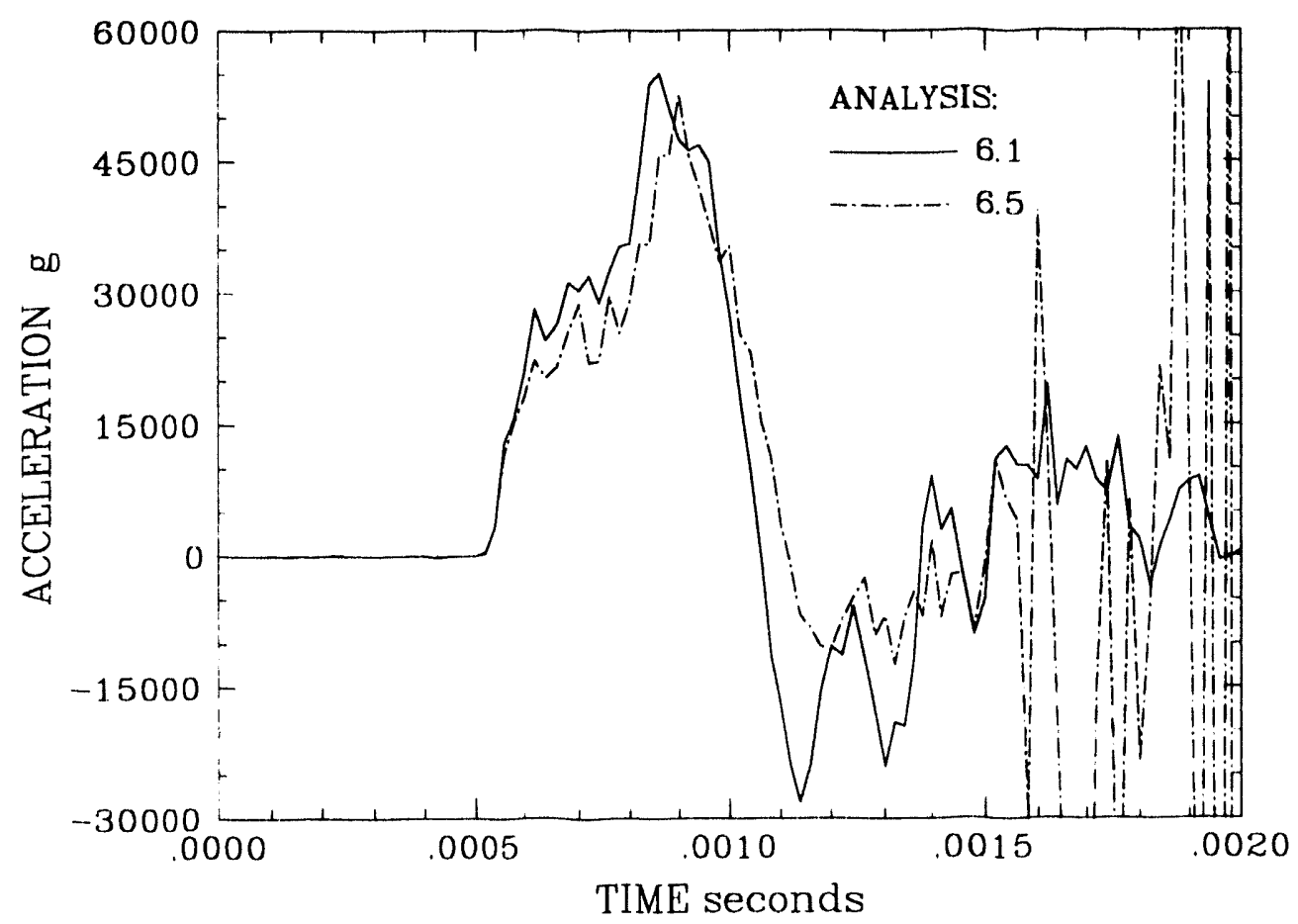

Figure 6.11. ('ontainer Acceleration Predicted by Analysis 6.5 with the Soil and ('rushable Foam Model.

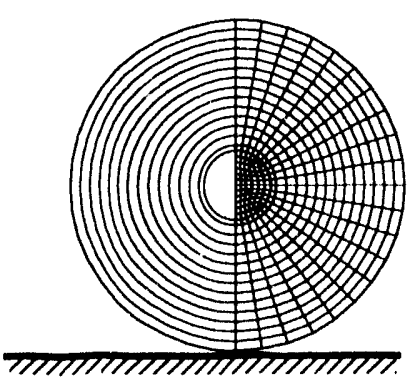

$0.0 \mathrm{msec}$.

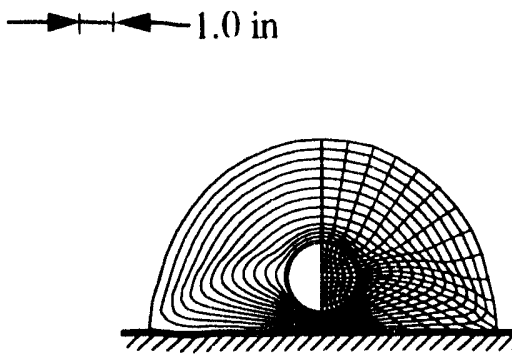

$1.0 \mathrm{msec}$.

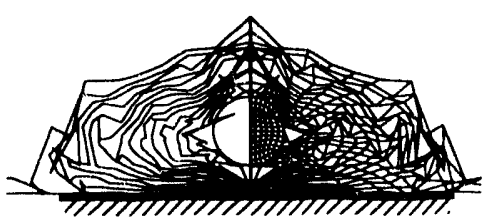

2.0 nisec.

Figure 6.12. Deformed Shape of Finite Element Model at Various Time Steps During Analysis 6.5 - Soil and ('rushable Foam Model. 


\section{Benchmark Analyses - Steel Container with Layered Material Limiter}

A parkage with a sterel container and a layered material impart limiter was subjected to a side impart inter an essentially myled ling surface with an impart velocity of 424 fos. The purpeses of this experiment were to evaluate the hehavior of a layered material impart limiter and to generate data te benchmark romstitutive models for the layered material. In this rhaptere the side impare experiment is andyzed to determine if the new layered material model adequately simulates the impare limiter helavior during this impart event. These analyses were performed using the finte element model shown in Figure 7.1 and PRON'T(O) 3I) [6]. (Only ome-fourth of the parkage was modeled due to the symmetries present in the parkage and appropriate bemolary conditions were applied

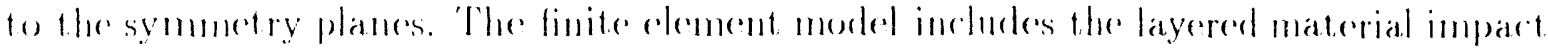
limiter. a steel containere and lead shot contents. There analyses were performed using varions material parameters for the layered material and the lead shot rontents ('Table i.1).
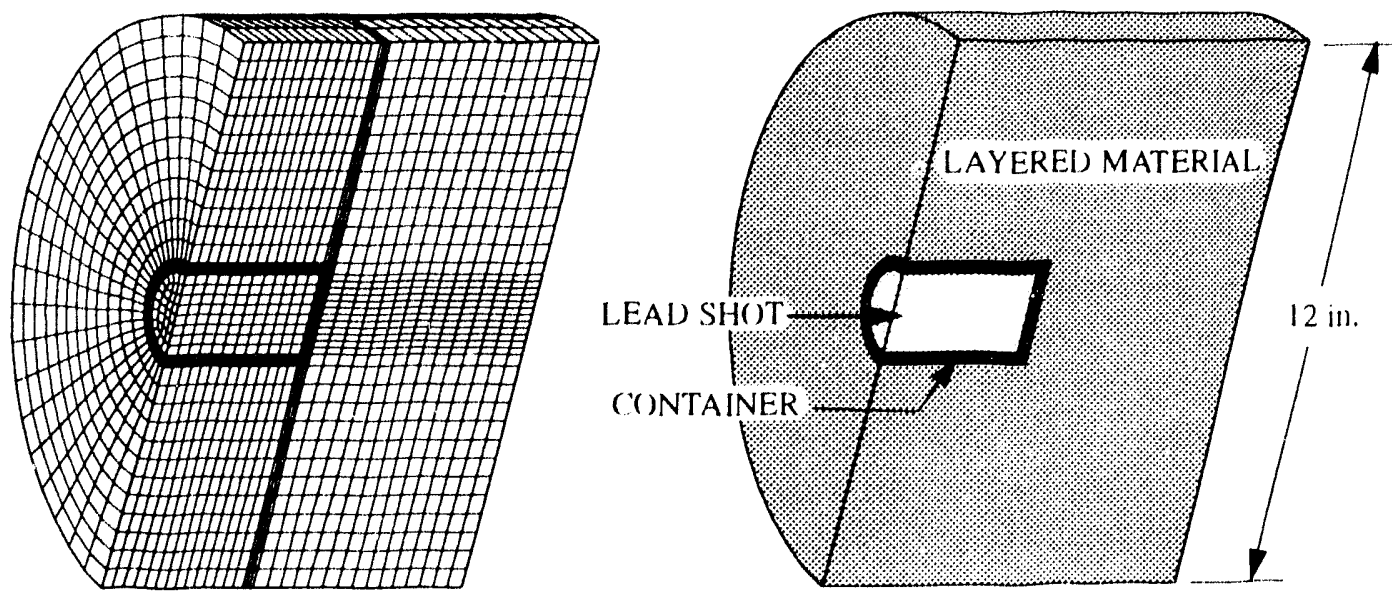

Figure 7.1. Three-1)imensional Finde Element Merdel of the Benchumark Parkage with a Sitoel ('ontainer.

In Analysis 7.1 , paraneters for the layered material were chesen to mateh the resilts from the moiaxial material eharacterization tests. During the mambarture of the package, layers of impart limiter material are womed together and not simply starked up as they were for the maiaxial rompression tests. The winding process gemerates a compressive stress between the layers and the layers are precomperessed prior to the impart event.

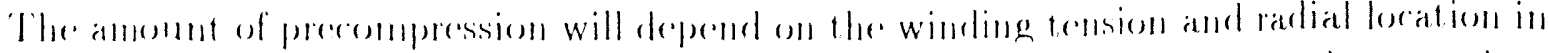

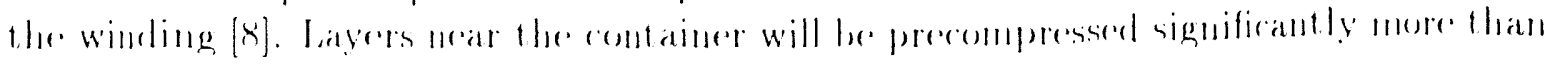


Table 7.1. Material Parameters Used in the Benchmark Analyses

\begin{tabular}{|c|c|c|c|c|c|c|}
\hline \multicolumn{2}{|c|}{ Layered Material: New Model } \\
\hline $\begin{array}{c}\text { Analysis } \\
\text { Number }\end{array}$ & $\begin{array}{c}\text { Elastic } \\
\text { Modulus } \\
(\mathrm{psi})\end{array}$ & $\begin{array}{c}\text { Poisson's } \\
\text { Ratio }\end{array}$ & $a$ & $b$ & $\tau$ & Density \\
\hline 7.1 & $1.0 \times 10^{5}$ & 0.0 & 17.0 & 8.68 & 12,000 & $4.17 \times 10^{-5}$ \\
$7.2,7.3$ & $1.0 \times 10^{5}$ & 0.0 & 120.0 & 8.68 & 12,000 & $1.17 \times 10^{-5.5}$ \\
\hline
\end{tabular}

\begin{tabular}{|c|c|c|c|c|c|c|}
\hline \multicolumn{7}{|c|}{ ASlg Steel Container: Elastic-Plastic } \\
\hline $\begin{array}{l}\text { Analysis } \\
\text { Number }\end{array}$ & $\begin{array}{l}\text { Elastic } \\
\text { Modulus } \\
\text { (psi) }\end{array}$ & $\begin{array}{c}\text { Poisson's } \\
\text { Ratio }\end{array}$ & $\begin{array}{c}\text { Yield } \\
\text { Strength } \\
\text { (psi) }\end{array}$ & $\begin{array}{l}\text { Mardening } \\
\text { Modulus } \\
\text { (psi) }\end{array}$ & Bota & $\begin{array}{l}\text { I)(nsity } \\
\text { (II) } \mathrm{s}^{2} \mathrm{in}^{-4} \text { ) }\end{array}$ \\
\hline 7.1 to 7.3 & $30.0 \times 10^{6}$ & 0.3 & $56.0 \times 10^{3}$ & $1.5 \times 10^{6}$ & 0.0 & $7.72 \times 10^{-4}$ \\
\hline
\end{tabular}

\begin{tabular}{|c|c|c|c|c|c|c|}
\hline \multicolumn{2}{|c|}{ Lead Shot: Elastic or Elastic-Plastic } \\
\hline $\begin{array}{c}\text { Analysis } \\
\text { Number }\end{array}$ & $\begin{array}{c}\text { Elastic } \\
\text { Modulus } \\
(\mathrm{psi})\end{array}$ & $\begin{array}{c}\text { Poisson's } \\
\text { Ratio }\end{array}$ & $\begin{array}{c}\text { Yield } \\
\text { Strength } \\
(\mathrm{psi})\end{array}$ & $\begin{array}{c}\text { Hardening } \\
\text { Modulus } \\
(\mathrm{psi})\end{array}$ & Bota & Density \\
\hline $7.1,7.2$ & $40.0 \times 10^{3}$ & 0.3 & - & - & 0.0 & $3.084 \times 10^{-4}$ \\
7.3 & $2.0 \times 10^{6}$ & 0.3 & 1200.0 & 100.0 & 0.0 & $3.084 \times 10^{-4}$ \\
\hline
\end{tabular}

layers near the onter surface of the limiter. The effect of a uniform precompression of the layers was investigated by increasing material parameter a to 120.0 psi in Analyses 7.2 and 7.3. In Analyses 7.1 and 7.2, the lead shot was modeled as an elastic material and in Analysis 7.3, the lead shot was modeled as an elastic-plastic material. Material parameters which are appropriate for solid lead were used in Analysis $7.3[9,10]$.

Displacement and acceleration histories for the container predicted by these analyses are shown in Figures 7.2 and 7.3. The displacement plots indicate that the anomt of layered material deformation generated during an impact event is significantly affected by the amount of precompression generated during assembly (Figure 7.2). The aceeleration plots indicate that the container is subjected to a peak acceleration of approximately $60,000 \mathrm{~g}$ 's. The acceleration plots are not very smooth since plot data was only stored at. time intervals of 0.05 msec. due to memory constraints. However, the two-dimensional, plane strain analyses of a section near the center of the container which were presented in the previous chapter also predicted a peak accoleration level of approximately $60,000 \mathrm{~g}$ 's (Figure 6.8). A PLO'T HISTORY option which allows for the storage of the acceleration data at every solution step but only at a limited number of nodes in the finite element. mesh was recently implemented in PRONT()-31) [6]. This option can be used in future analyses to generate accurate acceleration history plots. 


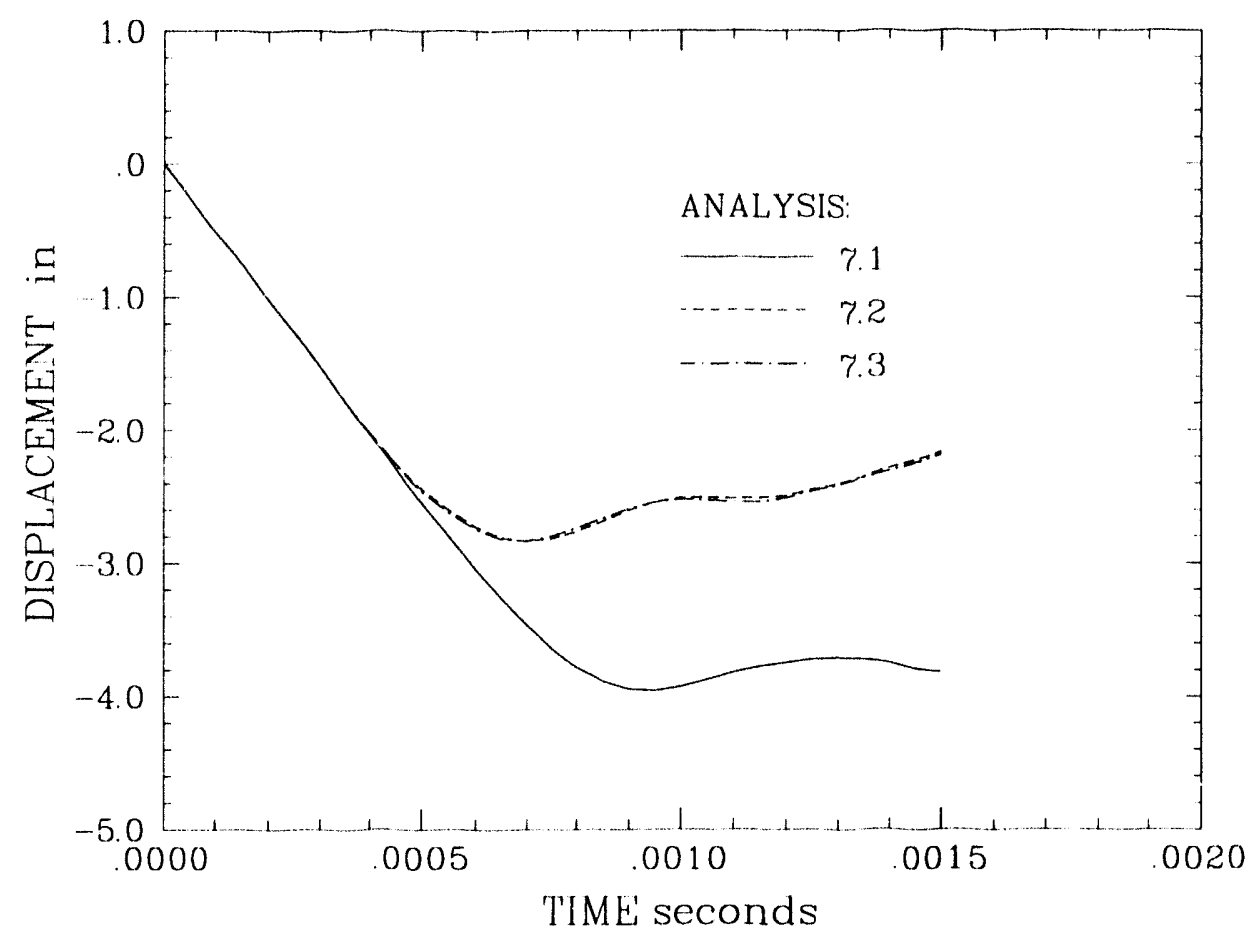

Figure 7.2. Steel Container Displacement Predicted by the Three-Dimensional Finite Element Analyses of a Side Impact.

The cylindrical part of the limiter for this package contained 30 layers of Kevlar fabric and 208 layers of aluminum screen wire. The Kevlar fabric layers alone will give the limiter material an initial tensile strength of $8615 \mathrm{psi}$ in a circumferential direction. As the layered material is crushed, the spacing between the Kevlar layers will decrease and the tensile strength of the layered material will increase if the Kevlar layers are not damaged. The tensile load in a single kevlar layer was estimated by first computing the principal Cauchy stresses in the layered material between the container and the impact surface. As expected, the maximum tensile stresses were oriented in a direction perpendicular to the package velocity. Element tractions were then computed using the maximum tensile stress and the current element, size. Finally, kevlar layer loads were estimated by dividing the element tractions by the number of Kevlar layers in the element. Recall that the Kevlar layers have a tensile strength of $1400 \mathrm{lbs}$ per inch of width. In Analyses 7.1, 7.2 and 7.3, the predicted maximum Kevlar layer loads are 360, 590, and $560 \mathrm{lbs}$./inch, respectively. Thus, the Kevlar layers are not expected to fail.

As predicted by these analyses, the layered material limiter did remain in place during the $424 \mathrm{fps}$ side impact test. Unfortunately, during the impact test on the experimental package, lead wires to the accelerometers and strain gages were lost and no experimental gage data was obtained. Therefore, the only comparisons between analysis and experiment which could be made were of the final deformed shape of the package. Deformed shapes of the models predicted during the three analyses are shown in Figures 7.4 to 7.6. 


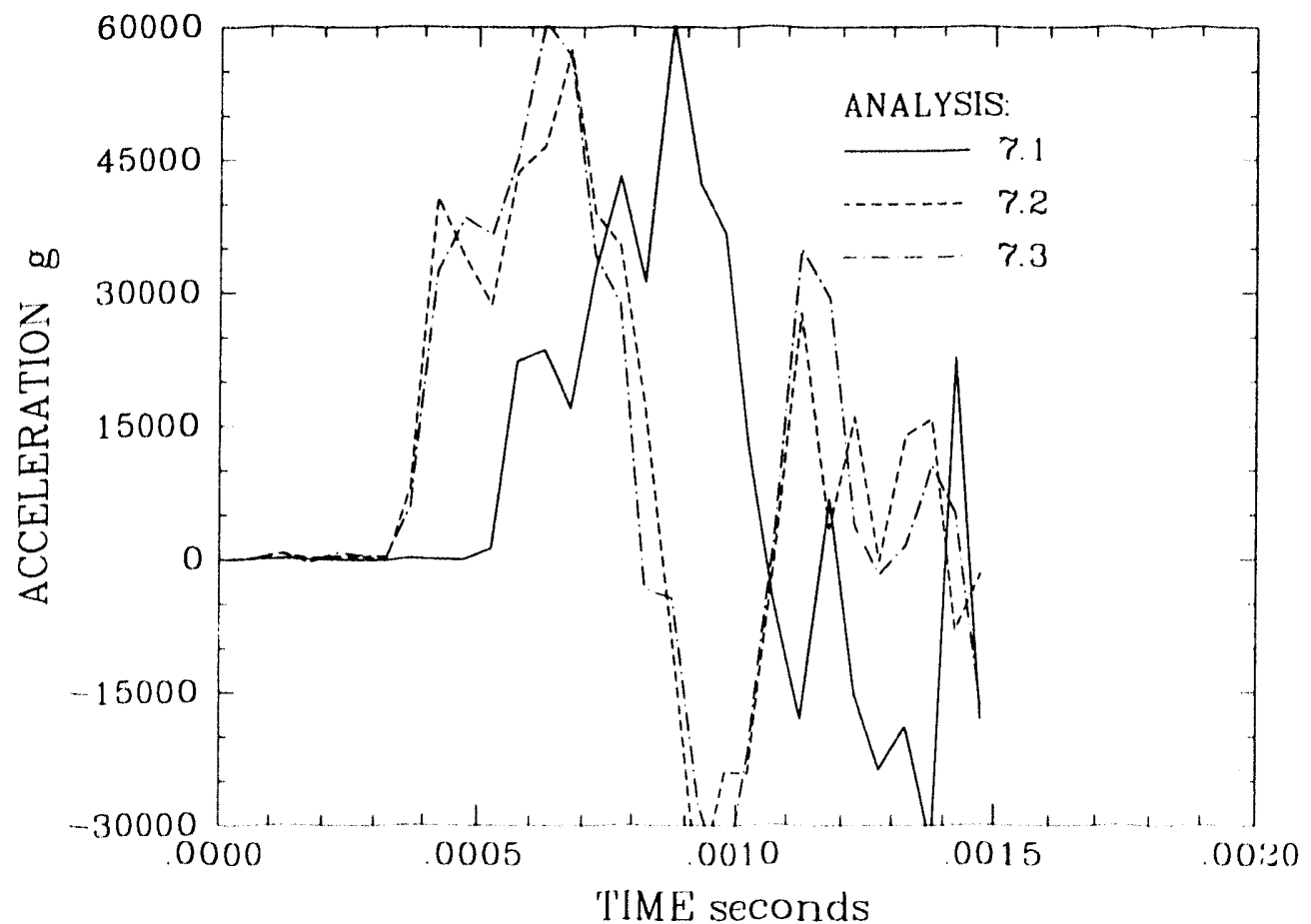

Figure 7.3. Steel Container Acceleration Predicted by the Three-Dimensional Finite Element Analyses of a Side Impact.

Permanent deformations predicted by these analyses are compared with the experimental results in Table 7.2. During the impact experiment, layered material beneath the center of the container was permanently compressed 2.75 inches. The container was deformed 0.082 inches into an oval shape near its midplane (Figure 7.7). Layered material above the container was compressed 2.125 inches. Analysis 7.1 predicted 3.8 inches of layered material crush between the container and the impact surface. Analyses 7.2 and 7.3 both predicted 2.5 inches of layered material crush beneath the container which is reasonably close to the experimental measurement of 2.75 inches. Also, Analyses 7.2 and 7.3 predicted 2.05 inches of layered material crush above the container which is reasonably close to the experimental measurement of 2.125 inches. Thus, reasonable deformation predictions for the wound impact limiter were obtained by using a value of 120 psi for material parameter $a$. 


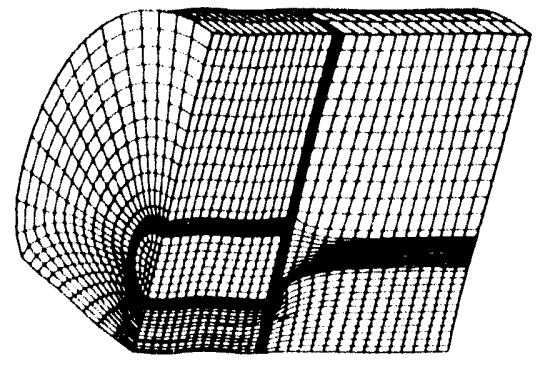

().8 insece.

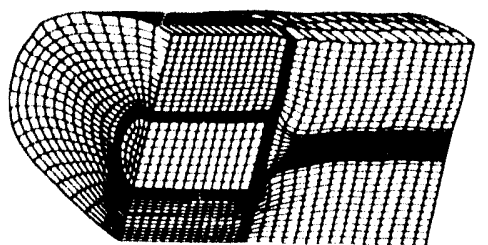

$1.5 \mathrm{msec}$.

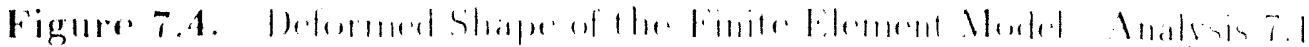

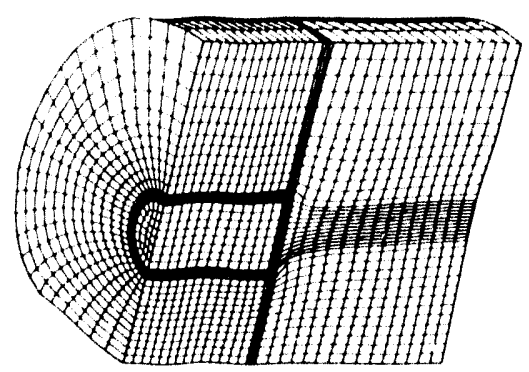

$0.8 \mathrm{msec}$.

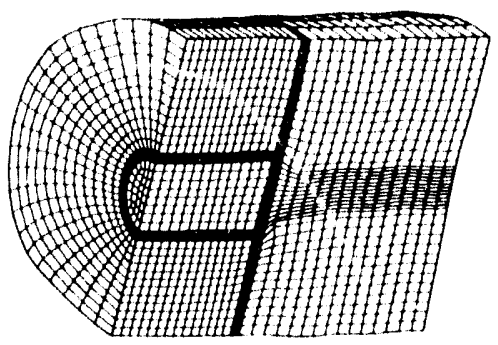

$1.5 \mathrm{msec}$.

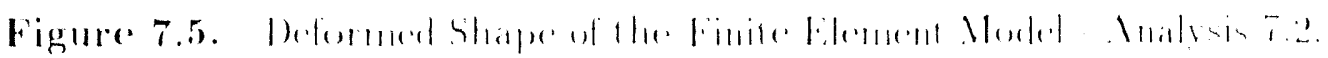

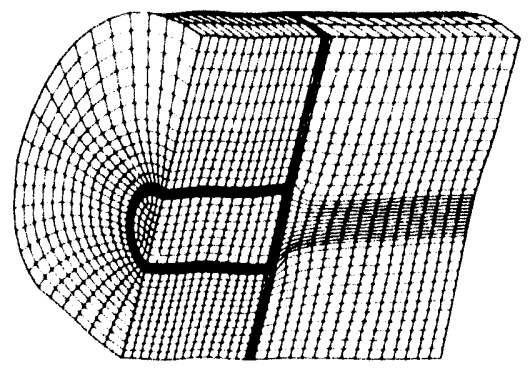

().8 misec.

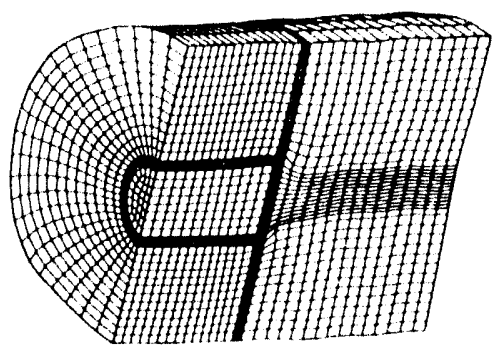

1.5 msece.

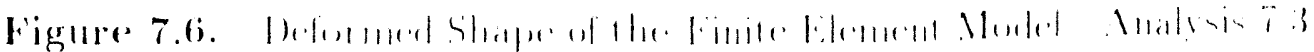




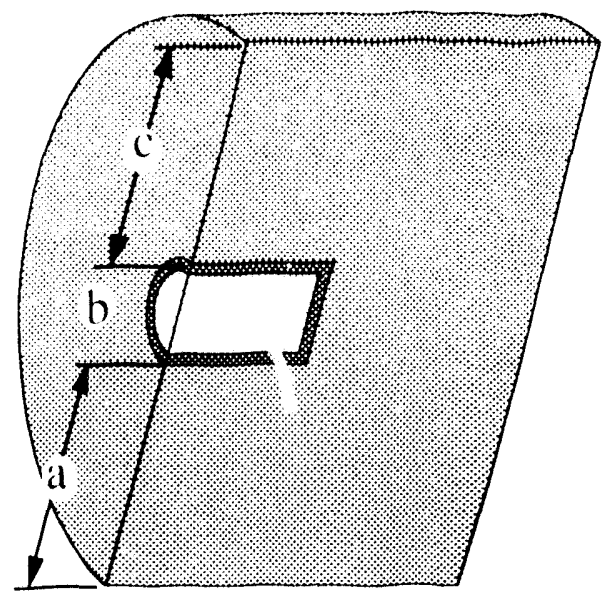

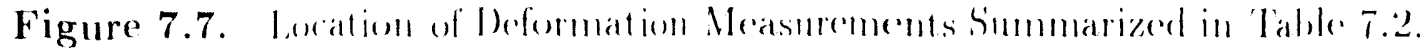

Table 7.2. Permanent Deformatioms Predieted hy He Bemehmark Analyses

\begin{tabular}{|c|c|c|c|c|}
\hline Measmbement & Expremental & \multicolumn{3}{|c|}{ Deformation Predieted hy Analysis: } \\
\hline $\begin{array}{l}\text { Soration } \\
\text { Nimmler }\end{array}$ & $\begin{array}{l}\text { Mratsume men!n } \\
\text { (iii) }\end{array}$ & $\begin{array}{l}\text { i. } \\
\text { (iii) }\end{array}$ & $\begin{array}{l}7.2 \\
\text { (iil) }\end{array}$ & $\begin{array}{l}7.3 \\
\text { (iii) }\end{array}$ \\
\hline a & 2.75 & $3 . \times(1)$ & 2.50 & 2.70 \\
\hline 1) & $0.11 \times 2$ & $0.066 \mathrm{~s}$ & $0.0 \times()$ & 0.130 \\
\hline 1 & 1.2.1:2 & 3.0010 & 2.05 & 2.0 .5 \\
\hline
\end{tabular}

Analysis 7.2 prediond that the rentainer womld walize and be permanently deformed 0.080 indere near its midplatere. This prediction is very clese to the experimental observat

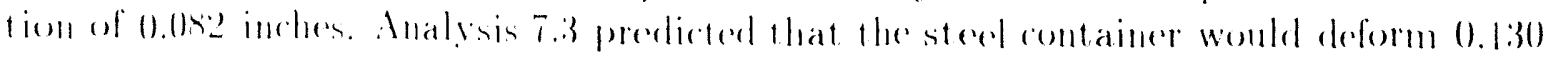

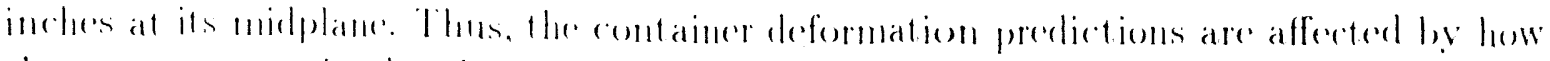

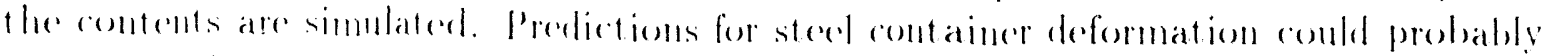

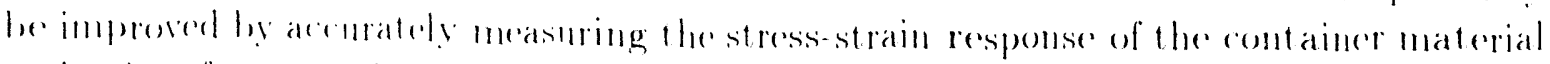
and using. for example. the deviatorie plastirity medel with power law hardening which

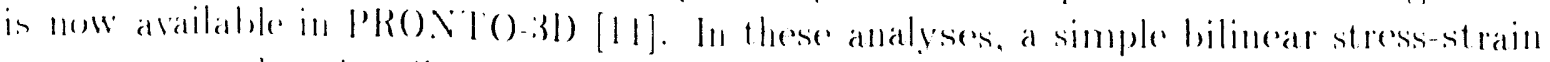

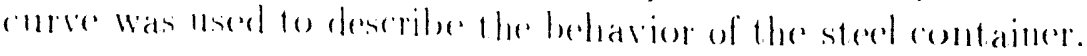




\section{Air Transport Package Analyses - End Impact}

A onc-fonth scale morlel of an air transport parkage was subjerterl to an end impart with

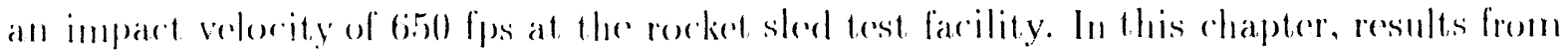
axisymmetrie, two-dimensional analyses of end impart events are presented and rompared with the experimental results. These andyses were performed using the axisymmetre linite element model shown in Fignere 8.1 and PRON'T()-21) [5]. This finite element model represents the package that was subjected to an end impart at the rocket sted test lacility. The model includes: the layered material limiter. alumimum load spreader plates. perforated aluminum plugs, the titanimm container, and the learl shot contents. The thin stainless steel shell which surronnds the limiter was not included in these analyses because axisymmetrie sherl elements are not available in PRON'T()-21) [5].

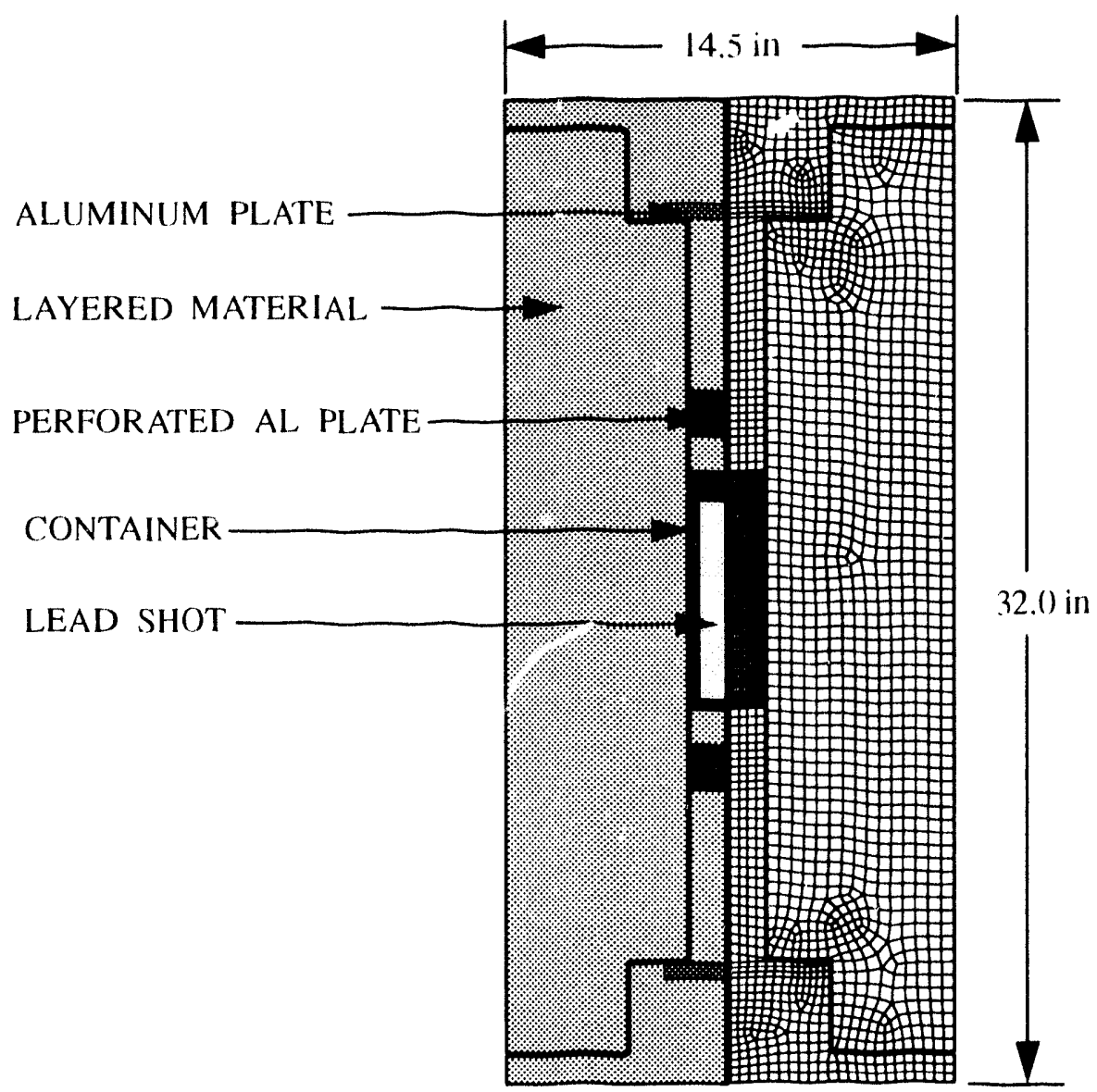

Figure 8.1. Axisymmetric Finite Element Model of an Air Transport Package. 


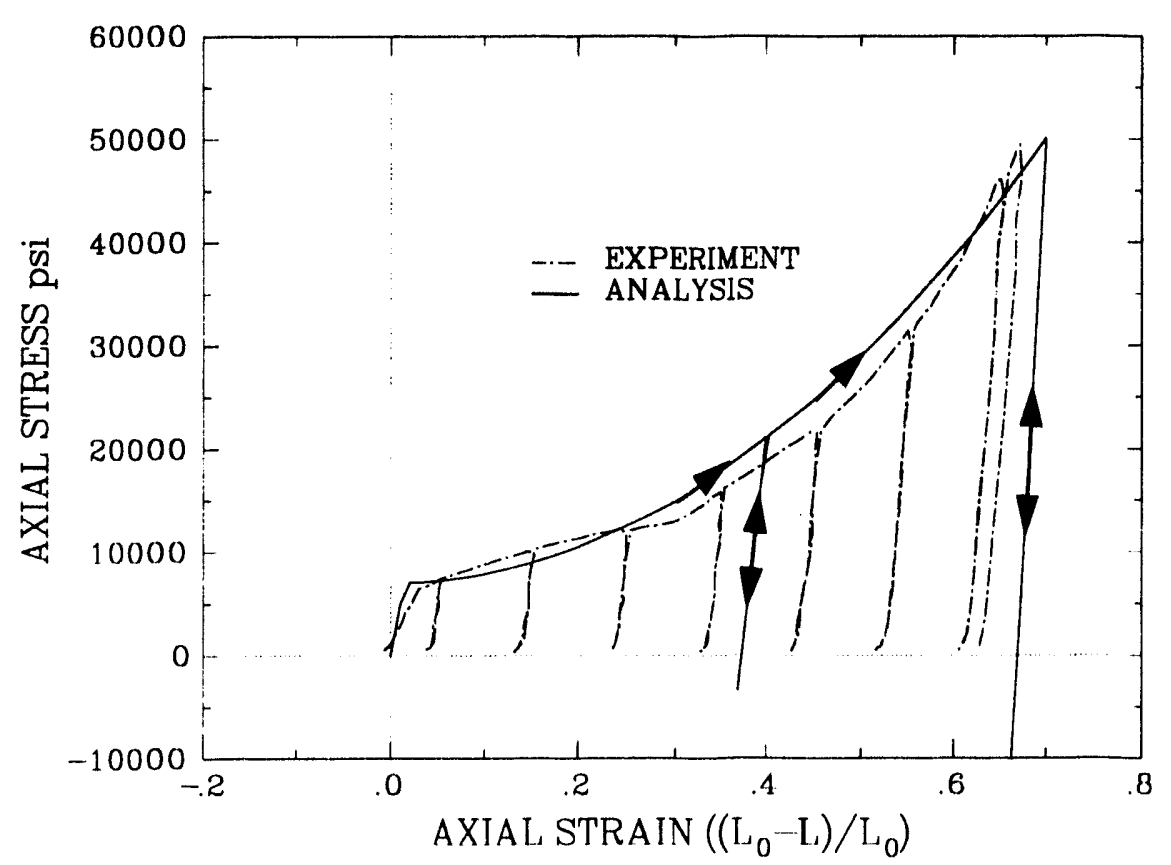

Figure 8.2. Axial Stress-Strain Behavior of Perforated Aluminum Plate Material.

The perforated aluminum plate material was partially characterized with an unconfined compression test. During this test, the perforated aluminum plate behaved much like a rigid foam material (Figure 8.2). The polyurethane foam plasticity model [1] with a yield function given by

$$
\Psi^{i}=-\sigma^{i}-\left(a+b \gamma^{2}\right)
$$

was used to simulate the compressive response of this material. To ensure that the modified foam plasticity model captured the behavior of the perforated aluminum plate, the unconfined compression test was analyzed using the finite element model shown in Figure 5.1 and material parameters given in Table 8.1. The analysis revealed that the modified plasticity model would capture the uniaxial response of the perforated aluminum plate (Figure 8.2). The modified plasticity model may not capture the response of the perforated aluminum to other load paths; however, the model is sufficient for the end impact simulation in which the perforated aluminum plate is subjected to uniaxial compression. The behavior of the perforated aluminum material is being thoroughly evaluated by Brown [12].

End impact events were then analyzed using the finite element model shown in Figure 8.1. The material parameters used in these analyses are given in Table 8.1. The material densities were chosen such shat the various parts of the model would have the same total mass as the corresponding parts in the actual package. Analyses 8.1 and 8.2 were performed using elastic contents and layered material parameters which are appropriate for precompressed layered material. In the remaining four analyses, the effects of content and layered material modeling variations were investigited. Analyses 8.3 and 8.4 were 
Table 8.1. Material Parameters Used in End Impact Analyses

\begin{tabular}{|c|c|c|c|c|c|}
\hline \multicolumn{6}{|c|}{ Perforated Aluminum: Modified Plasticity Model } \\
\hline $\begin{array}{l}\text { Analysis } \\
\text { Number }\end{array}$ & $\begin{array}{c}\text { Elastic } \\
\text { Modulus } \\
\text { (psi) }\end{array}$ & $\begin{array}{c}\text { Poisson's } \\
\text { Ratio }\end{array}$ & $\begin{array}{c}a \\
(p s i) \\
\end{array}$ & $b$ & $\begin{array}{c}\text { Density } \\
\text { (1b } \mathrm{s}^{2} \mathrm{in}^{-4} \text { ) }\end{array}$ \\
\hline 8.1 to 8.6 & $5.0 \times 10^{5}$ & 0.0 & $7.0 \times 10^{3}$ & $88.0 \times 10^{3}$ & $1.3 \times 10^{-4}$ \\
\hline
\end{tabular}

\begin{tabular}{|c|c|c|c|c|c|c|}
\hline \multicolumn{6}{|l|}{ Layered Material: New Model } \\
\hline $\begin{array}{c}\text { Analysis } \\
\text { Number }\end{array}$ & $\begin{array}{c}\text { Elastic } \\
\text { Modulus } \\
(\mathrm{psi})\end{array}$ & $\begin{array}{c}\text { Poisson's } \\
\text { Ratio }\end{array}$ & $a$ & $b$ & $\tau$ & Density \\
\hline $8.1,8.3$ & $1.0 \times 10^{5}$ & 0.0 & 120.0 & 8.68 & 12,000 & $3.625 \times 10^{-5}$ \\
$8.2,8.4$ & $1.0 \times 10^{6}$ & 0.0 & 120.0 & 8.68 & 36,000 & $3.625 \times 10^{-5}$ \\
8.5 & $1.0 \times 10^{5}$ & 0.0 & 17.0 & 8.68 & 12,000 & $3.625 \times 10^{-5}$ \\
8.6 & $1.0 \times 10^{6}$ & 0.0 & 17.0 & 8.68 & 36,000 & $3.625 \times 10^{-5}$ \\
\hline
\end{tabular}

\begin{tabular}{|c|c|c|c|c|c|c|}
\hline \multicolumn{2}{|c|}{ Titanium Container: Elastic-Plastic } \\
\hline $\begin{array}{c}\text { Analysis } \\
\text { Number }\end{array}$ & $\begin{array}{c}\text { Modastic } \\
\text { (psi) }\end{array}$ & $\begin{array}{c}\text { Poisson's } \\
\text { Ratio }\end{array}$ & $\begin{array}{c}\text { Yield } \\
\text { Strength } \\
(\mathrm{psi})\end{array}$ & $\begin{array}{c}\text { Hardening } \\
\text { Modulus } \\
(\mathrm{psi})\end{array}$ & Beta & Density \\
\hline 8.1 to 8.6 & $19.0 \times 10^{6}$ & 0.3 & $136.0 \times 10^{3}$ & $15.0 \times 10^{3}$ & 0.0 & $4.08 \times 10^{-4}$ \\
\hline
\end{tabular}

\begin{tabular}{|c|c|c|c|c|c|c|}
\hline \multicolumn{2}{|c|}{ Lead Shot: Elastic or Elastic-Plastic } \\
\hline $\begin{array}{c}\text { Analysis } \\
\text { Number }\end{array}$ & $\begin{array}{c}\text { Elastic } \\
\text { Modulus } \\
(\mathrm{psi})\end{array}$ & $\begin{array}{c}\text { Poisson's } \\
\text { Ratio }\end{array}$ & $\begin{array}{c}\text { Yicld } \\
\text { Strength } \\
\text { (psi) }\end{array}$ & $\begin{array}{c}\text { Hardening } \\
\text { Modulus } \\
(\mathrm{psi})\end{array}$ & Beta & Density \\
\hline $8.1,8.2$ & $40.0 \times 10^{3}$ & 0.3 & - & - & 0.0 & $3.189 \times 10^{-4}$ \\
8.3 to 8.6 & $2.0 \times 10^{6}$ & 0.3 & 1200.0 & 100.0 & 0.0 & $3.189 \times 10^{-4}$ \\
\hline
\end{tabular}

\begin{tabular}{|c|c|c|c|c|c|c|}
\hline \multicolumn{2}{|c|}{ Aluminum Spreader Plate: Elastic-Plastic } \\
\hline $\begin{array}{c}\text { Analysis } \\
\text { Number }\end{array}$ & $\begin{array}{c}\text { Elastic } \\
\text { Modulus } \\
(\mathrm{psi})\end{array}$ & $\begin{array}{c}\text { Poisson's } \\
\text { Ratio }\end{array}$ & $\begin{array}{c}\text { Yield } \\
\text { Strength } \\
(\mathrm{psi})\end{array}$ & $\begin{array}{c}\text { Hardening } \\
\text { Modulus } \\
(\mathrm{psi})\end{array}$ & Beta & Density \\
\hline 8.1 to 8.6 & $10.6 \times 10^{6}$ & 0.3 & $20.0 \times 10^{3}$ & $5.0 \times 10^{5}$ & 0.0 & $2.60 \times 10^{-4}$ \\
\hline
\end{tabular}

\begin{tabular}{|c|c|c|c|c|c|c|}
\hline \multicolumn{2}{|l|}{ Foam Pads: Elastic } & & & \\
\hline $\begin{array}{c}\text { Analysis } \\
\text { Number }\end{array}$ & $\begin{array}{c}\text { Elastic } \\
\text { Modulus } \\
(\mathrm{psi})\end{array}$ & $\begin{array}{c}\text { Poisson's } \\
\text { Ratio }\end{array}$ & Density & & & \\
\hline 8.1 to 8.6 & $1.0 \times 10^{5}$ & 0.0 & $3.625 \times 1 \mathrm{~s}^{-4}$ & & & \\
\hline
\end{tabular}


identical to Analyses 8.1 and 8.2 except that the contents were modeled as an clasticplastic material. Analyses 8.5 and 8.6 were identical to Analyses 8.3 and 8.4 except that, the layered material parameter a was reduced to 17.0 psi to simmlate layered material that is not precompressed. During assembly of the package, the ends of the limiter were manufactured by simply stacking up the layered material inside a stainless steel shell and manually compressing the layers some undefined anount. In Analyses 8.1, 8.3 and 8.5 the package was given an impact velocity of $424 \mathrm{fps}$ and in Analyses 8.2, 8.4 and 8.6 the package was given an impact velocity of $650 \mathrm{fps}$. In the 6.50 fps analyses, the layered material was compressed enough such that the layered material obtained a langent modulus in excess of $1.0 \times 10^{5}$ psi; thus, an elastic modulus of $1.0 \times 10^{6}$ was 11 sed for the layered material in these analyses. In the 424 fps analyses, the layered material was given an clastic modulus of $1.0 \times 10^{5} \mathrm{psi}$. This variation in elastic modulus is only expected to affect the predicted rebound velocity of the package. Also, in the 650 fps analyses the tensile strength of the layered material was increased to 36,000 psi so that in the simulations the layered material would remain elastic in tension.

Container displacement and acceleration histories predicted by these analyses are shown in Figures 8.3 and 8.4. The displacement plots show that, as expected, the amount of layered material crush increases with impact velocity. Also, significantly more impact liniter crush is gencrated in Analyses 8.5 and 8.6 when the layered material is not precompressed. The acceleration plots indicate that the container is subjected to peak accelerations of approximately 30,000 and $60,000 \mathrm{~g}$ 's during impact cvents with impact velocities of 424 and $650 \mathrm{fps}$, respectively. The acceleration plots for Analyses 8.1 and 8.2 indicate that the container will be subjected to acceleration levels in excess of $90,000 \mathrm{~g} g$ 's when the package is rebounding from the impact surface. These high acceleration levels are caused by the elastic contents impacting the inner walls of the container. In Analyses 8.3 to 8.6 , the contents were modeled as elastic-plastic materials and high acceleration levels were not generated in the container during rebound. 


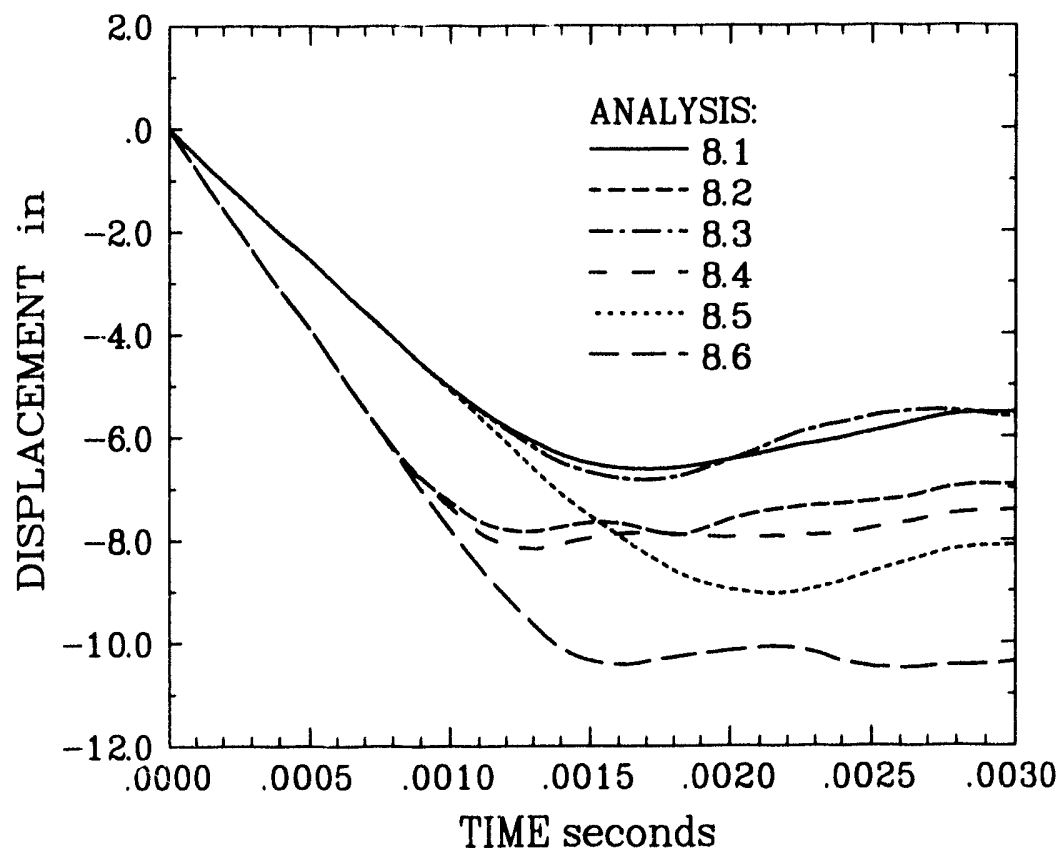

Figure 8.3. Container Displacement Predicted by the End Impact Analyses. 

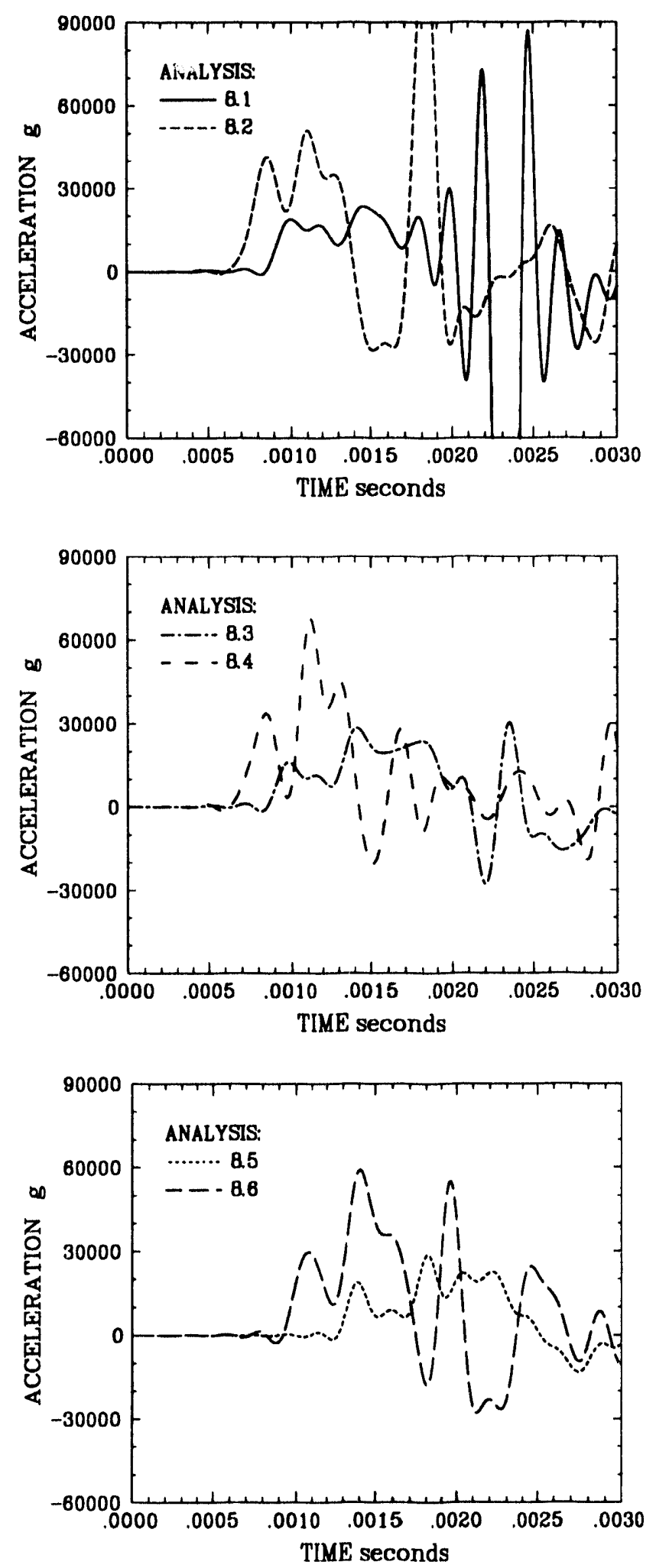

Figure 8.4. ('ontainer Acceleration Predicted by the End Impact Analyses. 
The end sections of the package limiter have approximately 60 layers of wire mesh and 4 layers of Kevlar fabric per inch. The Kevlar fabric layers alone will give the limiter an initial tensile strength of $5600 \mathrm{psi}$ in directions perpendicular to the axis of the package. Using the procedure outlined in Chapter 7 , the predicted maximum tensile load in the Kevlar layers was computed from the maximum principal Cauchy stresses. The predicted maximum tensile loar in a single Kevlar layer is given in Table 8.2. Recall that a single Kevlar layer has a tensile strength of $1400 \mathrm{lbs} / \mathrm{in}$. Analyses $8.1,8.3$ and 8.5 indicate that the Kevlar layers will not fail during a 424 fps impart event. Analyses 8.2 and 8.4 predict that Kevlar layers between the aluminum spreader plate and the impact surface will nearly fail during a $650 \mathrm{fps}$ impact event, and Analysis 8.6 predicts failure of these Kivilar layers.

('ontainer and package deformations predicted by these analyses are summarized in Table 8.2. As expected, the impact limiter deforms more when the layered material is not precompressed and when the impact velocity is increased. Plots of the deformed package shape predicted by Analyses 8.2, 8.5 and 8.6 are shown in Figure 8.5. In Analysis 8.2, the contents are elastic and a maximum equivalent plastic strain of 5.3 percent is generated near the end of the container opposite the lid (Figure 8.6). In Analyses 8.4 and 8.6. the contents are elastic-plastic and maximum equivalent plastic strains of 8.9 and 8.1 percent, respectively, are generated near the lide end in the cylindrical wall of the container (Figure s.6). This plast ie deformation leads to bulging of the container and a permanent increase in the ontside diameter of the containes. Analyses 8.3 and 8.5 indicate that the container will experience little permanent deformation when the impact velocity is reduced to 424 fjs.

Table 8.2. Permanent Deformations Predicted by the End Impact Analyses

\begin{tabular}{|c|c|c|c|c|}
\hline $\begin{array}{l}\text { Analysis } \\
\text { Number }\end{array}$ & $\begin{array}{l}\text { Maximum } \\
\text { lievlar } \\
\text { Load } \\
\text { (lb/in) }\end{array}$ & $\begin{array}{l}\text { Package } \\
\text { Heighı } \\
\text { Decrease } \\
\text { (in) }\end{array}$ & $\begin{array}{l}\text { ('ontainer } \\
\text { Heright } \\
\text { Decrease } \\
\text { (in) }\end{array}$ & $\begin{array}{c}\text { ('ontainer } \\
\text { O.l). } \\
\text { Increase } \\
\text { (in) }\end{array}$ \\
\hline 8.1 & 590 & 11.0 & 0.000 & 0.002 \\
\hline 8.2 & 13660 & 14.0 & 0.029 & 0.006 \\
\hline 8.3 & 6.40 & 11.0 & 0.000 & 0.001 \\
\hline 8.4 & 1360 & 14.0 & 0.120 & 0.140 \\
\hline 8.5 & 460 & 16.0 & 0.000 & 0.012 \\
\hline 8.6 & 1580 & 19.2 & 0.080 & 0.136 \\
\hline Experiment & - & - & 0.120 & 0.100 \\
\hline
\end{tabular}

1. Maximum In-plane Tensile Load In a Kevlar Layer.

A scale model package was manufactured and subjected to an end impact at the rocket sled trest facility. During this test. a stationary package was impacted with a steel and reinforced concrete block which was carried by a sled and accelerated to a velocity of 650 


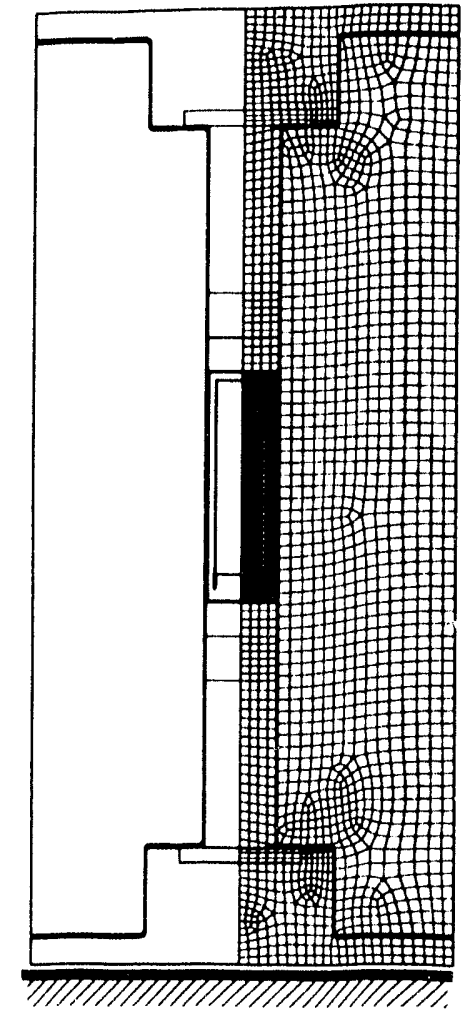

a. undeformed

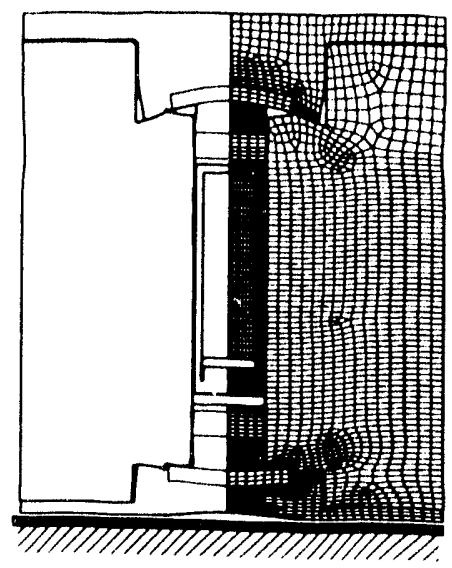

c. Analysis 8.5

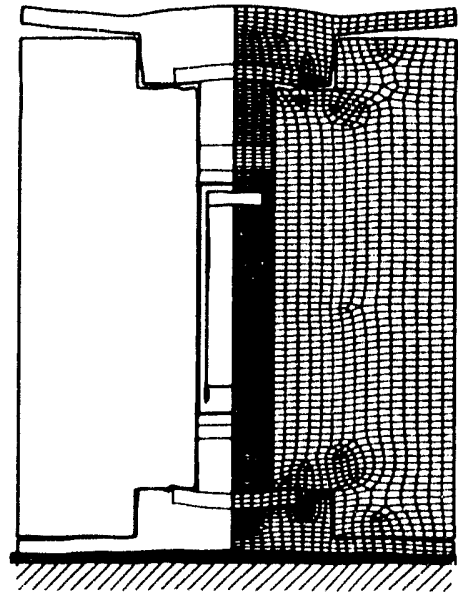

b. Analysis 8.2

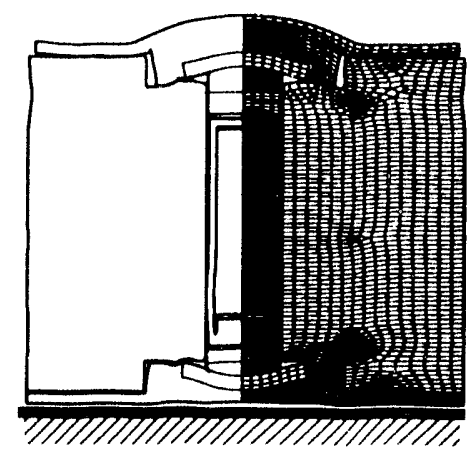

(d. Analysis 8.6

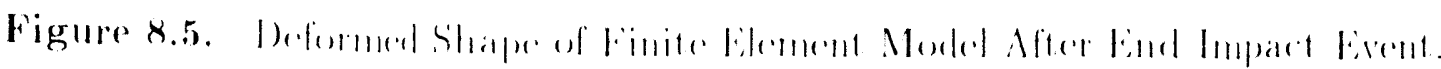



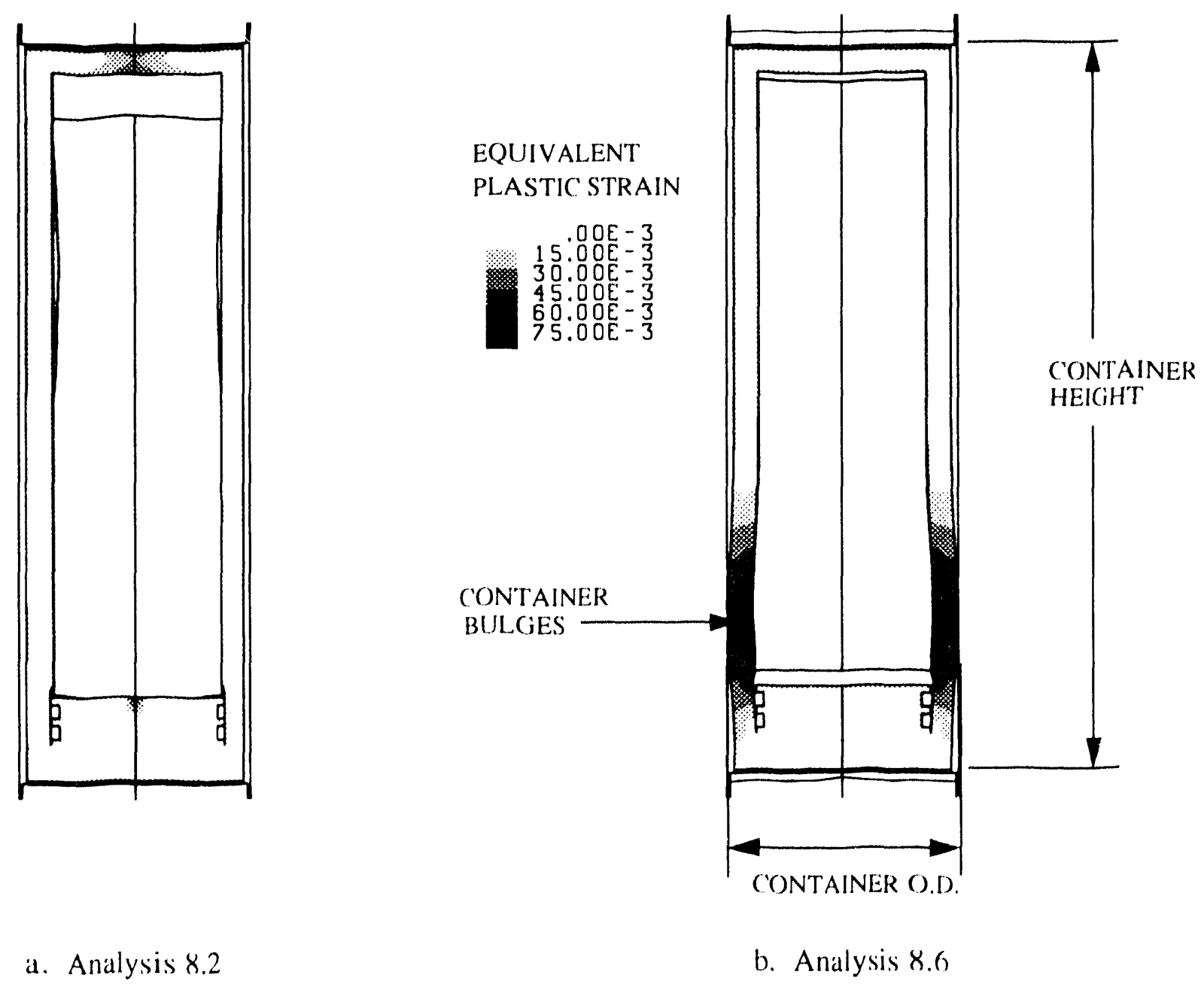
a. Analysis 8.2
b. Analysis 8.6

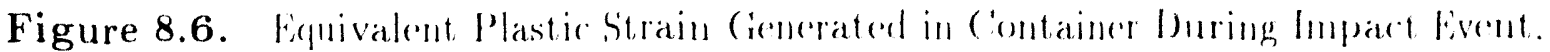




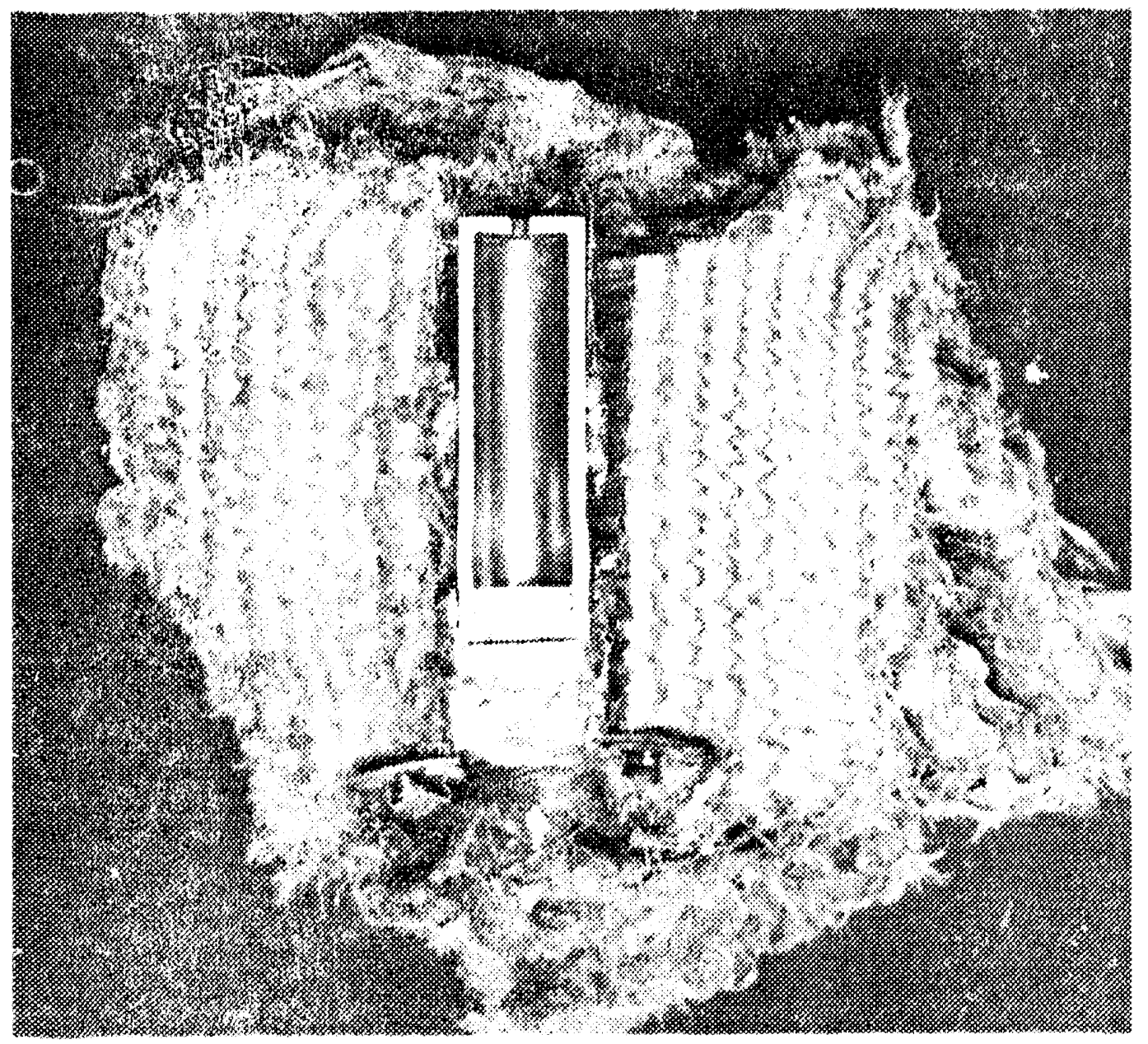




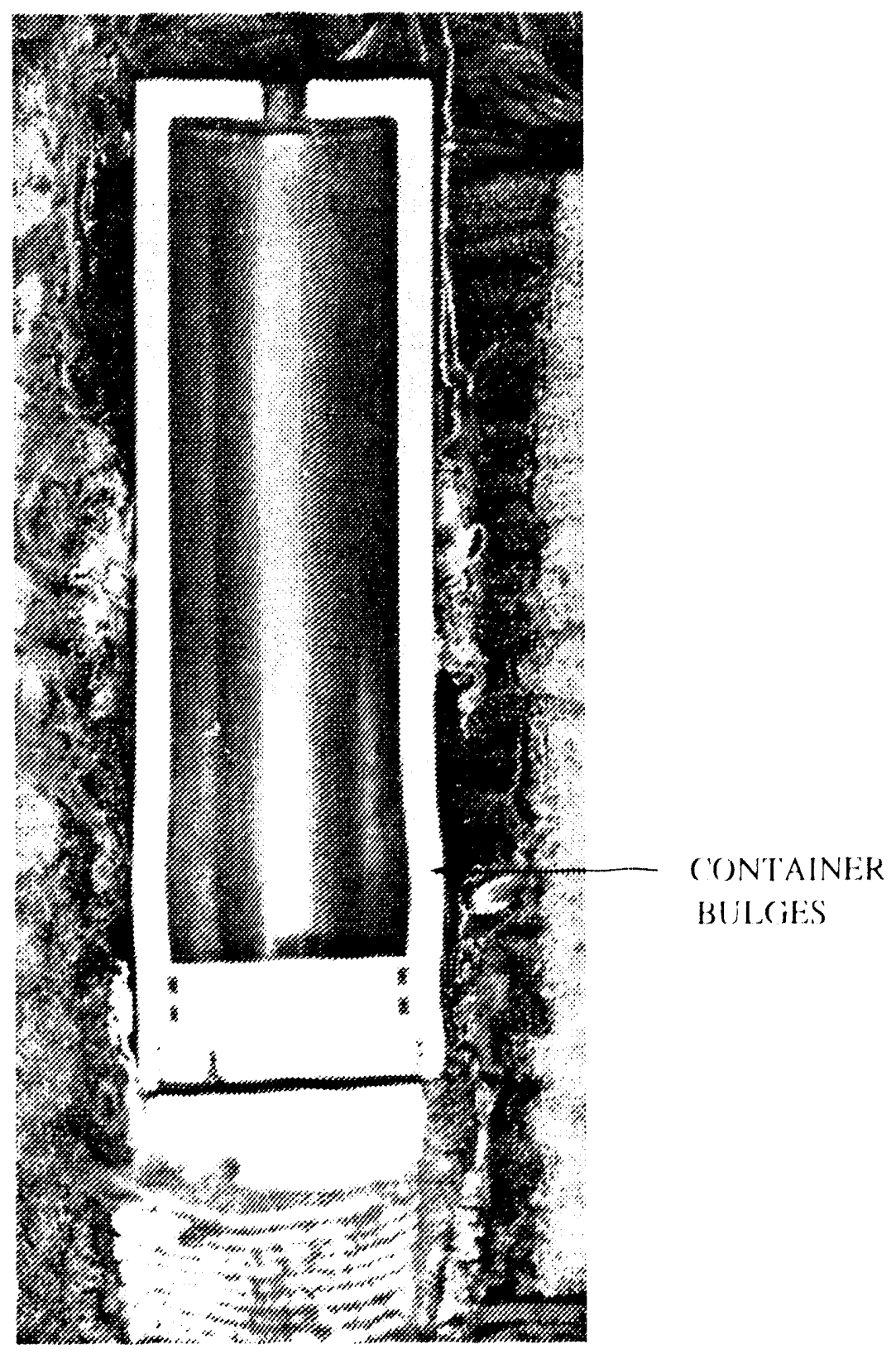

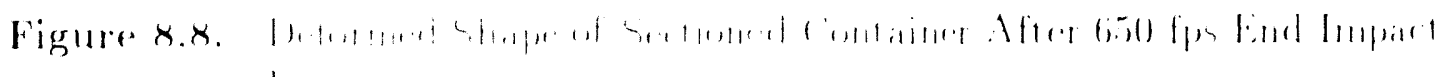

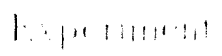




\section{Air Transport Package Analyses - Side Impact}

A one-fourth scale model of an air transport parkage with a layered wire mesh and kevlar labric impact limiter was subjerted to a side impart reverse ballistie test with an impart relocity of 428 foet per second. In this chapter, results from three-dimensional finite element analyses of sice impart events are presented and compared with the experimental results. These andyses were performed using the finite element model shown in Figure 9.1 and PRONT()-3I) [6]. Only one-half of the package was modeled due to the symmetry present in the package geometry and loading. Appropriate boundary ronditions were applien to the symmetry plane. The entire model is shown in the top half of Figure 9.1 and a close-np view of the foam pads, titanimm container, and lead contents is shown in the hottom half. The model has a layered material impact limiter which is surrounded hy a 304 Stainless Siteel shell. The steel shell was modeled using the shell elements in PRONT()-3[) [1:3]. The rest of the paskage was modeled nsing three-dimensional contimumm elements.
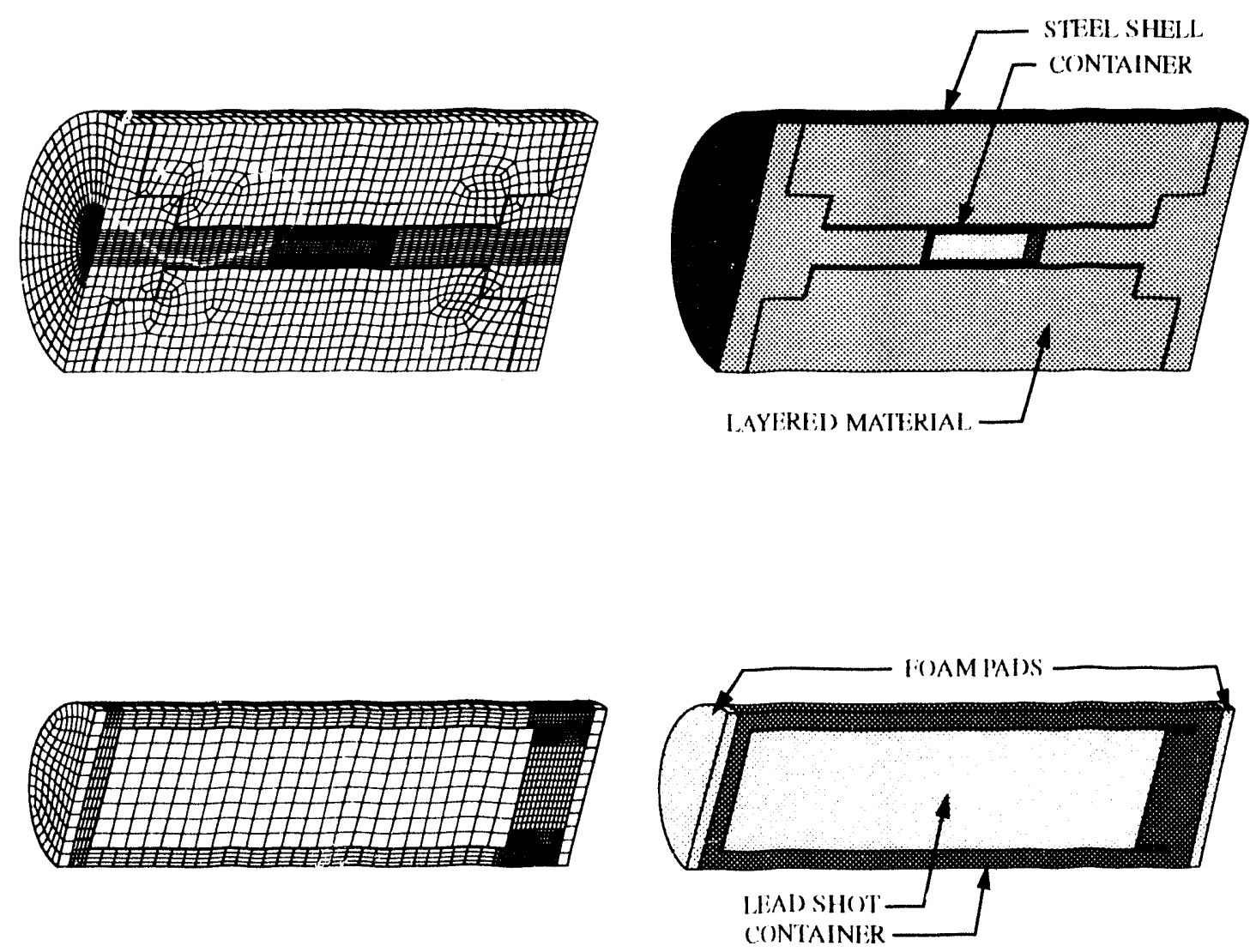

Figure 9.1. Three-1)imensional Finite Element Model of an Air Transport Parkage. 
Table 9.1. Material Parameters Used in the Side Impact Analyses

\begin{tabular}{|c|c|c|c|c|c|}
\hline \multicolumn{6}{|c|}{ Layered Material: New Model } \\
\hline Elastic & Poisson's & $a$ & $b$ & $\tau$ & Density \\
\hline $\begin{array}{l}\text { Modulus } \\
\text { (psi) }\end{array}$ & Ratio & (psi) & & (psi) & (Il) $s^{2} i^{-4}$ ) \\
\hline $1.0 \times 10^{5}$ & 0.0 & 120.0 & 8.68 & 12,000 & $3.625 \times 10^{-5}$ \\
\hline
\end{tabular}

\begin{tabular}{|c|c|c|c|c|c|c|}
\hline Lead Shot: Elastic & & & \\
\hline $\begin{array}{c}\text { Elastic } \\
\text { Moclulus } \\
(p s i)\end{array}$ & $\begin{array}{c}\text { Poisson's } \\
\text { Ratio }\end{array}$ & Density & & & \\
\hline $10.0 \times 10^{3}$ & 0.3 & $\left.3.189 \times 1 \mathrm{~s}^{2} \mathrm{in}^{-4}\right)$ & & & & \\
\hline
\end{tabular}

\begin{tabular}{|c|c|c|c|c|c|}
\hline \multicolumn{6}{|c|}{ Titanimm Container: Flastic Plastic } \\
\hline $\begin{array}{l}\text { Elastic } \\
\text { Moclulus } \\
\text { (psi) }\end{array}$ & $\begin{array}{c}\text { Poisson's } \\
\text { Ratio }\end{array}$ & $\begin{array}{c}\text { Yicld } \\
\text { Strongth } \\
\text { (psi) }\end{array}$ & $\begin{array}{l}\text { Mardruing } \\
\text { Modulus } \\
\text { (psi) }\end{array}$ & Beta & $\begin{array}{l}\text { Domsity } \\
\left.\text { (11, } \mathrm{s}^{2} \mathrm{in}^{-1}\right)\end{array}$ \\
\hline $19.0 \times 10^{6}$ & 0.3 & $1: 36.0 \times 10^{3}$ & $15.0 \times 10^{3}$ & 0.0 & $1.108 \times 10^{-11}$ \\
\hline
\end{tabular}

\begin{tabular}{|c|c|c|c|c|c|c|}
\hline \multicolumn{7}{|c|}{304 Stainless Steed Shell: Elastic-Plastic, Power Law Hardening } \\
\hline $\begin{array}{l}\text { Elastir } \\
\text { Modulus } \\
\text { (psi) }\end{array}$ & $\begin{array}{l}\text { Poisson's } \\
\text { Ratio }\end{array}$ & $\begin{array}{c}\text { Yiold } \\
\text { Strength } \\
\text { (psi) }\end{array}$ & $\begin{array}{l}\text { Mardening } \\
\text { ('onstant }\end{array}$ & $\begin{array}{l}\text { Mardening } \\
\text { lixponent }\end{array}$ & $\begin{array}{l}\text { Luder's } \\
\text { Strain }\end{array}$ & $\begin{array}{l}\text { Densily } \\
\left.\text { (ll, } s^{2} \text { in }{ }^{-1}\right)\end{array}$ \\
\hline $28.0 \times 10^{6}$ & 0.3 & $28.0 \times 10^{3}$ & 192716.0 & $0.7 .1 \times 190$ & (0.0) & $7.5 \times 10^{1}$ \\
\hline
\end{tabular}

\begin{tabular}{|c|c|c|c|c|c|c|}
\hline Foam Pads: Elastic \\
\hline $\begin{array}{c}\text { Elastic } \\
\text { Modulus } \\
(p s i)\end{array}$ & $\begin{array}{c}\text { Poisson's } \\
\text { Ratio }\end{array}$ & Density & & & & \\
\hline $1.0 \times 10^{5}$ & 0.0 & $3.625) \times 10^{-5}$ & & & & \\
\hline
\end{tabular}

Material parameters used in these analyses are given in Table 9.1. The layered matrerial was modeled nsing the same mechanical parameters as in the previens analysis. The densities of the layered material, titanium container, and lead shot rontents were selected such that these components had the same total mass as the actual parts which were used in the side impact experiment. The lead shot was modeled as an elastir material with a low elastic modulus of 40,000 psi. The 304 Stainless Steel shell was modeled using the elastic-plastic, power law hardening material model [11]. The thin form parls were morleled as an elastic material with the same elastic properties as the layered material. 
In the first analysis, the model was subject to an side impact into a rigid target with an impact velocity of $424 \mathrm{fps}$ and in the second analysis the model was given an impact velocity of $650 \mathrm{fps}$. Displacement and acceleration histories for the container predicted by these analyses are shown in Figures 9.2 and 9.3. The displacement plots indicate that the amount of layered material crush increases with impac: velocity. The acceleration plots indicate that the container is subjected to peak accelerations of approximately 55,000 and 85,000 s's for impact velocities of 424 and $650 \mathrm{f} p \mathrm{~s}$, respectively. The acceleration plots are not very refined since plot data was only stored at lime intervals of 0.05 nisec.; however, the acceleration history for the $424 \mathrm{fps}$ impact event is similar to the acceleration history shown in Figure 7.3 for the package with a steel container subjected to a 424 fps side impact. 'These container acceleration levels obtained during side impacts events with the air transport package (Figure 9.3) are significantly higher than the acceleration levels obtained during the end impart events (Figure 8.4).

The cylindrical part of the limiter for this parkage contained 24 layers of kevlar fabric and 37. layers of aluminum screen wire. 'The maximmm tensile load in a hevlar layer was estimated using the procedure ontlined in (hapter 7 . A comparison of the predicted maximum tensile load with the tensile strength of a single layer, 1400 lbs/in., revealed that the layered material between the container and the impact surface would not fail during a 124 fps impact event but would, at least, begin to fail during a 650 fps impact event. Maximum tensile Kevlar layer loads of $970 \mathrm{lbs} / \mathrm{in}$. ant. 1930 lbs./in. were predicted for impact velocities of 424 fps and 650 fps, respectively. Additional kevlar layers shonld be added to prevent limiter failure during a 650 fps impact event.

A one fonth scale model package was manufactured and subjected to a side impact at the rocket sled test facility. An impact velocity of 428 fos was generated during this test. As predicted by the finite element analyses, the limiter did not fail in tension during this test. No strain gage or accelerometer data were obtained during the experiment; thus, the only comparisons between analysis and experiment which cond be made were of the final deformed shape of the parkage. Deformed shapes of the models predieterl during these analyses are shown in Figures 9.4 and 9.5 . The iitanium containers stopped moving towards the target at 0.8 msec. and 0.7 msece during the 424 fos and 6.50 fps impact covents, respectively. The 424 fps and 650 fps analyses were terminated at $1.5 \mathrm{msec}$ and 1.4 msere, respectively. The deformed shape of a section of the tested impact limiter is shown in Figure 9.6. The predicted deformed shapes of the impact limiters compare reasonably well with the experimental result. However, the analyses indicated that the center of the titanium container would be permanently deformed 0.060 in. during the 424 fps impact event and $0.160 \mathrm{in}$. during the 650 fps impact event. Measurements of the titanium container after the 428 fps impact indicated that the container was not permanently deformed. 'This discrepancy could be due to inadequate modeling of the container or the the contents. The two-dimensional analyses of the end impact event which were presented in (hapter s showed that the container deformation predictions are significantly affected by content modeling assumptions. 


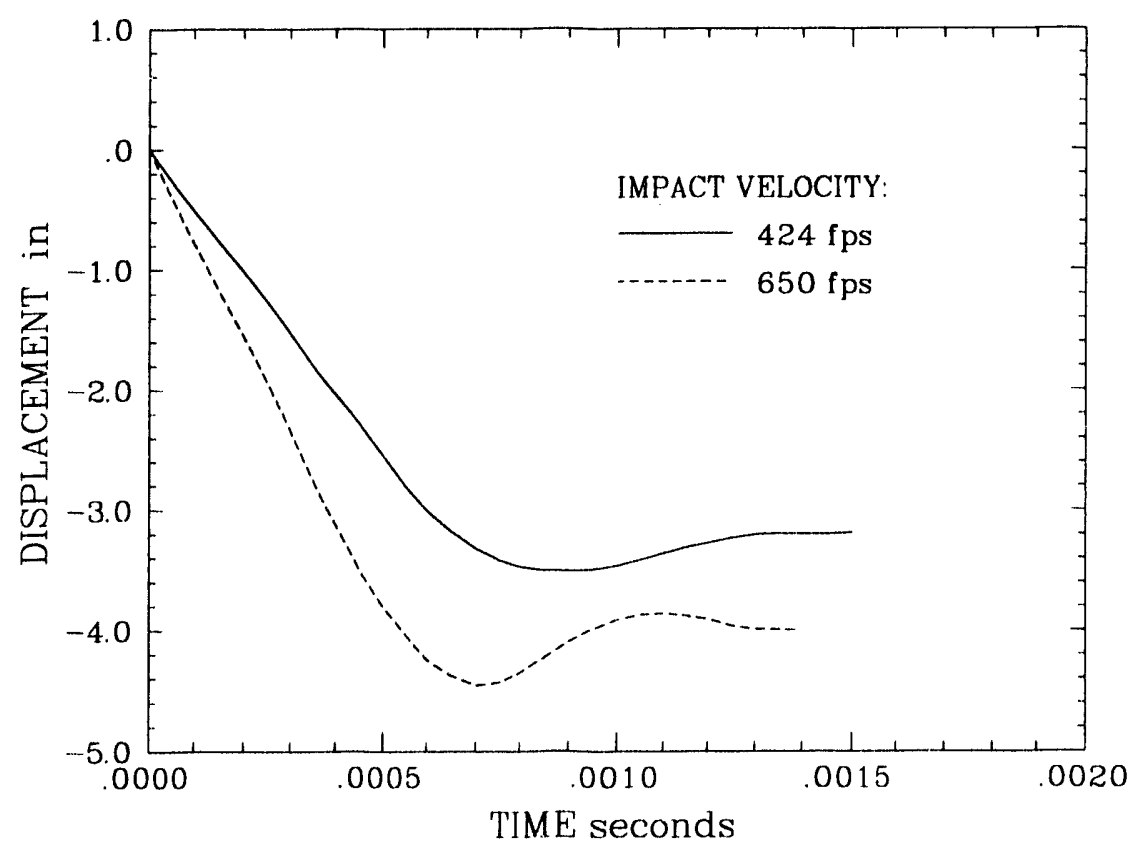

Figure 9.2. Container Displacement Predicted by the Side Impact Analyses.

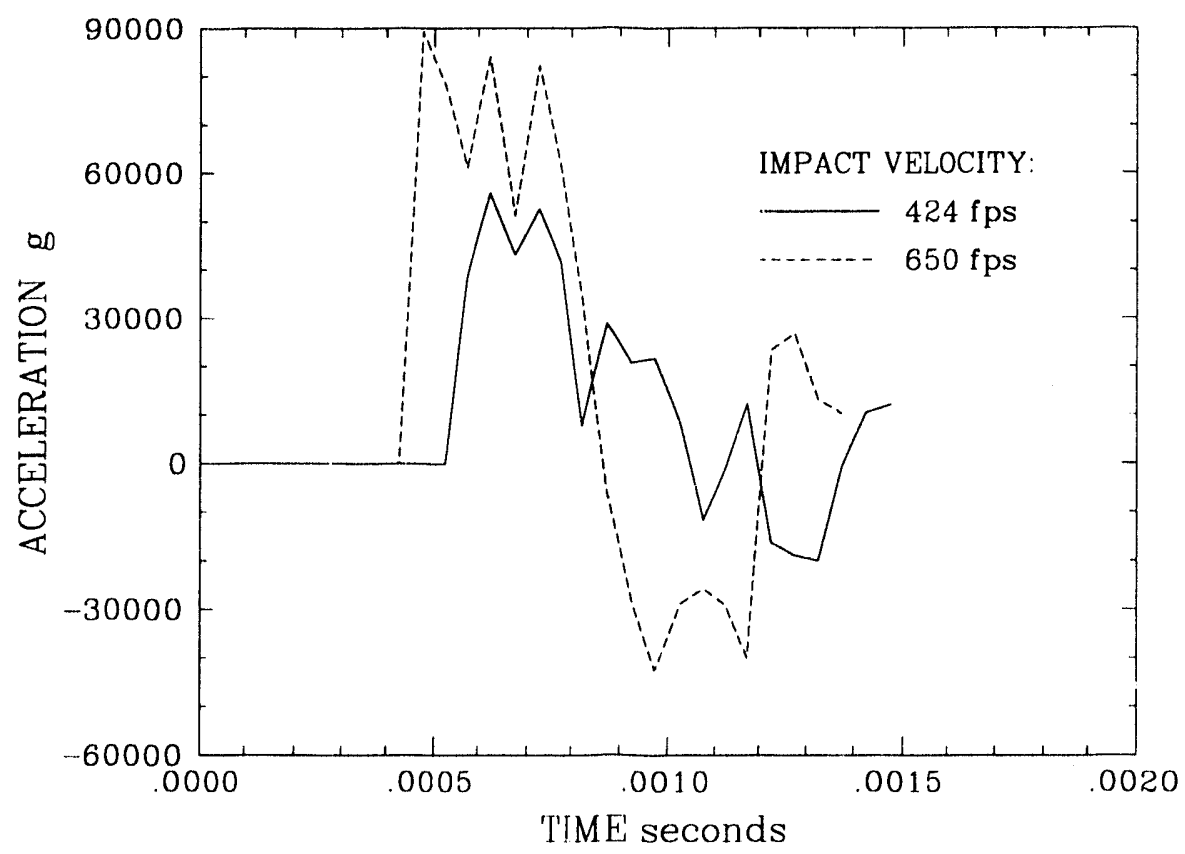

Figure 9.3. Container Acceleration Predicted by the Side Impact Analyses. 


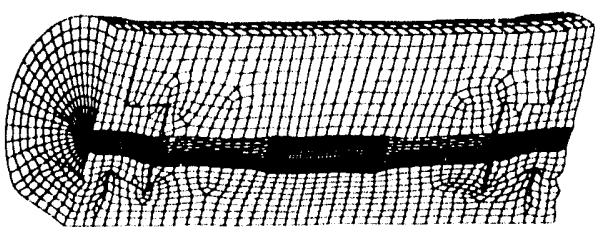

(). $8 \mathrm{msec}$.

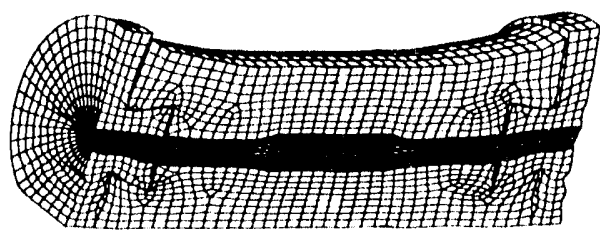

$1.5 \mathrm{msec}$.

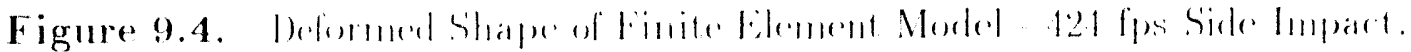

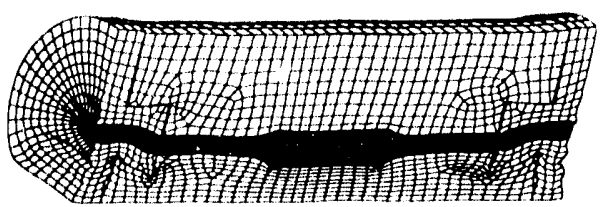

(). 7 msec.

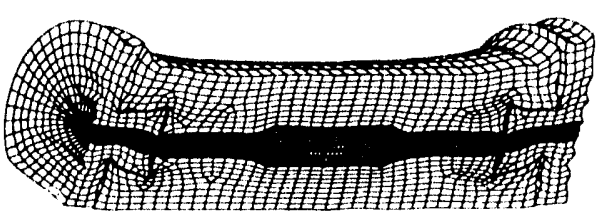

$1.4 \mathrm{msec}$.

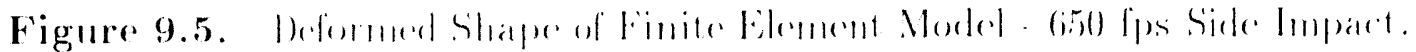

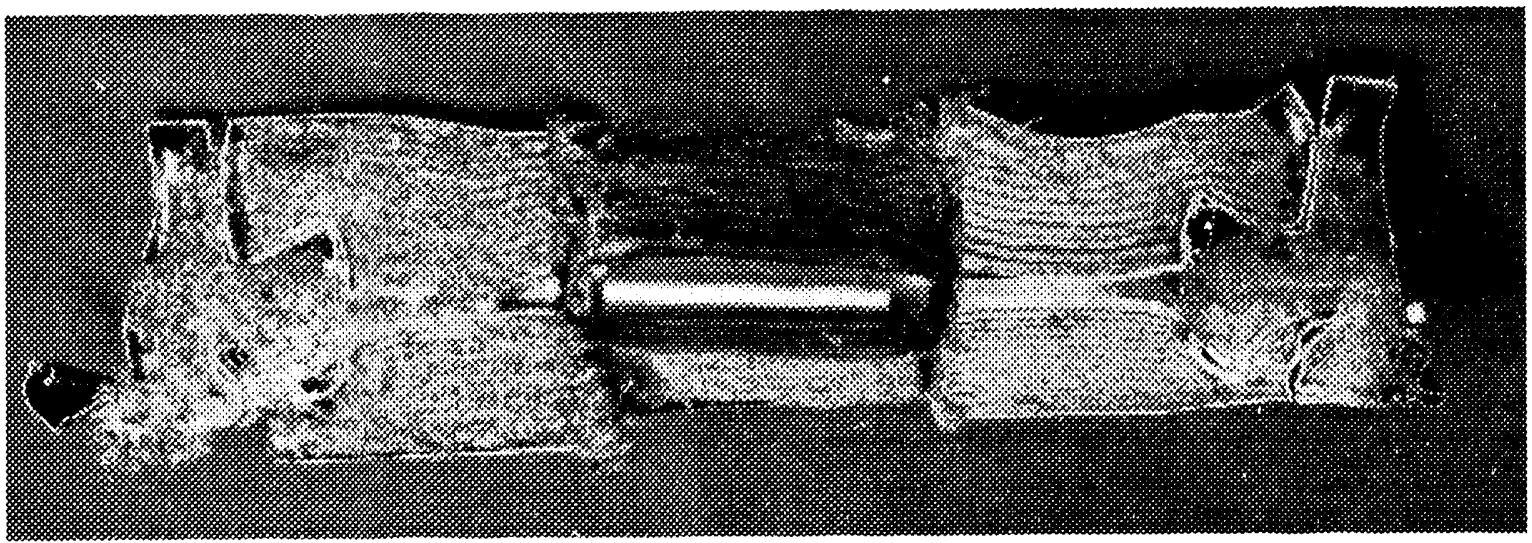

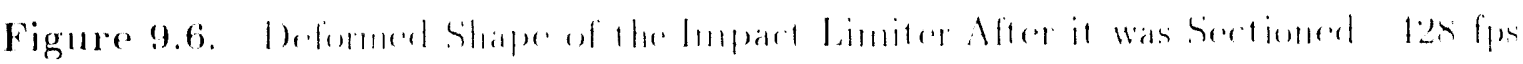

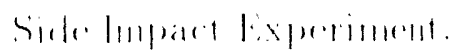




\section{Summary}

An isotropic plasticity model for composite layered wire mesh and Kevlar fabric material has been developed and used in the investigation of hypothetical air transport package accidents. Results from a limited number of unconfined and confined compression tests were used to obtain material parameters for the new layered material model. The material characterization experiments were then analyzed to ensure that the new plasticity model captured the material behavior exhibited during these tests. The new plasticity model accurately captures the isotropic compressive response of the layered material but does not capture: (1) increases in the elastic stiffness as the material is compressed and (2) anisotropic tensile response and layer separation. A material model which captures the increase in layered material stiffness as it is compressed was recently developed by krieg and Brown [3, 12]. 'This new model should be used in future analyses of hypothetical accidental impact events. The current investigation revealed that an accurate simulation of the anisotropic tensile response of the layered material is not needed to generate accurate load transfer and container deformation predictions; thus, an isotropic model for the layered material should be adequate for most impact event simulations.

Results from both the finite element analyses and the experiments indicate that a composite layered wire mesh and Kevlar fabric impact limiter will remain intact during a 650 fps impact event if the number of Kevlar layers is adequate. However, the layered wire mesh and Kevlar fabric impact limiter allows for the transmission of rather high load levels to the primary inner container. The primary container was not plastically deformed during the $428 \mathrm{fps}$ side impact experiment but was plastically deformed during the 650 fps end impact experiment. The amount of load transmitted to the primary container may be reduced by either adding wire mesh layers or replacing the wire mesh layers with layers of material which absorb more energy than the wire mesh. 'These modifications to the baseline design should be investigated further. Also, the analyses presented in this report reveal that content behavior can have a significant positive or negative effect on primary container deformation. For example, the 650 fps end impact simulation revealed that the internal pressure generated by the plastically deforming contents contributes to the undesirable bulging of the containment vessel. Content behavior must be considered in the development of air transport package designs. 
( ) 


\section{References}

1. M.K. Neilsen, H.S. Morgan, and R.I). Krieg, A Phenomenological ('onstitutive Model for Low Density Polyurethane Foams, SAND86-2927, Sandia National Laboratories, Albuquerque, NM, April 1987.

2. S.W. Attaway, A Local Isotropic / Global Orthotropic Finite Eilement Trehnique for Modeling the (rush of Wood, SAND88-1449, Sandia National Laboratories, Albucquerque, NM, 1988.

3. R.D. Krieg and K. Brown, Computer Modeling of Wrapped Impact Limiters, Final Report 98-816, University of 'Tennessee, Knoxville, 'T'N, September $199^{2} 2$.

4. ('M. Stone, SANTOS A Two-Dimensional Finite Element Program for the Quasistatic, Large Deformation. Inelastic Response of Solids. SAND90-0543, Sandia National Laboratories, Albuquerque, NM, in preparation

5. L.M. Taylor and D.P. Flanagan, PRONTO-DD A Two-Dimensional Transient Solid Dynamics Program, SAND86-0594, Sandia National Laboratories. Abuquerque, NM, March 1987.

6. L.M. Taylor and D.P. Flanagan, PRONTO-BD A Thee-Dimensional T'ransient Solid Dynamics Program, SAND87-1912, Sandia National Laboratories, Albuquerque, NM, March 1989.

7. Krieg, R.I)., A Simple Constitutive Description for Soils and ('rushable Foams, S(-DR-72-0883, Sandia National Laboratories, Albuquerque, NM, 1978.

8. Reuter, R.('. and Allen, J..J., Prediction of Mechanical States in Wound Capacitors, ASME Journal of Mechanical Design, Vol. 113, December 1991.

9. Van Vlack, L.H., Materials Science for Engineers, Addison Wesley, Reading, MA, 1970 .

10. Rack, H.J., and Knorovsky, (i.A., An Assessment of Stress-Strain Data Suitable for Finite-Element Elastic-Plastic Analysis of Shipping ('ontaincis, SANDTT-1872, Sandia National Laboratories, Albuquerque, NM, September 1978.

11. C.M. Stone, G.W. Wellman, and R.D. Krieg, A Vectorined Elastic Plastir Power Law Hardening Material Model Including Luders Strain, SAND90-0153, Sandia National Laboratories, Albuquerque, NM, March 1990. 
12. K.H. Brown, A Large Volume Strain Plasticity Constitutive Model for Impact Limiter Materials, M.S. Thesis, Engineering Science and Mechanics Department, The University of Tennessee, Knoxville, TN, December 1992.

13. V.L. Bergmann. Transient Dynamic Analysis of Plates and Shells with PRONTO3D, SAND91-1182, Sandia National Laboratories, Albuquerque, NM, September 1991. 


\section{Unlimited Release}

U. S. Department of Energy

Office of Civilian Waste Management

Attn: W. Lake, RW-431

Mail Stop RW-40

1000 Independence SW

Washington, DC' 20585

U.S. Department of Energy

Northwestern On-Site

Remediation Branch

Attn: J. (:. Lehr, EM-442

Mail Stop EM-442

B-205

19901 (iermantown Road

Germantown, MD 20585

U.S. Department of Energy

Office of Waste Operations

Attn: S. P. Cowen, EM-30

Mail Stop EM-30

A-214A

19901 Germantown Road

(iermantown, MD) 20585.5

U.S. Department of Energy (2)

Office of Waste Operations

Attn: J. Lytle, EM-30

L. Harmon, EM-30

Mail Stop EM 30

7A-049

1000 Independence SW

Washington, DC 20585

U.S. Department of Energy (5)

Attn: L. Blalock, EM-561

R. Brancato, EM-561

M. Conroy, EM-561

M. Keane, EM-561

E. McNeil, EM-561

Mail Stop EM-561

Washington, DC, 20585-0002

U.S. Department of Energy

Oak Ridge Operations Office

Attn: M. Heiskell

P.O. Box E

Oak Ridge, TN 37831
U.S. Department of Energy (4)

Albuquerque Operations Office

Albuquerque Headquarters

Attn: J. Bickel

K. (i. Golliher

P. A. Saxman

D. Bandy

P.O. Box 5400

Albuquerque, NM 87115

Argonne National Laboratory

Attn: (i. Popper

9700 South Cass Ave.

Argonne, IL 60439

U.S. Department of Transportation

Office of Materials Transportation

Attn: K. Smith

400 Seventh Street, SW

Washington, DC: 20590

U.S. Nuclear Regulatory ('ommission (2)

Office of Nuclear Materials Safety

and Safeguards

Attn: R. Chappell C. MacDonald

Washington, DC: 20555

(ius A ramayo

Oak Ridge National Laboratory

P.O. Box 2008

MS-63332

Oak Ridge, TN 378.31

Ermes DeMaria

Senior Transportation Safety Specialist

Radiopharmaceutical Division

Du Pont Merck Pharmaceutical Company

331 Treble Cove Road

North Billerica, MA 01862

Frank Falci

8905 Copenhaver Drive

Potomac, MD 20854

Paul Hagan

U.S. Department of Energy/Rocky Flats

P.O. Box 928

Golden, CO 80401 
James Hummer

Westinghouse - Hanford ('o.

P.O. Box 1970

MS $(12-02$

Richland, WA 99352

Prof. Ray Krieg (5)

Engineering Science and Mechanics

301 Perkins Hall

University of Tennessee

Knoxville, TN 37923-6819

Eric Opperman

Packaging and Transportation (iroup)

Westinghouse Savannah River ('ompany

Savannah River Laboratories

P.O. Box A

Aiken, SC 29802

Joanne Passaglia

Transportation Management Program

Office of Technology Development

U.S. Department of Energy

Trevion II Building, EM-561

Washington, DC: 20585

Bill Pearson

U.S. Department of Energy

$704 S$ Area

Field Office, Savannah River

P.O. Box A

Aiken, $S C$ : 29808

Ronald Pope

Oak Ridge National Laboratory

P.O. Box 2008

Building $4500 \mathrm{~N}, \mathrm{MS}-273$

Oak Ridge, TN 378:31-627:3

Frank Punch

Packaging and Transportation Specialist

EH-33.3 GTN

U.S. Department of Energy

Washington, DC: 20585-0001

Prof. H.L. Sichreyer

Dept of Mechanical Engineering

University of New Mexico

Albuquerque, NM 87131
James Szenasi

OPEP

U.S. Department of Energy

Field Office, Albuquerque

P.O. Box 5400

Albuquerque, NM 87115

Bob Towell

U.S. Department of Energy

19901 (iermantown Road, EH-33.3.3

(iermantown, MI) 20874

Mike Wangler

Transportation and Packaging

Safety Division

U.S. Department of Energy, EH-33.3

Room 6138

19901 Gormantown Road

Germantown, MD 20874 
Internal Distribution:

0324 P.E. D'Antonio 0333 C.Ci. Shirley

1425 J.H. Biffle

1425 S.W. Attaway

1425 M.L. Blanford

1434 D.R. Martinez

1500 D.J. Mc.Closkey

1501 C.W. Peterson

Route to: 1512, 1513, 1551, 1552

1502 P.J. Hommert

Route to: 1503, 1511, 1553, 1554

1561 H.S. Morgan

1561 M.K. Neilsen (15)

1561 M.W. Heinstein

1561 E.L. Hoffman

1561 (.M. Stone

1561 J.R. Weatherby

1561 C.W. Wellman

1562 R.K. Thomas

1562 F.J. Mello

1562 (i.D. Sjaardema

5165 N.R. Hansen

5365 (i.C'. Story

5365 R.D. Monson

6000 I).L. Hartley

6600 J.B. Woodard

6603 R.E. Luna

Attn: TT(: Master File

6603 'TTC: Library (15)

6641 R.P. Sandoval

6641 J.I). Mc('Iure

6642 (i.F. Hohnstreiter

6642 D.J. Ammerman

6642 J.(i. Bobbe

6642 I).L. Bolton

6642 D.C. Harding

6642 J.D. Pierce (15)

6642 K.B. Sorenson

6642 H.R. Yoshimura

6643 T.L. Sanders

8246 W.Y. Lu

8401 C.L. Knapp

8702 C.W. Robinson

8741 G.A. Benedetti

8741 M.L. Chiesa

8742 P.E. Nielan

8743 M.L. Callabresi

8746 W.A. Kawahara

7141 Technical Library (5)

7151 Technical Publications
7613-2 Document Processing for DOE/OSTI (10) 8523-2 Central Technical Files 

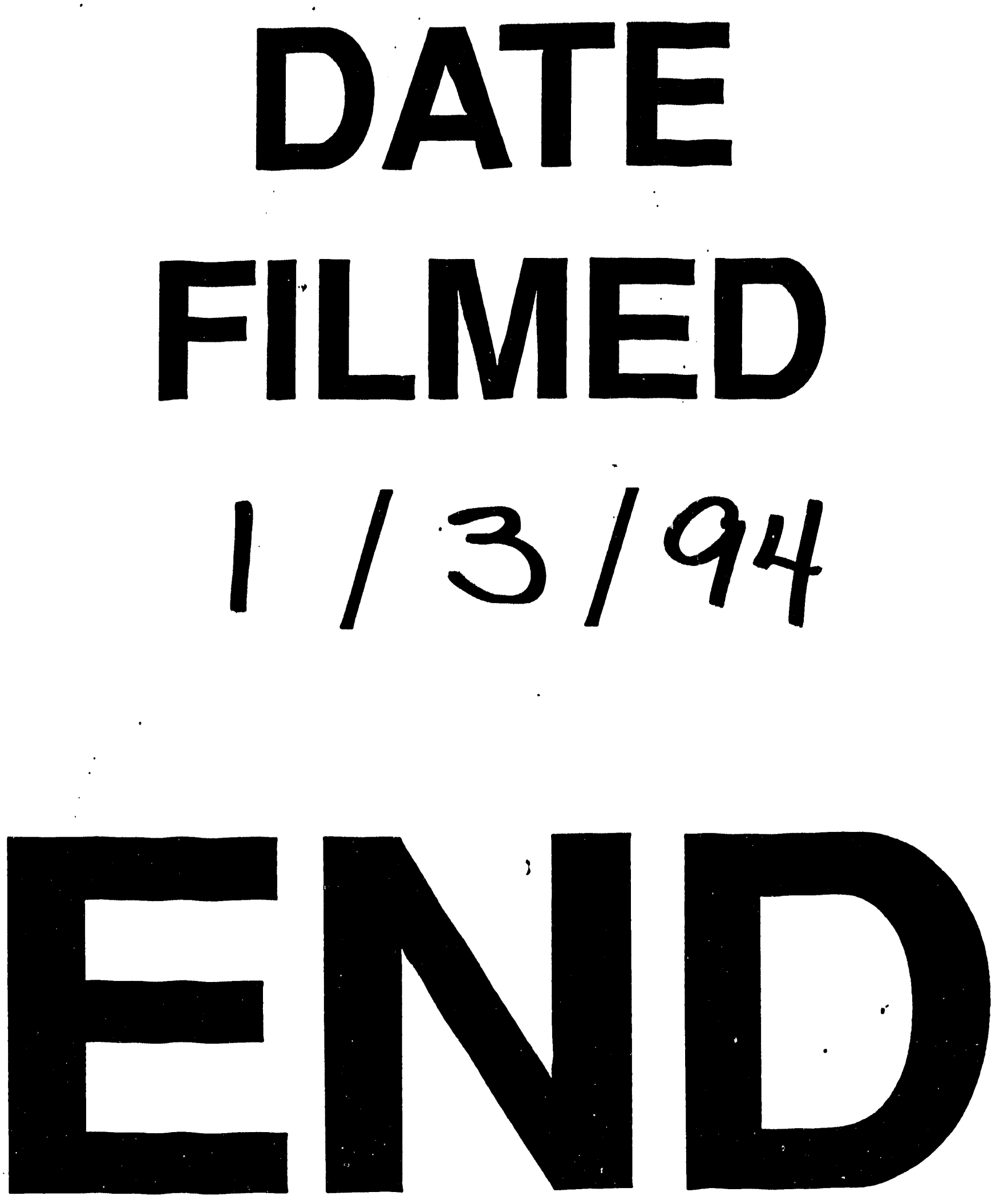
